\title{
LOS DESAFÍOS DE LAS MIGRACIONES PARA UNA ESTRATEGIA GLOBAL DE LA UNION EUROPEA
}

\author{
Gloria Inés Ospina ${ }^{1}$ \\ UNISCI
}

\begin{abstract}
Resumen:
En este artículo se analizan los desafíos que los movimientos migratorios irregulares pueden producir en la seguridad de la UE. Se analizan a partir de la Estrategia Europeas de seguridad de 2003, y el Informe de su aplicación de 2008 y se constata que no se siguen las directrices que se proponen, que las políticas de migración y asilo se han incumplido, y que las actuaciones han sido irresponsables, primando la dispersión y la improvisación. La Estrategia de 2016 lo reconoce y llama la atención a los dirigentes europeos a reconsiderar la forma de funcionamiento de la UE, proponiendo que haya mayor unidad y colaboración y apuesta por una política migratoria más eficaz. No obstante, el artículo señala que prácticamente todos los apartados ya se contemplaban en las anteriores estrategias, sólo que en esta última, la acción ya se ha emprendido, proponiendo y firmando acuerdos de readmisión con importantes países de donde proceden las migraciones irregulares.
\end{abstract}

Palabras clave: Movimientos migratorios irregulares, refugiados, acuerdos de readmisión, política migratoria de la UE, Estrategia Global de la UE.

Title in English: The Challenge of Migration and the Global Security Strategy of the European Union

\begin{abstract}
:
This article discusses the challenges of irregular migration for the security of the EU. They are analyzed starting with the European Security Strategy 2003, and the Report on its Implementation, 2008, and notes many failures: The EU Members did not follow the directives adopted in Brussels, the mismanagement of migration and asylum policies, and numerous actions that can be characterized or described as improvised, scattered or irresponsible. The 2016 Global Strategy recognizes these failures and call attention to the European leaders to reconsider how the EU functions and operates, suggesting the need for greater unity and cooperation to achieve a more effective migration policy. However, the article points out that practically all of the sections of the new Strategy dealing with migration were already embodied in previous Strategies, and stress that in parallel with the publication of the 2016 Global Strategy, actions are already undertaken, such as the EU readmission agreements signed with several important third countries of origin.
\end{abstract}

Keywords: Irregular migration flows, refugees, readmission agreements, migration policies of the EU, Global Strategy of the EU.

Copyright $(\mathcal{C}$ UNISCI, 2016.

Las opiniones expresadas en estos artículos son propias de sus autores, y no reflejan necesariamente la opinión de UNISCI. The views expressed in these articles are those of the authors, and do not necessarily reflect the views of UNISCI.

\footnotetext{
${ }^{1}$ Gloria Inés Ospina es investigadora de UNISCI

E-mail: gloriainesospinas@gmail.com

DOI: http://dx.doi.org/10.5209/RUNI.53789
} 


\section{Introducción. Las migraciones en la actualidad.}

El estudio que aquí presentamos no es un trabajo sobre migraciones, sino un análisis sobre los desafíos, retos y consecuencias que los movimientos migratorios, en especial los irregulares, pueden producir en la seguridad de la Unión Europea. Para ello partimos del estudio de la primera Estrategia de Seguridad que se publicó en la Unión Europea en 2003 y que tenía por objetivo la prevención de una serie de fenómenos que podrían afectar la seguridad de los países componentes de Schengen, abordando los problemas que fueran surgiendo en un mundo cada vez más interconectado y que afectara a la UE. Se hará una breve incursión en el intento de renovación de la Estrategia de Seguridad en el año de 2008, para pasar luego, a analizar la propuesta de los Ministerios de Exteriores de cuatro países europeos y su pretendida puesta a punto de una nueva Estrategia con vistas a muy largo plazo y terminar nuestra investigación con las nuevas iniciativas de una Estrategia Europea de Seguridad, por parte de la representante de la política exterior europea, Federica Moguerini.

Como hemos venido señalando en diversos estudios ${ }^{2}$, las migraciones actuales son un fenómeno único y de dimensiones mundiales. Lo reitera también el Consejo Europeo en la reunión de 28 de junio de 2016 cuando suscribe que: "la migración es un reto mundial que requiere una respuesta firme de la comunidad internacional". ${ }^{3}$ En la actualidad, cerca de 250 millones de personas son migrantes por todo el mundo ${ }^{4}$, frente a los 232 millones del año 2013, de ellos aproximadamente el 10\% son inmigrantes irregulares y 88 millones migrantes menores no acompañados en el mundo. La mayor parte de estos migrantes lo hacen para lograr mejores condiciones de vida de las que tienen en sus países de origen. A ellos hay que sumar 24 millones de refugiados que huyen de la guerra y 40 millones de desplazados internos, que han tenido que abandonar sus casas dentro de su propio país.

Como bien puede comprobarse por los datos de las agencias de ACNUR para el mundo y FRONTEX en el caso de la Unión Europea, la mayor parte de la migración mundial lo hace de forma regular o legal, es decir, con un permiso de entrada a un país extranjero. Por tanto, esta migración no está contemplada en las estrategias de seguridad de la Unión Europea, como potencialmente peligrosa. Sí lo es por el contrario la inmigración irregular, por la forma de entrada, por la vía que escogen para dirigirse a los países de destino y también por la vulnerabilidad que sufren en los países a dónde logran llegar.

En cuanto al número de migrantes irregulares que han entrado por las fronteras exteriores de la Unión Europea en este año 2016 y el pasado 2015 las cifras que nos ofrecen las agencias como FRONTEX Y ACNUR, son aproximadas. En primer lugar, porque no se han llevado registros fiables de entradas por las fronteras exteriores, el carácter oculto de la inmigración irregular dificulta cualquier tipo de cuantificación ${ }^{5}$, y en segundo lugar, porque las estimaciones no son estadísticas reales, y se basan en diferentes metodologías, unas cuantifican las entradas por fronteras exteriores marítimas solamente y otras cifras son de

\footnotetext{
${ }^{2}$ Ospina, Gloria Inés: "Los movimientos migratorios irregulares en la Estrategia de Seguridad Nacional 2013”, en Marquina, Antonio (ed), (2015): La Estrategia de Seguridad Nacional 2013. Un pavimento deslizante. Madrid, UNISCI, pp. 487-525. Y Ospina, Gloria Inés: “La inmigración desde el Magreb. Un reto para la Unión Europea”, en Marquina, Antonio, (ed), (2015): La Unión Europea y el Magreb. Reestructurando un imaginario, Madrid, UNISCI, pp. 253-292.

3 Reunión del Consejo Europeo. Secretaría General del Consejo Europeo. Bruselas, 28 de junio de 2016, p. 3

4 "Migración Internacional en su máximo histórico". Banco Mundial. 2015, en:

http://www.bancomundial.org/es/news/press-release/2015/12/18/international-migrants-and-remittancescontinue-to-grow-as-people-search-for-better-opportunities-new-report-finds

${ }^{5}$ Comisión Europea:Medidas Prácticas para la Reducción de la Migración Irregular. Comisión Europea. Red Europea de Migración. ANEXOS. Octubre 2012.
} 
entradas por fronteras marítimas y terrestres, con lo cual se pueden encontrar datos para el total de la Unión Europea de 1.039.000 migrantes irregulares ${ }^{6}$ que entraron en 2015, y de 1.015.078, para el mismo año, entradas de migrantes solamente para entradas por Grecia e Italia, según sean datos de FRONTEX o de ACNUR. ${ }^{7}$ En lo que va de año, la cifra es de 301.583 entradas sólo por mar, de inmigración irregular, en la Unión Europea, según estimación de la agencia de la ONU.

La globalización de las comunicaciones ha influido de forma general en el movimiento de personas por todo el mundo, de forma especial para todas las personas que buscan un empleo y las que aspiran a un mejor estatus de bienestar en países económicamente fuertes. El envejecimiento de las poblaciones y la reducción de la mano de obra en la mayor parte de los países desarrollados es también un incentivo que atrae a gran número de personas desde los países menos desarrollados. Según datos de la $\mathrm{OIT}^{8}$, una quinta parte de la población en los países desarrollados tiene 60 años y más, y según previsiones para el año 2050 la proporción se elevará a más del $30 \%$ de la población, mientras que en la mayor parte de los países en desarrollo menos del 10\% de la población tiene 60 años.

La atracción que de forma particular ha ejercido la Unión Europea sobre sus vecinos, es una de las causas del movimiento migratorio que de forma desordenada se está produciendo con enorme presión desde hace unos años sobre las fronteras europeas. Unas veces por causa de la inestabilidad, pobreza e inseguridad de los países de origen de la migración, como la miseria en Kosovo y la tiranía en Eritrea, otras debido a la serie de conflictos que se incrementan en el vecindario, especialmente los de Siria, Irak, Libia, sin olvidar Afganistán. También influye en esos movimientos de inmigración la estabilidad, seguridad y libertad que ofrece un espacio como Schengen, del que se benefician 28 países de la Unión Europea y es polo de atracción para las poblaciones con menores recursos económicos y falta de seguridad en sus países de origen y sobre todo, la búsqueda de refugio, que impulsa a gran número de personas, solicitantes de asilo, a conseguir su objetivo sea por la vía que sea.

Una de las cuestiones que debe resolver la Unión Europea en conjunto es la puesta en práctica de un sistema de asilo y migración justo, equitativo y coherente, que sea vinculante a todos y cada uno de los países que forman Schengen, ${ }^{9}$ abandonando la discrecionalidad que tienen los Estados en este asunto.

La migración irregular es objeto de preocupación para la seguridad de cualquier país, y en este caso para la Unión Europea. Migración irregular de personas que viajan sin documentación que les autorice a vivir y a permanecer en otro país fuera del suyo propio, que se ponen en manos de "pasadores", o mafias que los transportan de mano en mano, desde los países de origen hasta los de destino, si es que pueden llegar a contarlo. Mafias que, en la mayoría de los casos, están compuestas por personas cercanas, familiares, hermanos, tíos, vecinos, padres, amigos, que les prometen que el viaje es seguro y que llegarán a su destino. Una forma que les hace confiar en aquél o aquellos en quienes han depositado su esperanza. Les animan a salir de sus países para conseguir mejorar su existencia y les prometen un futuro

\footnotetext{
${ }^{6}$ Según la agencia FRONTEX para el año 2015, en: http://frontex.europa.eu/trends-and-routes/centralmediterranean-route/ y http://frontex.europa.eu/trends-and-routes/eastern-mediterranean-route/

7 "Refugees/Migrants Emergency Response-Mediterranean". UNHCR, en: http://data.unhcr.org/mediterranean/regional.php

8 "Promover una migración equitativa", Oficina Internacional del Trabajo. 105 Reunión.(2016)

${ }^{9}$ Véase el epígrafe: El Asilo Prioritario.
} 
de auténtica abundancia ${ }^{10}$. Pero nada de eso resulta ser cierto. A cambio, les exigen el pago del viaje, que al principio no es demasiado costoso, pero que se va incrementando a medida que van avanzando en el camino y van cruzando fronteras. Migración abocada a toda clase de atropellos, a las que se les roba todo lo que tienen y no tienen, porque los viajes no son gratis, y las condiciones de riesgos son enormes, incluida la pérdida de la propia dignidad y la pérdida de la vida. La mayoría, por no decir todos, quedan endeudados de por vida con los traficantes de personas, y las familias que han dejado quedan enlazadas con las deudas que se han ido contrayendo a lo largo del viaje hacia el pretendido paraíso. ${ }^{11}$

La característica por tanto de este $10 \%$ de los movimientos migratorios actuales es la ilegalidad de los mismos, el manejo por parte de pasadores, que son los que se benefician de este tráfico de personas, porque en sí mismo, es un tráfico ilegal de personas, mafias que saben perfectamente cuando hay que salir, por dónde hay que cruzar las fronteras y los que están marcando la pauta de las políticas de migración de los países occidentales, principalmente de la Unión Europea y de los Estados Unidos de América. Se caracteriza por el desorden, la vulnerabilidad en que transportan a los migrantes, los costes del viaje, que son desorbitantes, condenando al migrante a la cuasi esclavitud, la fórmula del atajo es la que predomina, cruzando clandestinamente las fronteras, donde cuentan con facilitadores $^{12}$, obligados a deshacerse de cualquier identidad, para evitar la deportación, y arriesgándose a vivir con total indefensión en los países de destino.

Otro tipo de migrantes son los denominados legales, con permisos de entrada, visados de turista y permisos de estancia de corto período. Entran por aeropuertos y puertos y se quedan en los países a donde fueron a hacer turismo, donde parece que no existe un seguimiento de los extranjeros que han entrado por alguno de los puestos fronterizos y no han vuelto a su país de origen. Aquí también se crea migración irregular y vulnerable, por la carencia de permisos, que abocan a esta migración a aceptar cualquier tipo de oficio o trabajo, sin tener derecho a reclamar ante injusticias, y a vivir clandestinamente.

Está la migración de trabajadores contratados en origen, de todo tipo, altamente cualificados, temporeros, investigadores, y podríamos incluir también a los estudiantes, que con todos los permisos necesarios para vivir sin miedo y con su identificación vigente, vienen para enriquecer a los países de destino, con su trabajo, con su emprendimiento y también para

\footnotetext{
${ }^{10}$ Analistas sobre seguridad opinan sobre la falta de investigación con la que cuenta la UE respecto a la migración que está en camino hacia sus fronteras, lo que le hace muy vulnerable frente a la posición de las mafias que mueven las corrientes migratorias según los informes que les llegan por móviles o internet . Si la UE no tiene personal que se adelante en los datos o cifras de migrantes y les persuada de no arriesgar sus vidas por un espejismo, habrá siempre una asimetría de conocimiento. Se acusa también por parte de investigadores de universidades europeas a la UE, a los dirigentes de la UE de estar creando inestabilidad en las fronteras de los países vecinos, debido a sus cambiantes políticas de fronteras. Parkes Roderick: "Migration to Europe: the numbers game", European Union Institute for Security Studies (EUISS). no 18, junio 2016, pp 2, en: http:/www.iss.europa.eu/uploads/media/Brief 18 Migration.pdf

${ }^{11}$ Al respecto existe un interesante y estremecedor reportaje publicado por el periódico el País: "Desierto del Sáhara: el otro Mediterráneo". En él se cuentan las increíbles experiencias de varios migrantes que trataron de llegar a la Unión Europea por medio de rutas clandestinas, dominadas por pasadores o mafias que se adentran al desierto del Sáhara de dónde la mayor parte de los migrantes perecen en el camino, a causa de la falta de agua, agobiados por la arena que les traga, literalmente, o por los maltratos y abusos que sufren a manos de sus "pasadores". Los migrantes que pudieron contar sus experiencias lograron huir de ese infierno en lugares donde existían oficinas de la Organización Internacional de las Migraciones. Lucas, Angeles:“Desierto del Sáhara: el otro Mediterráneo" El País, 7 de enero de 2016, en: http://elpais.com/elpais/2015/12/09/planeta futuro/1449663616 844803.html

${ }^{12}$ Comisión Europea: Medidas Prácticas para la Reducción de la Inmigración Irregular. Red Europea de Migración, octubre 2012. p. 7.
} 
adquirir unos estudios y habilidades profesionales que les servirán más adelante para contribuir al desarrollo y prosperidad de sus países de origen.. Migración laboral que se extiende por todas las regiones del mundo, de los cuales el 48,5\% se concentran en dos regiones, América del Norte y la Unión Europea. ${ }^{13}$ Migración que avalan todos los gobiernos y agencias internacionales como la Organización Internacional del Trabajo, que apuestan por una migración laboral que podría equilibrar el envejecimiento de sociedades avanzadas y también equilibrar los beneficios para las economías en desarrollo y desarrolladas. ${ }^{14}$

Por tanto, debemos tener en cuenta que en este abanico de migrantes, los más indefensos de todos y los más abocados a una vida dominada por redes mafiosas en los países de destino es la migración denominada irregular. De ahí que sea este tipo de migración la que crea desafíos a la seguridad de los países a donde se dirige, no porque los migrantes en sí mismos no sean fiables, sino porque las circunstancias que les rodean les pueden llevar a ser “carne de cañón” de gente sin escrúpulos. En la misma situación se encuentra la migración de Menores No Acompañados. ${ }^{15}$

En la Estrategia de Seguridad de 2003 y la puesta al día de la misma en 2008 se califica a los movimientos irregulares como Delincuencia Organizada y son considerados como desafíos a la seguridad de la Unión Europea.

\section{Una Europa segura en un mundo meior.}

Este es el título de la Estrategia Europea de Seguridad de diciembre de 2003. En su preámbulo se manifestaba que, "Europa no ha sido nunca tan próspera, tan segura ni tan libre. La violencia de la primera mitad del siglo XX ha dado paso a un periodo de paz y estabilidad sin precedentes en la historia europea". ${ }^{16}$

Europa había superado las contiendas que jalonaron su Historia, y más en concreto las dos contiendas mundiales que la llevaron a enfrentamientos sangrientos en su suelo en los primeros años del siglo XX, por tanto, era lógico que el optimismo envolviera el texto. Sin embargo, el mundo experimentaba cambios impredecibles y una interconexión cada vez mayor, en todos los aspectos, incluido el del movimiento de personas de forma irregular. Y por si fuera poco, los "mensajes contradictorios" desde el exterior de la Unión Europea, indicaban que la paz no era un hecho en sí, sino una voluntad de conseguirla. El sistema mundial se veía afectado progresivamente por el terrorismo, esencialmente de origen islamista, en variadas vertientes, y lo sorprendente era el lenguaje que se acabó utilizando en la Estrategia de de Seguridad Europea de 2003, muy al contrario de lo que se venía experimentando, en cuanto a seguridad, desde el año 2001, con el atentado a las torres gemelas en septiembre de ese mismo año, en Nueva York.

Con la perspectiva que se anunció por parte de la Estrategia Europea de Seguridad de 2003, se configuraba un mundo, con la Unión Europea, como espacio libre de conflictos, polo de atracción, para todo el mundo, y "baluarte de estabilidad”. Por tanto, se dio la imagen de la UE como de "paraíso" a donde todo el que lo quisiera se podía dirigir para resolver sus problemas.

\footnotetext{
${ }_{13}^{13}$ Promover una migración equitativa. Oficina Internacional del Trabajo. 105ª Reunión.(2016)

14 Ibid.

${ }^{15}$ Véase el epígrafe: Menores No Acompañados: Una Grave Responsabilidad Europea.

${ }^{16}$ Preámbulo de la Estrategia Europea de Seguridad. 2003, Una Europa Segura en un mundo mejor. Estrategia Europea de Seguridad, Bruselas, 12 de diciembre de 2003.
} 
No sólo era un sitio seguro para todo el necesitado de protección, sino que los avistados "pasadores" de migración irregular vieron cómo poder montar su negocio aprovechándose de la necesidad de sus compatriotas y de los refugiados que huían de los conflictos. ${ }^{17}$

\subsection{Las migraciones en la Estrategia Europea de Seguridad de 2003.}

Se enfatizaba que esta Estrategia de 2003 era una herramienta que la Unión Europea debía darse para asumir la responsabilidad en el mantenimiento de la seguridad mundial y contribuir a la construcción de un mundo mejor.

El contexto mundial en el que se ultima esta Estrategia está jalonado por la puesta en marcha del Tratado de $\mathrm{Niza}^{18}$, por las sombras que aún quedaban de la sangrienta Guerra de los Balcanes, (1991-2001), y en la que la Unión Europea fue una mera espectadora incapaz de comprometerse, y con el inicio de la Guerra de Irak.

A este respecto es importante enfatizar que, si la Unión Europea quiso comprometerse con la seguridad mundial, fue en parte como "acompañamiento" de la seguridad que garantizaban los Estados Unidos por medio de la OTAN. Así se reconoce en la propia EES, cuando se dice: "Estados Unidos, con una posición dominante como potencia militar, había desempeñado un papel esencial en la integración y la seguridad europeas, por medio de la OTAN". ${ }^{19}$ Con lo cual se desprende que era importante para la UE implicarse un poco en la seguridad del mundo y apoyar así al país que tanto había hecho por Europa en el pasado y en la construcción europea.

Es decir, un mundo cada vez más convulso y una Unión Europea pretendiendo ser un Actor Global, en cuyo territorio reinaba la "paz", promocionando también la resolución pacífica de los conflictos, antes que la prevención, pero con un "defensor" como los Estados Unidos que eran en esos momentos los que garantizaban la seguridad occidental.

En relación con nuestro tema, la Estrategia Europea de Seguridad 2003, considera los flujos migratorios irregulares como una de las vertientes de la Delincuencia Organizada, haciendo hincapié que "Europa era un objetivo de esta clase de delincuencia". Manifestando también que este tipo de movimientos de migración irregulares representaban una amenaza interna para la seguridad de la UE con una dimensión exterior, manifestada por el tráfico transfronterizo de drogas, mujeres, y armas. Haciendo hincapié en que todo estos tráficos

\footnotetext{
${ }^{17}$ Primero fueron los propios vecinos de países como Senegal, Gambia, Mauritania, Malí, Guinea Conakri, Cabo Verde, Sierra Leona, Ghana, los que ofrecían la posibilidad de embarcar a los más jóvenes y aventureros, ofreciéndoles la oportunidad de una mejora en las condiciones de vida, luego serían grupos de mafias. Las madres en Senegal se dispusieron a evitar estos viajes, después de haber tenido noticias de naufragios y muerte de sus hijos, dedicándose a evitar que otras madres sufrieran lo que ellas habían padecido. El colectivo se llamó Colectivo de Mujeres para el desarrollo integrado y lucha contra la emigración clandestina, dirigido por Yayi Bayam Diouf. Movilización contra todos los que engañan a los jóvenes haciéndoles creer que van a llegar al soñado “paraíso europeo". Véase: Ospina, Gloria Inés:” La inmigración desde el Magreb. Un reto para la Unión Europea”, pag. 259, en: Marquina, Antonio (ed), (2015): La Unión Europea y el Magreb. Reestructurando un imaginario, Madrid, UNISCI, 500 pp.

${ }^{18}$ Tratado de Niza. Por el que se modifica el Tratado de la Unión Europea, los Tratados Constitutivos de las Comunidades Europeas y determinados Actos conexos. (2001/C/80/01). Diario Oficial de las Comunidades Europeas. 10.3.2001. El tratado fue elaborado por el Consejo europeo para modificar los tratados vigentes. Las principales reformas introducidas en el Tratado de Niza incluyen las cooperaciones reforzadas, cuestiones institucionales y la ampliación del uso de mayorías calificadas. El sistema de cooperaciones reforzadas, introducido en el Tratado de Amsterdam, fue fortalecido en Niza y facilitaba una integración más rápida y profunda.

${ }^{19}$ Una Europa segura en un mundo mejor. Estrategia Europea de Seguridad 2003, Bruselas 12 de diciembre de 2003.
} 
podían tener conexiones con el terrorismo. Manifestando que la UE desde 2003 había logrado avances en la lucha contra este problema, en el contexto del Programa de la Haya de $2004 .^{20}$

Si tan seguros estaban de todos estos desafíos, ¿por qué la Unión Europea no actuó en consonancia con lo que predicaba? Si se consideraba a las migraciones irregulares como delincuencia organizada, por qué se ha dejado que el fenómeno avance y aumente en proporciones no deseables para la Unión Europea? ¿Por qué se ha dejado que el fenómeno se "pudra" de tal forma, que sean los traficantes de migrantes irregulares los que hayan tomado la iniciativa de sus "negocios", desde 2001 hasta 2016 ?

Son cuestiones que hoy en día se intentan manejar desde una perspectiva de la "mala conciencia" que aqueja últimamente a gran parte de los habitantes de la Unión Europea, que los países por su cuenta no quieren abordar y mucho menos dar respuesta en coordinación con las Directivas que se han promulgado desde Bruselas para acometer este asunto de los flujos migratorios irregulares.

Volviendo a la Estrategia 2003, se enumeraban así mismo las causas que promovían todos estos tráficos irregulares, tales como el debilitamiento y fragilidad de los Estados, señalando que uno de los componentes de esta descomposición se encontraba en la producción de drogas que minaban las estructuras estatales. De igual manera, en conexión con los movimientos migratorios irregulares se evaluaban los tráficos ilícitos de mercancías como los diamantes, armas ligeras, maderas, que alimentaban conflictos en diversas partes del mundo. Se hacía también una reflexión de cómo todas estas prácticas ilícitas atacaban el imperio de la ley y al orden social. Se advertía sobre la posibilidad de que la delincuencia organizada podría llegar a dominar al Estado. Se hacía igualmente una enumeración de las consecuencias de esta delincuencia como por ejemplo el cultivo de adormideras, de donde se saca la heroína, cuyas mayores plantaciones se encontraban en Afganistán, donde su cultivo servía para pagar ejércitos privados. Heroína que se distribuía por medio de redes de delincuentes de los Balcanes, que en esos años eran responsables de la trata de mujeres. A todo ello se sumaba la piratería marítima, de la que se decía que se debía prestar mayor atención.

Los desafíos a la seguridad de la Unión Europea no hicieron más que ir empeorando, "el mundo libre" cada vez se complicaba más y los retos se globalizaban cada vez con más fuerza.

\section{Algunos de los retos que la UE debió tener en cuenta.}

Desde los años noventa, los movimientos migratorios irregulares venían constituyendo un reto importante para la Unión Europea, especialmente los procedentes de los países del Magreb, a lo que se unió los desplazamientos de refugiados inducidos por las guerras de los Balcanes que afectaron al espacio Schengen, creado en 1985 y que había empezado a funcionar en 1995.

Reto en cuanto a seguridad, como orden público, por la entrada irregular de personas por las fronteras exteriores de una asociación de 28 Estados, que habían "eliminado" sus fronteras interiores entre ellos.

\footnotetext{
${ }^{20}$ El contexto en que se promulga la EES 2003 es claramente de apertura de fronteras para las transacciones comerciales y la inversión, el desarrollo tecnológico y la expansión de la democracia, lo que producía una interacción de los aspectos internos y externos de la seguridad, así como la intervención de grupos no estatales en los asuntos internacionales.
} 
Reto en cuanto a aspectos sociales, con migrantes en situación precaria, sin identificación la mayoría de ellos, porque la han perdido, se la han robado los mafiosos que controlan los flujos migratorios, o porque la han querido ocultar para evitar así la deportación a sus países de origen. Abocados en la mayoría de los casos a vivir de la mendicidad, de la ayuda social o de la propia delincuencia, con mafias que controlan en muchos casos a esta migración y que la dirigen a la prostitución o a la delincuencia en general. Sin contar los que puedan ser dirigidos hacia la delincuencia terrorista.

Reto para la economía, pues la inmigración irregular abastase a la denominada "economía sumergida", que evade los impuestos que los demás ciudadanos estamos obligados por ley a pagar.

Reto también en cuestiones culturales, pues la mayoría de la inmigración procede de países con valores culturales contrarios a los que se defienden en la cultura europea, con normas que se rigen por la religión que envuelve todo su aspecto social, desde la política a la vida privada. Aspectos que en la UE se han eliminado paulatinamente, creándose sociedades con separación de Iglesia y Estado, con sociedades civiles, donde predomina la laicidad, y en donde el derecho de familia está claramente insertado en las leyes nacionales. Cuestiones que se deberían haber tenido en cuenta en las relaciones con los países vecinos, especialmente con los del Magreb y África, donde los productos culturales y los valores culturales son divergentes respecto a los europeos.

Con el agravante, de que estos migrantes de origen islámico no aceptan prácticamente ninguna de las costumbres de la UE. Desde la comida, solicitando otro tipo, hasta las costumbres más democráticas, como es que las mujeres en puestos de dirección no son aceptadas por ellos para dirigirlos. En este sentido es muy elocuente la petición que hacen de que las mujeres policías europeas deben ser apartadas de todos los puestos que les corresponda mandar a un musulmán que ha venido a la UE. Esto sucede en casi todas las Comisarías en donde hemos tenido ocasión de investigar.

\section{Precedentes para la revisión de la Estrategia Europea de Seguridad en 2008.}

En cuanto al tema migratorio se refiere, 2005 fue un año que puso en alerta no sólo a las autoridades españolas sino también a las de la Unión Europea. Desde 2001 la inmigración irregular iba año a año en aumento y los puntos de entrada a Schengen eran las costas italianas, las costas griegas y principalmente por Ceuta y Melilla, ciudades españolas frontera exterior de la UE en suelo africano. Con la "regularización de inmigración clandestina" del año 2005, y la puesta en marcha de Planes Estratégicos para la Integración, España se convertía en un punto atractivo para la inmigración irregular procedente de África, que gracias al efecto “tapón” ejercido por Marruecos había descendido significativamente, pasando de 10.042 personas que llegaron en el primer semestre del año 2004, a 6.361 en el mismo semestre de 2005.

Si para España disminuía la inmigración irregular, para Marruecos cada día representaba un problema. En este país de "tránsito de la inmigración irregular" se iban concentrando personas procedentes de Nigeria, Malí, Mauritania, Niger, Argelia y Libia, como consecuencia directa del blindaje electrónico del Estrecho y Canarias que produjo un "cuello de botella" en la frontera con Ceuta y Melilla, dando lugar a sucesos dramáticos por el asalto por la fuerza de la frontera con Ceuta y Melilla. ${ }^{21}$

\footnotetext{
${ }^{21}$ España procede a reforzar la frontera con Marruecos y envió efectivos pertenecientes a la Legión y a los Regulares. El ministro del lnterior, José Antonio Alonso y su homólogo marroquí Mustafá Sahel, estuvieron de
} 
En 2006: Llegada masiva de inmigración irregular a Canarias. El blindaje del Estrecho obligó a los inmigrantes irregulares a buscar rutas más al sur y más peligrosas. Rutas que partían directamente de las costas de Senegal y de Mauritania, en cayucos, que daban la seguridad de arribar a Canarias, suelo europeo. Este año 2006 llegaron 31.000 inmigrantes a las islas Canarias, lo que alarmó al gobierno del presidente Rodriguez Zapatero, con la consiguiente reunión de su vicepresidenta, María Teresa Fernández de la Vega con el presidente de la Comisión europea, Durao Barroso, el vicepresidente Franco Frattini y con la Comisaria de Asuntos Exteriores, Benita Ferrero-Waldener, para analizar la situación, quienes le prometieron toda la ayuda que necesitara España. ${ }^{22}$

La petición de ayuda por parte de España, vino a reforzar la idea que se venía proponiendo desde los Consejos de Niza y Laeken, respecto a cómo acometer el complejo tema de la inmigración, también tenido en cuenta en el Programa de Acción de la Haya 20052010, referente a la toma de posición de la Unión Europea, por medio del Consejo y del Parlamento para ir implantando una política común de inmigración, por lo que la legislación nacional de los 27 estados miembros, tendría que adaptarse a favor de la comunitaria.

Este mismo año se acuerda por parte de la Comisión Europea un Plan de Política sobre inmigración legal, se publica también una Comunicación sobre el nexo entre migración y desarrollo y otra Comunicación que propone un programa común para la integración de inmigrantes. ${ }^{23}$

Cabe destacar que es un año en que se inician las cumbres y reuniones que tendrán en cuenta a África, en su conjunto, dando como resultado la Conferencia Euroafricana de Migraciones, celebrada en julio de 2006 en Rabat y también la reunión ministerial entre UE y África, sobre migraciones y desarrollo que tendría lugar en Lisboa, en noviembre del mismo año. Reuniones donde se sientan las bases para la acción conjunta dirigida a la lucha contra la inmigración irregular y las causas profundas de las mismas.

En 2007: Año del inicio de la crisis financiera mundial, crisis que afectó directamente a la UE, y con mayor virulencia a los países del sur, como Italia, Grecia, España y Portugal, precisamente los tres primeros frontera exterior de Schengen a donde se dirigían los flujos migratorios irregulares. Año también de la aprobación del Tratado de Lisboa, que iba a constituir la Carta Magna de la nueva Unión Europea o "más Europa”. El capítulo 2, artículo 62, está dedicado a las Políticas sobre Controles de Fronteras, Asilo e inmigración. Entre los cometidos se indicaba que la Unión Europea "garantizaba los controles de las personas y la vigilancia eficaz en el cruce de las fronteras exteriores", así como se comprometía a "instaurar progresivamente un sistema integrado de gestión de fronteras exteriores".

En relación a la política de asilo, la Unión Europea se comprometía a desarrollar una política común en materia de asilo, protección subsidiaria y protección temporal destinada a ofrecer un estatuto apropiado a toda persona procedente de un tercer país que necesitara protección internacional y garantizando el respeto del principio de no devolución.

acuerdo con el refuerzo fronterizo, que también se implementó por parte marroquí, con 1.600 efectivos de seguridad. Medidas disuasorias que sirvieron para que por las costas andaluzas disminuyera también la inmigración irregular.

${ }^{22}$ Ministerio de la Presidencia: "15 Medidas urgentes de la UE contra la inmigración ilegal” Vicepresidencia Primera del Gobierno. Centro de Prensa, 24 de mayo de 2006.

${ }^{23}$ Comunicación de la Comisión sobre las prioridades politicas en la lucha contra la inmigración ilegal de los nacionales de terceros países. Bruselas 19.7.2006 
También se comprometía, por el Tratado de Lisboa, a que el Parlamento y el Consejo adoptarían, con arreglo al procedimiento legislativo ordinario, medidas relativas a un sistema europeo común de asilo que incluyera:

a) un estatuto uniforme de asilo para nacionales de terceros países, válido en toda la Unión;

b) un estatuto uniforme de protección subsidiaria para los nacionales de terceros países que, sin obtener el asilo europeo, necesiten protección internacional;

c) un sistema común para la protección temporal de las personas desplazadas, en caso de afluencia masiva;

d) procedimientos comunes para conceder o retirar el estatuto uniforme de asilo.

Incluía también la asociación y la cooperación con terceros países para gestionar los flujos de personas solicitantes de asilo o protección subsidiaria o temporal.

Es precisamente este año cuando se refuerzan los compromisos sobre la lucha contra las causas profundas de las migraciones irregulares en la Cumbre Europa-África-Europa, celebrada en Lisboa el 9 de diciembre de 2007.

Se conocían los desafíos que las migraciones irregulares lanzaban a la seguridad de la Unión Europea, se habían estado elaborando y celebrando infinidad de reuniones, cumbres y encuentros para dar una solución a todo estos temas, se recogía en el Tratado de Lisboa todo la batería de medidas que en estos momentos se está volviendo a retomar en Bruselas para dar una salida medianamente digna a este embrollo en que se ha metido la Unión Europea con el tema complejo y sangrante de las migraciones irregulares y los solicitantes de asilo, y llegamos a 2016 y todavía parece que no se han tomado en cuenta seriamente las propuestas y buenas palabras que llenan las Directivas de la Unión Europea sobre cómo abordar el tema de las migraciones en general y de sus causas profundas.

\section{El Sahara: ¿Espacio opaco para la delincuencia?}

Este es otro de los asuntos que no se aborda de forma decidida y franca. Desde el año 2005, cuando se produjo la crisis migratoria en las ciudades españolas de Ceuta y de Melilla, debido al tapón que se ejercía en Marruecos, junto con las medidas disuasorias del blindaje electrónico del Estrecho y Canarias, se dieron las voces de alarma, por parte de investigadores, especialmente magrebíes, que conocían ya lo que estaba sucediendo en el desierto del Sahara. Un espacio transformado por efecto de la globalización, en opinión del profesor Alí Bensaad, Geógrafo y profesor de la universidad de Provence e IREMAN, "lugar donde la distancia ha afectado a todas las configuraciones espaciales", especialmente las que actuaban como señales que canalizaban e impulsaban el movimiento de personas. "El rodeo sahariano", como lo califica, era uno de los más desatendidos ${ }^{24}$. Lugar cruzado por innumerables camiones-catedrales, que se pierdían en el desierto, yendo cargados con $100 \mathrm{y}$ hasta 200 personas. Este movimiento de personas por el desierto del Sahara se había convertido en el mayor que se conocía en el mundo. Movimiento perjudicial por lo clandestino, que iba convirtiéndose en más informal, deslizándose por un espacio periférico y extremadamente opaco. Estas últimas características, periférico y opaco le han convertido en uno de los principales itinerarios para llegar a la Unión Europea, hasta el punto que, como indicaba Bansaad, "podía convertirse en un grave riesgo geopolítico y social, tanto para el Magreb como para la Unión Europea y para el resto de África”. Lo más preocupante es la transformación paulatina que van experimentando las redes de inmigrantes irregulares en

\footnotetext{
${ }^{24} \mathrm{Al}$ respecto consultar el capítulo sobre el Sahara y Mali, en este mismo número.
} 
redes que sostienen a la delincuencia organizada, aunque los migrantes no sean conscientes de ello. ${ }^{25}$

\section{Revisión de la EES en 2008. ¿Por qué?}

En el preámbulo del Informe sobre la aplicación de la Estrategia Europea de Seguridad, de 11 de diciembre de 2008 se dice: "A los cinco años de la adopción de la Estrategia Europea de Seguridad, pesan sobre la Unión Europea más responsabilidades que en ningún otro momento de su historia". ${ }^{26}$

La Unión Europea también se había ampliado y por medio de ello había extendido la democracia y la prosperidad a todo el continente. Se vislumbraba una estabilidad también respecto a los países vecinos tanto del Este como del Sur. Sin embargo, los retos y amenazas que la Unión Europea debía enfrentar se habían vuelto más complejos e interdependientes

De acuerdo con los principios de las Naciones Unidas se ponía énfasis en la prevención de los conflictos, pero se seguía actuando para su resolución de forma pacífica. En cuanto a la seguridad se enfatizaba que "si queremos proteger nuestra seguridad y responder a las expectativas de nuestros ciudadanos", deberíamos estar en condición de determinar los acontecimientos. Entre los principios que se esgrimían, basados en la Carta de las Naciones Unidas y en los compromisos de la OSCE, la Unión Europea debía "tener claro que el respeto de la soberanía, de la independencia y de la integridad territorial de los Estados y la resolución pacífica de los conflictos no son negociables". Para luego dejar claro que no era admisible que las cuestiones territoriales se resolvieran con amenazas o el uso de la fuerza militar en ningún lugar.

A este respecto es muy elogiable que la UE mantenga estos principios, pero es un contrasentido respecto a las fronteras del espacio Schengen donde no parece que haga respetar su soberanía.

Con esta Estrategia Europea de Seguridad 2008, el Consejo Europeo no pretendía sustituir la anterior del año 2003, sino reforzarla, ante los retos y principales amenazas que en esos años se habían acentuado. Así lo reconoce la Estrategia Europea de Seguridad 2008, cuando subraya que: "el fracaso de los Estados afecta a nuestra seguridad en forma de delincuencia, de inmigración ilegal (sic), y en los hechos de piratería. El terrorismo y la delincuencia organizada han evolucionado y representan un nueva amenaza, incluso en el seno de nuestra propia sociedad".

En lo que a nuestro tema se refiere, las migraciones irregulares se incluían ahora en un apartado titulado: Terrorismo y Delincuencia Organizada, como un todo, sin especificar más nada, cuestión que en la Estrategia Europea de Seguridad de 2003, era considerado como un tráfico de personas. Se promulgaba en el mismo texto que era muy importante redoblar los esfuerzos de la lucha contra la radicalización y la captación de terroristas, haciendo frente a las ideologías extremistas y persiguiendo la discriminación. Ponía como ejemplo la

\footnotetext{
${ }^{25}$ Bensaad, Alí:”Le Sahara, vecteur de mondialisation”, Maghreb-Maachrek, no 185 (Otoño 2005), pp.7-12 y "Les migrations transsahariennes. Une mundialisation pour la marge", Magreb-Maachrek, no 185 (Otoño 2005), pp. 13-36. El Informe sobre Migraciones del año 2013, al analizar las rutas de la migración a escala mundial, no nombra la que tiene lugar por el desierto del Sahara. En: "Informe sobre las Migraciones en el Mundo 2013. El bienestar de los migrantes y el desarrollo". Organización Internacional para las Migraciones. (OIM), Ginebra (2013).

${ }^{26}$ Informe sobre la aplicación de la Estrategia Europea de Seguridad. Ofrecer seguridad en un mundo en evolución. Bruselas 11 de diciembre de 2008
} 
importancia del diálogo intercultural, en foros como el de la Alianza de Civilizaciones. Igualmente se hacía referencia a este tema en el apartado sobre el Cambio Climático, considerando que las migraciones irregulares y los refugiados crecerían en forma exponencial, ya que este asunto del clima era "un multiplicador de amenazas", y por consiguiente afectaría directamente a la seguridad de la Unión Europea, como un factor de inestabilidad. ${ }^{27}$

En cuanto a la promoción de los valores europeos en su vecindario por medio de la Política Europea de Vecindad, y más concretamente hacia el Mediterráneo, se hacía una evaluación un tanto pesimista en la EES 2008, porque siendo una zona de importancia y fuente de oportunidades para la UE, se consideraba que planteaba muchos problemas complejos, entre los que se enumeraban la insuficiencia de las reformas políticas y las "migraciones ilegales" (sic.).

A este respecto, cabe añadir que se fundaban las esperanzas en la acción que pudiera llevar a cabo la Unión por el Mediterráneo, iniciada en julio de 2008, que pudiera dar un impulso político renovado para acometer estos procesos con los vecinos del sur, a través de un programa de trabajo amplio, que incluyera entre otras cosas, la seguridad marítima, la energía, el agua y las migraciones.

Debemos también decir que, visto los empujes migratorios de los últimos años, especialmente a partir de 2015 hasta la fecha en que se publique este estudio, los resultados en cuanto a ordenar los flujos migratorios desde los países del Magreb, son nulos. Con el agravante de poner en cuestión la política de migración y asilo de la Unión Europea.

En diferentes contextos se incluía el asunto de las migraciones, pues no en vano se aseguraba en ambas EES que sin seguridad no había desarrollo. Concretamente, en el apartado titulado: Relación entre seguridad y desarrollo, se especificaba que como se reconoció en la EES 2003 y en el consenso europeo sobre desarrollo de 2005, no podía existir desarrollo sostenible sin paz y seguridad, y sin desarrollo y erradicación de la pobreza no se podría lograr una paz sostenible. ${ }^{28}$

\section{Contexto mundial de Informe de aplicación de la Estrategia 2008.}

El mundo iba cambiando y los desafíos eran cada vez más complejos. La denominada "era Bush" estaba desapareciendo. Al año siguiente, con la nueva administración americana del presidente Barak Obama se daba paso a la "retirada o intento de desenganche" de todos los conflictos en los que los Estados Unidos participaba con tropas. La sensación que se creaba era de ir hacia una progresiva y deseada paz universal. Sin embargo, con la progresiva retirada de los Estados Unidos y sus socios de la OTAN de los centros de conflictos, incluso con su sólo anuncio, las fuerzas enemigas fueron recolocándose en el escenario del conflicto. Un ejemplo son Afganistán e Irak. Lugares que se convirtieron en estos últimos años en sitios

\footnotetext{
${ }^{27}$ Desde el año 2008 con la publicación del libro Marquina Antonio (ed) (2008): Flujos migratorios subsaharianos hacia Canarias-Madrid, Madrid, UNISCI, se puso el acento por primera vez, en nuestro país, sobre la importancia y la repercusión que tendría en los movimientos de personas, a no muy largo plazo, el proceso denominado cambio climático. En el prólogo del mismo se señalaba que:"es un libro que trata de ser innovador, (...), en la aproximación al tema migratorio abordando las variables medioambientales e integrándolas como uno de los hilos conductores más significativos que a medio plazo incidirá en el incremento de los flujos migratorios procedentes del África Subsahariana”.

${ }^{28}$ Esta condición a la que se alude se lleva repitiendo en todos los documentos y Estrategias Europeas de Seguridad que se han elaborado desde 1992. ¿Por qué ha habido tanta dejadez en este asunto, tan importante para el bienestar de nuestros vecinos, que es el bienestar nuestro? Véase al respecto el epígrafe: Promover los valores europeos a su vecindario, ¿Error o acierto? Epígrafe 8.
} 
invivibles, y, por lo tanto, desde los cuales, hoy en día, proceden la mayoría de los migrantes irregulares que intentan acceder por las fronteras exteriores de Schengen. Países vecinos como Pakistán son otro de los puntos de procedencia de esta migración irregular, que recoge también los migrantes irregulares desde Afganistán,con el agravante de que son las autoridades de puestos fronterizos con Irán las que facilitan documentación falsificada para las mafias. También participan de estos negocios gran cantidad de ciudadanos turcos. ${ }^{29}$

Durante el segundo semestre de 2008, bajo la presidencia francesa de la UE, se vuelve a hacer hincapié en la importancia de desarrollar una política europea global en el ámbito migratorio. Para ello nada mejor que la propuesta de un Pacto europeo sobre migración y asilo en el marco del Consejo Europeo. ${ }^{30}$ Pacto destinado a sentar las bases de una política común reforzada con un espíritu de responsabilidad y solidaridad, en donde se incluían cuatro dimensiones del enfoque global de las migraciones, como eran: mejor organización de la inmigración legal, lucha más eficaz contra la inmigración ilegal, fomento de una estrecha colaboración entre los países de origen, tránsito y destino de los inmigrantes, y mejorar los controles de fronteras exteriores de Schengen.

Se llamaba la atención sobre la importancia de la coordinación en el seguimiento de las Directivas del Consejo Europeo, sabiendo que "en un espacio de libre circulación de personas, como es el espacio Schengen, las decisiones tomadas por unos, repercuten en los otros estados". ${ }^{31}$

El primer paso para conseguir tan deseado pacto europeo para la inmigración fue la aprobación por la Eurocámara de la Directiva de Retorno, de 18 de junio de 2008. Con ello se promovía el retorno voluntario de inmigrantes ilegales (sic), procedentes de países no comunitarios. Se volvía a remarcar la importancia de promover la migración regular y perseguir la irregular.

Período de progresos en la globalización a escala mundial. Si antes la mundialización se inscribía en el ámbito económico esencialmente, ahora el progresivo avance de la tecnología permitió que la interconexión fuera real, no sólo para el progreso sino también para el delito. Por tanto, una interconexión global de riesgos y amenazas ${ }^{32}$.

\section{Promover los valores europeos a su vecindario. ¿Error o acierto?}

La Política Europea de Vecindad, en su punto 8, sobre migración y movilidad, destaca que es "un punto clave para la cooperación de la Unión Europea y sus socios vecinos". De ahí la importancia que se le suele dar a los encuentros entre los países de ambas orillas del Mediterráneo en materia de inmigración, especialmente ahora que la situación en Libia está propiciando una salida ingente de migrantes con destino a las costas italianas.

Esta política se centra especialmente en los beneficios de la movilidad para la educación, la cultura y la ciencia y respecto a la inmigración irregular, indica que es un desafío común. Para

\footnotetext{
${ }^{29}$ Estudios sobre el modus operandi de las mafias de la migración clandestina, revelan las ganancias y la forma de dirigir los flujos migratorios hacia la Unión Europea. Desde Pakistán-Irán y hacia las fronteras Schengen en rutas clandestinas, terrestres, andando y en lanchas. Total del viaje 8.000 euros. Utilizando a los migrantes como jefe de expedición para no ser arrestados por las autoridades. En: Study on smuggling of migrants. Characteristics, responses and cooperation with third countries. Case study: Pakistan, Turkey, Greece. European Commission. 2014

${ }^{30}$ Pacto europeo sobre migración y asilo. Consejo de la Unión Europea. Bruselas, 24 de septiembre de 2008

${ }^{31}$ Una Europa que actúa para hacer frente a los desafios actuales. Programa de Trabajo, Presidencia francesa del Consejo de la Unión Europea. 1 de julio-31 de diciembre de 2008

${ }^{32}$ Véanse los capítulos de esta misma publicación dedicados a toda esta serie de amenazas.
} 
hacer frente a este desafío se introduce en los Planes de Acción de la Política Europea de $\mathrm{Vecindad}^{33}$, en el ámbito de la Justicia y de Asuntos de Interior, una serie de aspectos, que abarcan desde la cooperación estrecha en la gestión de fronteras, la migración y la lucha contra el terrorismo, el tráfico de seres humanos, el tráfico de estupefacientes y armas y la lucha contra la delincuencia organizada, el blanqueo de dinero y los delitos económicos y financieros. Nuevamente se ponen de relieve los temas reiterados durante años, pero a los que no se da solución de forma seria.

Como lo indicamos anteriormente, la Unión Europea en sus relaciones con los países vecinos ha tenido como objetivo conseguir la estabilidad, la buena vecindad y la prosperidad de los mismos, basados en los "intereses mutuos y los valores compartidos", para lo cual estimó oportuno la necesidad de ampliar el abanico de la Política de Vecindad no sólo a los vecinos de las repúblicas de la antigua Unión Soviética, como lo hizo en 2003, sino también a sus vecinos del Magreb meridional, que además de compartir valores europeos con los vecinos de la margen sur del Mediterráneo, se proponía también el ordenamiento de los flujos migratorios procedentes de países como Marruecos, Argelia, Túnez y Libia. Para conseguir la estabilidad y la seguridad la Unión Europea ofrecía un marco de relaciones privilegiadas, fundamentadas en valores como la democracia, los Derechos Humanos, el estado de Derecho, el buen gobierno, principios de economía de mercado y desarrollo sostenible, y fomento de buenas relaciones de vecindad.

Lo más llamativo a nuestro entender, es que la Comisión "mantuvo conversaciones exploratorias" con los socios de Europa oriental y el Mediterráneo meridional que tenían acuerdos de Colaboración o de Asociación con la Unión Europea para abordar la concepción de esta política de vecindad, y todos mostraron "interés por esta política de vecindad", dando sus puntos de vista sobre sus prioridades que se abordarían en los planes de acción.

Lo que sí queda medianamente claro es que a medida que iba avanzando la ampliación de la Unión Europea, se precisaba una política preventiva para evitar la aparición de" nuevas líneas divisorias entre la Unión Europea y sus vecinos", para lo cual nada mejor se le ocurrió a los dirigentes de Bruselas que "ofrecer a estos la oportunidad de participar en diversas actividades de la Unión Europea”, por medio de una mayor cooperación en los ámbitos de la política, la seguridad, la economía y la cultura.

Además, se recomendaba igualmente el "fomento de la cooperación e integración regionales, como medio para resolver ciertos problemas que se planteaban en las fronteras exteriores de la Unión Europea ampliada", concretamente para el Mediterráneo meridional se proponía que por medio de la Asociación Euromediterránea (el llamado proceso de Barcelona) se aprovecharan la totalidad de beneficios de esta asociación, para fomentar las interconexiones de infraestructuras y redes, en particular las de energía y desarrollar nuevas formas de cooperación.

Los promotores de esta política presuponían que con esta política de vecindad, además de una mayor integración regional, apoyándose en los logros que tenía la Asociación Euromediterránea, en el ámbito del comercio, se apuntalaban, de paso, los esfuerzos para alcanzar los objetivos de la Estrategia Europea de Seguridad $^{34}$ en el Mediterráneo y Oriente Próximo.

\footnotetext{
${ }^{33}$ Que son uno de los elementos vertebradores de la Política de Vecindad de la UE.

${ }^{34}$ Desde 1992 se tuvo la posibilidad de prevenir todos los problemas que hoy tenemos en los países del norte de África y especialmente en el Sahara en su conexión directa con Libia, por no mencionar Oriente Próximo y su
} 
La idea central de la Política Europea de Vecindad, como lo recoge el documento citado, era "contar con un anillo de países que compartan valores y objetivos fundamentales de la UE". Por medio de una cooperación estrecha, por medio de la integración económica y política. Los Planes de Acción constituían un primer paso para la realización de este objetivo y definían el camino a seguir en los próximos cinco años.

Tanto la Asociación Euromediterránea como luego la Unión por el Mediterráneo se propusieron unos objetivos que en su momento parecían alcanzables para afrontar el desequilibrio entre las dos orillas del Mediterráneo producidas por las inestabilidad entre los Estados y por los flujos migratorios, así como dar un nuevo impulso político y comercial al Mediterráneo, con el fin de construir un intercambio socio-cultural, cuyos protagonistas fueran las actores económicos. De los propósitos a la realidad, vemos que distan de haberse conseguido.

A este respecto, la pregunta que se plantea es la siguiente: ¿Son comunes estos valores propuestos por la Unión Europea para la Política de Vecindad entre las dos orillas del Mediterráneo? La respuesta es claramente negativa, pues los valores culturales no son los mismos aunque así lo puedan hacer creer los productos culturales. Comprendemos que la Unión Europea en su legítimo deseo de tener vecinos con gobiernos estables haya promulgado esta carta de buenas prácticas, que podían haber garantizado un armonioso entendimiento entre las dos orillas del Mediterráneo.

Sin embargo, como lo apunta muy acertadamente el artículo de la profesora Mercedes Guinea, en el libro La Unión Europea y el Magreb" "las disparidades y las brechas, no sólo económicas, políticas, culturales, sino también religiosas con el progresivo aumento del islamismo fundamentalista, han impedido que esta "buena y deseada práctica" no se haya visto realizada".

Las relaciones políticas de la Unión Europea con el Magreb se han centrado sobre todo en la seguridad y en los intercambios comerciales. Siempre se ha necesitado de esta vecindad que además tiene lazos fuertes sobre todo con países como Francia e Italia antiguas metrópolis coloniales.

Igualmente, los países magrebíes han necesitado de la Unión Europea como un vecino potenciador de su desarrollo e intercambios comerciales, en mayor o menor medida dependiendo de los países y de su política interna. Así, Marruecos y Túnez han estado siempre más dispuestos al acercamiento con Europa, que Argelia que ha tenido una política más recelosa a los cambios impulsados desde el exterior.

\footnotetext{
“cuasi eterna disputa", hoy agravada con la guerra en Siria. Entre los siete principios de la Declaración de Petersberg prevalecía la idea de "crear un área de confianza y estabilidad". Los riesgos en esta área vendrían principalmente de la "desestabilización del Sur, provocada por la proliferación de armas de destrucción masiva, el acceso al poder de grupos radicales, la presión demográfica, el subdesarrollo económico y las fracturas culturales". Véase: Sánchez Mateos, Elvira: "La Seguridad Global en el Mediterráneo", Revista CIDOB d'Afers Internacionals, $\mathrm{n}^{\circ} 57-58,(2002)$, p. 10

En el apartado sobre Delincuencia organizada, ya lo recoge la Estrategia Europea de Seguridad en 2003 y al respecto se indica que Europa es un objetivo primordial de este tipo de delincuencia como amenaza interna a la seguridad europea con una dimensión exterior vinculada al tráfico transfronterizo de drogas, mujeres, inmigrantes "ilegales" (sic) y armas, que conforman las actividades lucrativas de las bandas de delincuentes. Concluía: "Puede tener vinculaciones con el terrorismo". Véase: Una Europa Segura en un Mundo Mejor. Estrategia Europea de Seguridad, Bruselas 12 de diciembre de 2003.

${ }^{35}$ Guinea, Mercedes: "La política europea de vecindad hacia el Mediterráneo (2003-2015): Impotencia ante un entorno cada vez menos homogéneo y más hostil”, en: Marquina.Antonio (ed) (2015): La Unión Europea y el Magreb. Reestructurando un imaginario, Madrid, UNISCI, pp. 423-456.
} 
En todo este deseo de buena vecindad no se ha tenido en cuenta la asimetría de las relaciones entre las dos orillas del Mediterráneo. Por una parte están los países de la Unión Europea que se distinguen por presumir de Estados laicos, en donde hay separación de Iglesia y Estado, las sociedades se caracterizan por tener regímenes democráticos, elegidos por los ciudadanos, con separación del poder ejecutivo, legislativo y judicial, funcionen más o menos bien estos poderes, cuya economía se basa en las reglas de la economía de mercado, con sociedades que se caracterizan por la tolerancia, donde las mujeres y los hombres se dicen que tienen los mismos derechos. A todo esto hay que añadir que son países cuya política demográfica se caracteriza por tener unas tasas de natalidad bajísimas, con la consabida tasa de envejecimiento muy alta.

Por el contrario, los países de la ribera sur del Mediterráneo, se caracterizan por ser estados con una influencia importante de la religión islámica que conforma la sociedad civil y también la esfera política, a la que da legitimidad, con valores culturales muy alejados de los europeos, donde la mujer todavía no ha alcanzado un grado de igualdad con el hombre, y países cuyos regímenes distan bastante de ser del todo democráticos, incluso hacen alarde de no querer adoptar las características de los países europeos, aunque sus poblaciones anhelen la seguridad y la democracia que distinguen a la Unión Europea. A todo esto hay que añadir que en política demográfica se distinguen por ser sociedades muy jóvenes, con una tasa de natalidad cercana al 3 por mil y con una media por edad de los 15 a 25 años de cerca del $60 \%$ de la población.

Con esta asimetría en valores culturales, en los cuales la Unión Europea no ha tenido en cuenta la "reciprocidad" para conseguir un mínimo respeto por las actividades religiosas de las diferentes confesiones europeas en países musulmanes, sin embargo, sí se ha lanzado a ofrecer unos alicientes europeizantes auspiciando unas relaciones con los vecinos del sur del Mediterráneo que tienden a ser más políticas paternalistas, que de otro nivel, porque se indica que es lo que se debe conseguir, pero sin preguntar si los habitantes de esas naciones lo quieren o no. A este respecto podemos analizar los objetivos y logros de la Política Europea de Vecindad en su vertiente de migración, así como los instrumentos que la Unión Europea tiene para lograr una migración ordenada, pero que no parece que se hayan puesto en funcionamiento, porque lo que se evidencia es una improvisación en la puesta en marcha de todas las medidas relativas a ordenar los flujos migratorios, y más grave todavía, la Unión Europea, desde Bruselas da la impresión de ir siempre arrastras de las tragedias de la inmigración en el Mediterráneo.

La política de vecindad debía haber tenido en cuenta más los valores culturales de las dos orillas, pues ni los países europeos son el Magreb, ni el Magreb es la Unión Europea. Conocer a los vecinos es lo más importante, no regalar nuestros logros a cambio de nada.

En cierto sentido son unas relaciones inducidas por la euforia de la ampliación de la UE, sin tener en cuenta que hay que buscar la forma de conseguir unos valores que regalados no se aprecian, ya que la democracia en los países europeos se ha conseguido a base de mucho sufrimiento y de muchos años de fracasos y de privaciones y de "lucha por la participación ciudadana”. La historia europea ha sido larga en la consecución de las libertades y la seguridad jurídica de la que ahora disfrutamos, así también el tema de los Derechos Humanos se han promulgado como una carta de intenciones gracias a la privación de libertad que sufrió Europa, especialmente durante las dos guerras mundiales. 


\section{La Alianza de Civilizaciones como puente quebradizo para acercar posiciones.}

En septiembre de 2004, en la 59 a Asamblea General de la ONU, el ex presidente José Luís Rodríguez Zapatero propuso una alianza entre Occidente y el mundo musulmán con el fin de combatir el terrorismo internacional por un camino que no fuera un enfrentamiento militar. A esta propuesta se sumó el primer ministro turco Recep Tayip Erdogan, y se sumaron una veintena de países asiáticos, suramericanos y africanos, en especial la Liga Árabe. En el año 2010 se une a esta iniciativa el presidente Barack Obama.

En lo que a nuestro estudio se refiere, no es válida la Alianza de Civilizaciones, porque los campos de acción prioritaria donde se incluyen las migraciones son los Programas Plural Plus, Programas para restablecer la confianza, Comunidad online sobre migración legal e integración, que hacen referencia solamente a las migraciones regulares de estudiantes y trabajadores cualificados.

Por otra parte, es un diálogo "asimétrico"36 entre dos concepciones del mundo muy diferentes, con un "pilar" en Europa y el mundo occidental, que reniega de la religión en general, mientras que el otro "pilar", está representado por un mundo totalmente impregnado del factor religioso, que vertebra las sociedades desde la intimidad hasta la vida pública, con sociedades incluso teocráticas, como es el mundo islámico.

Se puede subrayar, como lo afirma el profesor Marquina, que, "Este planteamiento, precisamente por su asimetría, puede percibirse e incluso también llegar a definirse como una forma de extremismo que se dice querer combatir"

Es un diálogo también dispar porque va de arriba hacia abajo y no al contrario. Y también porque no se comprometen a nada. Es un foro de amigos "con planteamientos superficiales", que en el tema que nos ocupa no ha contribuido a potenciar las migraciones ordenadas, pero sí con un costo para el contribuyente, que está pagando "iniciativas convertidas en auténticos divertimentos".

\section{Las revoluciones árabes}

El estallido de protestas populares que se inició en Túnez a partir del 17 de diciembre de 2010 y que en pocas semanas se extiende por todos los países del Magreb, avanzando por Egipto y llegando hasta Siria, hizo tener la esperanza en la Unión Europea de una pronta democratización del mundo musulmán, con todos los valores occidentales que ello conlleva. Nunca mejor se pudo pensar que la propuesta de la Política de Vecindad estaba dando sus frutos, con nuevas sociedades que abrazaran la democracia, el estado de derecho, la laicidad y los Derechos Humanos.

Pero los “sueños sueños son”, y la realidad estaría conformada por nuevas amenazas a las sociedades occidentales.

Las revoluciones árabes, mal llamadas "Primaveras Árabes" estuvieron bien alejadas de estas siglas. Los grupos que estaban preparados y organizados eran precisamente los grupos fundamentalistas islámicos, que junto con la garantía económica que les proporcionaron países como Arabia Saudita y Qatar, se pudieron movilizar y dar el consabido cambio de

\footnotetext{
${ }^{36}$ Marquina. Antonio: "Nota Editorial", UNISCI DISCUSSION PAPERS, .n 14 (mayo 2007), en: http://www.ucm.es/data/cont/media/www/pag-72527/UNISCI14Nota.pdf
} 
dirección a las "revoluciones" tomando un rumbo antagónico a los valores promocionados por la Unión Europea.

Y como si los europeos, desde la dirección en Bruselas, no se hubieran enterado del rumbo que tomaban los acontecimientos, el 8 de marzo de 2011, por medio de la Alta Representante de la Unión para Asuntos Exteriores y Política de Seguridad, ${ }^{37}$ dieron como respuesta, a estos acontecimientos del norte de África, nada más ni nada menos que una iniciativa de "Asociación para la Democracia y la Prosperidad Compartida con los países del Mediterráneo Meridional" que debía construirse a partir de tres elementos:

1. -Transformación democrática y consolidación de las instituciones, con especial énfasis en las libertades fundamentales, las reformas constitucionales, la reforma del sistema judicial y la lucha contra la corrupción.

2. - Mayor asociación con los ciudadanos, con especial atención a la sociedad civil y mejores oportunidades de intercambios y contactos de persona a persona, con especial atención a los jóvenes.

3. -Desarrollo económico y crecimiento sostenible e integrador, en especial apoyo a las pequeñas y medianas empresas (PYMES), a la capacitación y formación profesional, a la mejora de los sistemas de educación y sanidad y al desarrollo de las regiones más necesitadas.

Se llevó el anhelo a tan grande optimismo, alejado del transcurrir de los acontecimientos, que se expresaba en el mismo documento el interés por un Mediterráneo meridional democrático, estable, próspero y pacífico, que, se afirmaba, era compartido por todos, lo que debía impulsar un salto cualitativo en las relaciones entre la Unión Europea y los vecinos del sur.

Lo que más llama la atención es que los dirigentes de Bruselas tuvieran tan poca información de los Servicios de Información europeos, respecto a la deriva que iban tomando los acontecimientos en el Magreb.

Continuando con el documento o "anhelo europeo", y en lo referente a los movimientos migratorios previstos, se lanzó la idea de reforzar los mecanismos para crear una movilidad basada en la legalidad. De esta forma se promovió la constitución de asociaciones para la movilidad, se aspiraba a reforzar la cooperación local Schengen y a aprovechar las mejoras del código de visados de la Unión Europea.

Se valoraba la importancia de los contactos entre personas como promoción del conocimiento mutuo y de las empresas que favorecieran el desarrollo cultural y económico de toda la región mediterránea y la integración de los migrantes en la Unión Europea.

Para conseguir este esperanzador proyecto, era imprescindible el desarrollo de las capacidades institucionales en los países del mediterráneo en materia de fronteras, migración y asilo, así como la cooperación más efectiva en servicios con funciones coercitiva con objeto de mejorar la seguridad en todo el Mediterráneo. Las asociaciones para la movilidad era otro de los elementos fundamentales con los países socios mediterráneos, con el objetivo de proporcionar

\footnotetext{
${ }^{37}$ Alta Representante de la Unión para Asuntos Exteriores y Política de Seguridad.: Comunicación Conjunta al Consejo Europeo, al Parlamento Europeo, al Consejo, al Comité Económico y Social Europeo y al Comité de las Regiones. Asociación para la Democracia y la Prosperidad Compartida con los países del Mediterráneo Meridional. Bruselas 8. 32011.
} 
un marco global que garantizara la gestión correcta de la circulación de las personas entre la Unión Europea y un tercer país.

A corto plazo la Comisión se comprometía a trabajar con los Estados miembros en materia de legislación sobre migración legal y política de visados para contribuir al objetivo de una mayor movilidad sobre todo de estudiantes, investigadores, y hombres y mujeres de negocios. Se promocionaba la migración legal con un régimen de visados y un marco jurídico de la migración económica. Se tuvo también previsto el desarrollo de capacidades institucionales para gestionar las remesas y para una adecuación entre demandas y necesidades de mano de obra, los programas de retorno y de reintegración, el ajuste a las normas de la UE de los sistemas de asilo.

Como contrapartida los dirigentes comunitarios exigían, a cambio de la mayor movilidad de personas desde los países del Magreb, que estos países debían estar dispuestos a reforzar el desarrollo de las capacidades institucionales y apoyo financiero para la gestión de fronteras, la prevención y lucha contra la migración irregular y el tráfico de seres humanos, incluida la intensificación de la vigilancia marítima, el retorno de los migrantes irregulares, incluidos los acuerdos de retorno y readmisión y poner en marcha los mecanismos con funciones coercitivas para luchar contra la corrupción y la delincuencia organizada transfronteriza.

Como se puede ver, la colaboración integral presuponía una implicación profunda de las dos partes, Unión Europea y países del Magreb, en cuestiones de seguridad fronteriza.

Se apelaba a los colegisladores a que adoptaran rápidamente las Directivas sobre trabajadores temporeros de terceros países y personas trasladadas dentro de una misma empresa, que contribuían a reforzar la movilidad hacia la Unión Europea. A largo plazo se preveía la posibilidad de la plena liberalización de visados con los países socios del norte de África, en función de las circunstancias específicas de cada caso y siempre que se dieran las condiciones para una movilidad segura y correctamente gestionada.

Sin embargo, no se previó el alcance de las "revoluciones árabes" ni sus resultados, como la Guerra en Siria, el debilitamiento de Libia, convirtiéndose en "Estado fallido", la situación de inestabilidad de Egipto, y los sucesivos esfuerzos por salir del atolladero de un país como Túnez. Las informaciones con que contaban los dirigentes europeos lejos estaban de la realidad y sus deseos de democratizar el Mediterráneo fueron superados con creces por la realidad.

Las consecuencias, en materia de migración fueron desastrosas. Las poblaciones de estos países quisieron huir en masa hacia las costas europeas, la llegada fue en aumento gradual desde el año 2011 hasta hoy.

Otra de las consecuencias más sangrantes de todos estos movimientos o "Primaveras Árabes" fue la radicalización del Islam, implantando la sharia y potenciando los movimientos yihadistas. Aquí estriba otro de los asuntos sustanciales en las relaciones del mundo islámico con el resto del mundo, porque los atentados, además del surgimiento del DAESH, hace tanto daño a la comunidad musulmana en general como a los occidentales en particular, pasando los primeros a ser sospechosos e irrelevantes por no manifestarse abiertamente contra los 
violentos. Debate que hoy en día se ha promovido en toda la Unión Europea y que debe ser atemperado para evitar profundas desconfianzas en el futuro. ${ }^{38}$

\section{Diversidad de rutas para la migración hacia la UE.}

Como era de esperar, si los acontecimientos del norte de África en 2011 no traían la democracia y la libertad, los movimientos de población huyendo de nuevas dictaduras que se aseguraban más sanguinarias y feroces que las que quisieron remplazar, como sucedió en Libia, era la lógica reacción de la mayor parte de la población que pudo hacerlo. A partir de estos acontecimientos los flujos de migración hacia el exterior fue constante y en progresivo aumento, primero hacia los países limítrofes como Egipto y más tarde hacia la Unión Europea.

El estallido del conflicto en Libia en el mes de febrero de 2011, hizo que la mayor parte de la población buscara refugio en países como Túnez y Egipto, a donde se dirigieron 800.000 personas de múltiples nacionalidades. Otros 35.000 se desplazaron hacia Italia y Malta, procedentes de Túnez y Libia. Los primeros meses de 2011 Italia y Malta recibieron a 112.844 migrantes, en febrero del mismo año llegaron a Lampedusa 4.000 inmigrantes en una sola semana.

Como consecuencia directa de las denominadas "Primaveras Árabes" y de la situación de guerra en Libia, la Unión Europea experimentó el aumento de migración irregular en un $80 \%$, según datos que facilitó el director de la Agencia Europea para la Gestión de la Cooperación Operativa en las Fronteras (FRONTEX), Gil Arias Fernández ${ }^{39}$, en una intervención que tuvo en la ciudad española de Cáceres. Allí mismo informó que los flujos se dirigieron desde Libia a la isla italiana de Lampedusa, donde llegaron 50.000 inmigrantes en el primer semestre de 2011, lo que representó el record de llegadas desde que existía FRONTEX.

A partir de este año 2011 también los flujos migratorios tomaron la ruta de entrada en la Unión Europea por Grecia y Malta.

Los países que aportaron mayor número de migrantes fueron Túnez, Afganistán, Nigeria y Pakistán, así como una salida masiva de subsaharianos desde Libia. A este respecto se llegó a advertir por parte del director de FRONTEX, que estaban evaluando si la migración desde Libia estaba siendo utilizada como un arma de negociación, en suma un "arma política". Porque se estaba a la espera de la desestabilización del régimen del dictador Moammar Gaddafi.

La expectativa y la incertidumbre dominaban el ambiente y como informó Gil Arias, respecto a la migración, esta era un negocio, si se tenía en cuenta que los migrantes habían pagado ese año entre 500 y 1.500 euros por ocupar una plaza en una embarcación que les llevara de Túnez a Italia, barcas en las que viajan hasta 200 personas. Gil Arias indicó igualmente que, en la Unión Europea en ese momento había entre 2 millones y 3.800.000

\footnotetext{
${ }^{38}$ El problema es que hoy en día el Islam aparece chocando en todos los continentes con las demás culturas y religiones:Hinduismo, Budismo, Iglesias cristianas, Animismo, Confucionismo, etc. No se trata meramente de Islam y sus relaciones con Occidente como planteó el gobierno español y el gobierno turco con la Alianza de Civilizaciones. No es tampoco un choque entre una religión, el Islam, y un indefinido Occidente.

39"Inmigración irregular en la UE aumenta 80\% a causa de la "Primavera Árabe", El Mercurio. Santiago de Chile, 25 de octubre de 2011, en http://www.emol.com/noticias/internacional/2011/10/25/509792/lainmigracion-irregular-en-la-ue-aumenta-un-80-por-la-primavera-arabe.html
} 
personas en situación irregular, de los cuales más de la mitad eran ciudadanos extranjeros, que habían entrado de manera regular, pero sus permisos de estancia habían caducado.

\section{Mali, una piedra más en el camino. ${ }^{40}$}

Como consecuencia del conflicto en Libia y la desaparición de Muammar Gaddafi, el país quedó en manos de cientos de guerrillas que se dedicaron a matar a sus enemigos, a saquear lo que quedaba, especialmente armas, y a fomentar mercenarios, muchos de ellos al servicio del dictador que tuvieron que huir hacia otros destinos, uno de ellos Mali. Esta llegada de mercenarios coincidió con el alzamiento de los tuaregs en enero de 2012, alimentando un conflicto más en la zona del Sahel. A este respecto, el Consejo de Seguridad de la ONU temió que la región del Sahe ${ }^{41}$ se convirtiera en un lugar para el contrabando de armas, a consecuencia del derrocamiento del régimen de Jaddafi. ${ }^{42} \mathrm{Y}$ por consiguiente terreno fértil para el terrorismo. Como, por desgracia, así ha sido en el caso de Mali.

Una vez los tuareg proclamaron su independencia de Bamako, la capital maliense, cuyo gobierno no atendió sus demandas de reconocimiento de su particularidad, como pueblo nómada que nunca había estado bajo el dominio de ninguna autoridad, el 6 de abril proclamaron oficialmente su independencia, y los tuareg que estaban dispersos por territorios del noroeste de Mali, noroeste de Niger y el sur de Argelia, Burkina Faso se convierten en el estado de Azawad.

El NMLA (Movimiento Nacional para la Liberación de Azawad) que no era un grupo homogéneo se alió con grupos islamistas-salafistas de la zona del Sahel, como Ansar al Dine (defensores de la fe), el Movimiento para la Unidad y la Yihad en África Occidental (MUJAO) y Al Qaeda en el Magreb Islámico (AQMI). Tres grupos que tenían un fuerte lazo de unidad y muchos de sus componentes habían luchado contra el ejército argelino. ${ }^{43}$

Como se podría esperar, los tuareg fueron desplazados de su territorio por estos grupos islamistas que proclamaron la sharia y han convertido el norte de Mali en un estado represivo y criminal. Las atrocidades cometidas por estos grupos islamistas han creado un clima de terror entre la población que ha producido temor también en el sur del país, cuyo gobierno solicitó la intervención del ejército francés para hacer frente a esta amenaza evidente. La herencia tuareg está en peligro de desaparición, poblaciones como Timbuktu, Goa y Kidal que conservaban mausoleos y tumbas de santones han sido prácticamente arrasadas. La lucha del ejército francés y de fuerzas de los países vecinos, como Chad, está centrada en impedir que toda Mali caiga en manos de los grupos islamistas-salafistas.

Como consecuencia de esta enorme crisis, la situación se ha devenido en invivible para las poblaciones locales, a lo que se une una feroz sequía y falta de agua, que ha inducido al desplazamiento de los habitantes fuera de sus hogares, logrando huir a los países vecinos

\footnotetext{
${ }^{40}$ Consultar al respecto el artículo sobre el Sahara y Mali, en este mismo número.

${ }^{41}$ Herrero, Rubén. y Machín, Nieva: "El Magreb-Sahel: La amenaza del terrorismo", en: Marquina, Antonio ( ed.) (2015): La Unión Europea y el Magreb. Reestructurando un imaginario, Madrid, UNISCI.

${ }^{42}$ Debate sobre la situación en el Sahel, en el que el presidente del Consejo de Seguridad de la ONU, Marrk Lyall Grant afirmó que el derrocamiento del presidente de Mali, Amadou Toumani Touré, era un síntoma de inestabilidad en la región. "La inestabilidad política del Sahel, caldo de cultivo para el terrorismo", El Mundo, 27 de marzo de 2012, en: http://www.elmundo.es/elmundo/2012/03/27/solidaridad/1332842531.html

${ }^{43}$ Grupos que han sido acusados de financiarse por medio del narcotráfico, convirtiéndose en grupos de crimen organizado. Véase: Barras, Raquel. y García, David: "Hacia un nuevo y diferente "flanco sur" en el Gran Magreb-Sahel.", en Marquina, Antonio (ed.) (2015): La Unión Europea y el Magreb. Reestructurando un imaginario, Madrid, UNISCI.
} 
como Burkina Faso, Mauritania y Níger, Togo, Guinea y Argelia ${ }^{44}$. Mali declaró la emergencia nacional ya en el año 2012, solicitando ayuda internacional para poder sobrevivir, debido a la sequía, también Burkina Faso, Chad, Mauritania, Níger y Gambia, y también amplias zonas de Senegal. Informaba Cruz Roja Internacional ${ }^{45}$, que por lo menos 13 millones de personas se encontraban al filo de la supervivencia en esta zona del Sahel, por la sequía y la falta de agua.

\section{Ruta a partir del año 2013 con la implosión de Mali.}

Mali ha sido siempre un país de migraciones y punto de tránsito de flujos migratorios dentro y fuera del país, así se constata en crónicas sobre los tránsitos de migración que se han venido sucediendo desde hace bastantes años, como nos lo describe Alí Bensasd ${ }^{46} \mathrm{en}$ su "Viaje al final del miedo".

Con la debacle de Libia regresaron al país 30.000 malienses y la crisis Centroafricana obligó al retorno de otros 1.800 malienses.

La ruta de Mali con dirección a Libia, se activa debido al cierre de la vía de migración a través de Senegál y Mauritania, por ella cruzaban cientos y miles de migrantes desde la región del Sahel. El cruce del desierto del Sahara hacia Libia es la ruta más peligrosa y cruel de todas las que existen. Libia desde siempre y mucho más ahora es un país muy inseguro para los migrantes, los cuales sufren toda clase de maltratos y abusos. Se tienen referencias de la dureza del viaje por el desierto y la penuria en la que muchos migrantes se ven envueltos, llegando incluso a intentar volver a sus países de origen y muchos otros pierden la vida. ${ }^{47}$

Por Mali la ruta tiene su punto de origen en Bamako, ruta que cruza la ciudad de Gao, pasa por Kidal llegando hasta Tamanrasset al sur del desierto de Argelia. Aquí en este punto se une la ruta que viene desde Niger, cuyo punto álgido está en Agadez, que recoge los migrantes de países como Costa de Marfil, Ghana, Togo, Benin, Nigeria y Camerún, pasando por Arlit llega hasta Tamnrasset.

Desde Agadez ${ }^{48}$ llegan a transitar hasta 2.000 inmigrantes por semana. Decenas de caravanas, con más de 100 vehículos y camiones "catedrales", por la cantidad de gente que transporta, se adentran al desierto llevando a más de 120.000 personas con sus pertenencias. ${ }^{49}$ La experiencia de viaje de muchos migrantes que tienen la suerte de contarlo es espeluznante.

A partir de las reuniones de la Unión Europea y la Unión Africana para llegar a algún acuerdo en la manera de frenar los flujos migratorios, estos parecen que han ido en aumento hasta el punto culmen de 2015 con la llegada de migración por las costas griegas, esta vez

\footnotetext{
${ }^{44}$ ACNUR:"Llevando esperanza a los refugiados de Mali", diciembre de 2012, en: http://www.acnur.org/quehace/respuesta-a-emergencias/mali/

45 Comité Internacional de la Cruz Roja: "Mali: una urgencia humanitaria en un contexto muy inestable". 27/04/2012, en: https:/www.icrc.org/spa/resources/documents/update/2012/mali-update-2012-04-27.htm 46 IOM : "Mali.", agosto 2014,en: https://www.iom.int/es/countries/mali. Véase también: Bensaad, Alí: "Os clandestinos do Sahel", Le Monde Diplomatique. no 27, (2001), pp 28-29.; y "Viaje al final del miedo", en http://diarioinmigracion.blogspot.com.es/2011/05/viaje-al-final-del-miedo.html

${ }^{47}$ Véase nota $\mathrm{n}^{\circ} 9$

${ }^{48}$ La inmensa región de Agadez constituye el 52\% del territorio de Niger, pero sólo está habitado por el 3\% de la población. Hogar también de tuaregs y comunidades bereberes y de otras poblaciones nómadas. Barrios,

Cristina: "Transit Niger: migrants, rebels and traffickers", European Union Institute for Security Studies, n 31 , (June 2015)

${ }^{49}$ Véase nota $\mathrm{n}^{\circ} 5$
} 
procedente de países como Siria, Afganistán, Pakistán y Eritrea. Ruta que volveremos a retomar en el epígrafe correspondiente.

\section{Aplicación de las dos estrategias en el tema migratorio. ¿Lagunas?}

Se han conseguido mínimos resultados, a la vista del desorden y la confluencia de un exponencial aumento de migrantes "irregulares" y de solicitantes de asilo en todos los puntos posibles de entrada al espacio Schengen, desde el Mediterráneo hasta el Ártico, con la afluencia de migración siria procedente de la ruta por Rusia. Esta es una de sus debilidades más notables.

No se quiso ver o no se actuó sobre un punto que siempre está repetido en las EES de 2003 y de 2008 y que les refuerzan las Directivas sobre migraciones que se han estado emitiendo desde Bruselas en estos últimos trece años, y es que a la inmigración irregular no se le debería permitir llegar a la Unión Europea. ¿Cómo? Favoreciendo los cauces legales para la entrada en el espacio Schengen y trabajando en la solución de las causas profundas de las migraciones.

Sin embargo, los inmigrantes irregulares siguen llegando a suelo europeo, y los solicitantes de asilo también, y por si fuera poco, los conflictos no han hecho más que aumentar. Lo que nos indica que no se ha tenido voluntad clara de actuar en consecuencia y a largo plazo, pues se están barajando medidas hoy en día en el Consejo y la Comisión europea, que ya se barajaron hace 10 y 13 años.

Las fronteras exteriores ya es hora de definir que son un problema de todos los países de la UE, no sólo de los que limitan con países terceros. Un cuerpo de guardacostas, un cuerpo de vigilancia, es lo mínimo que debe tener un macro-estado como se está convirtiendo la UE. Los tratados de readmisión que se cumplan, las devoluciones de aquellos migrantes que no tengan derecho al asilo, que se lleven a cabo. No puede ser que alrededor del $40 \%$ de las Ordenes de Expulsión no se llevan a cabo, pasando esta migración a mal vivir, sin una identificación, mejor dicho, pasan al limbo jurídico, a todos los efectos. Todos estos asuntos y algunos más que, iremos desgranando a lo largo de este capítulo, debieron ser la base para crear un espacio europeo sin fronteras interiores, pero reforzando las fronteras exteriores. Lo que no se debió hacer nunca fue "construir la casa por el tejado", como se ha hecho en este tema.

A pesar de todos estos fallos, o clara negligencia de los dirigentes europeos, el resultado más positivo fueron los Acuerdos de Readmisión y colaboración con países de la costa occidental africana promovidos por el gobierno del presidente Rodriguez Zapatero, después de la experiencia del verano de 2006, con la llegada masiva de inmigración irregular a Canarias. Es la fortaleza que se puede destacar en la aplicación de la Estrategia de Seguridad Europea 2003 y su revisión en 2008. ${ }^{50}$

Los cayucos dejaron de arribar a las islas Canarias, en la proporción anterior, sin embargo, las mafias que no quisieron perder el negocio, continuaron alentando a los jóvenes

\footnotetext{
${ }^{50}$ Ospina, Gloria Inés:. "Del vaivén de las políticas de extranjería hacia la convergencia”, en Marquina, Antonio (ed), (2008): Flujos migratorios subsaharianos hacia Canarias-Madrid, Madrid, UNISCI, pp.309-441. En el epígrafe titulado:'El Plan África o el seguimiento de las políticas comunitarias para África”, se abordó uno de los asuntos que por esos años, el gobierno del ex presidente Rodriguez Zapatero tuvo que resolver, tomando la iniciativa, por medio de acuerdos con los países de la costa occidental africana, origen de la migración irregular, para atajar esos flujos que llegaban a las islas Canarias y que, en el año 2006, produjo el máximo con 31.000 arribos de migrantes en cayucos.
} 
para cruzar el desierto y las fronteras de varios países africanos en su viaje hacia Marruecos, Argelia y últimamente hacia Libia, "tierra sin ley", con lo cual tenemos nuevas rutas que llegarán a Italia, principalmente a la isla de Lampedusa y a partir del verano de 2015 cruzarán por Turquía hacia Grecia.

\section{Las mafias de la migración.}

Los flujos migratorios irregulares continúan en aumento progresivo, alentados no sólo por la situación económica en los países de origen de la migración, sino también porque ya no son movimientos de iniciativa propia, sino manejados cada vez en mayor proporción por mafias o "pasantes de personas". El volumen de negocio de todos estos delincuentes se llega a calcular en varios miles de millones de dólares. Así, por ejemplo, durante el año 2015, los mafiosos que controlan las rutas y dirigen a los flujos de inmigración irregular hacia la Unión Europea tuvieron unos ingresos de 7 mil millones de dólares por el tráfico de personas, según informes del director de Europol (Agencia policial europea), Rob Wainwright, en una audiencia parlamentaria en Roma. Informó también que más de un millón de personas habían llegado al espacio Schengen durante el año 2015, procedentes de Siria en guerra y de Libia. También expresó su preocupación por las posibles conexiones entre organizaciones terroristas y redes de traficantes de personas. ${ }^{51}$

Y en lo que va de año, hasta mayo de 2016, habían entrado 184.000 inmigrantes, principalmente a través de Grecia e Italia, según la Agencia de Refugiados de las Naciones Unidas, a pesar del acuerdo que suscribió la Unión Europea y Turquía, que ha frenado un poco el número de llegadas.

¿Cómo trabajar para descubrir a los traficantes de seres humanos? Esta es una de las labores que se están realizando en estos momentos, ya que se sabe que las mafias y los flujos migratorios tienen contactos directos con el terrorismo, que usa estas corrientes humanas para transportar potenciales terroristas a Europa. Frontex, según su director actual Fabrice Leggeri $^{52}$ ha explicado cómo el personal de esta agencia se despliega en diferentes operaciones marítimas y terrestres en toda Europa, especialmente cuando detectan alguna anomalía. Diez años llevan realizando entrevistas a migrantes, pero hasta ahora han iniciado el acopio de datos. Toda una pena, porque desde hace ya bastantes años se sabe que las mafias actúan a sus anchas. Con el refuerzo de la Guardia de Fronteras y Costas, que empezó a operar el 6 de octubre pasado, se espera tener una información más completa, ya que esta agencia tiene competencias más amplias, pudiendo transferir datos personales a Europol. ${ }^{53}$ También puede transferirlos a las fuerzas de seguridad nacionales. Toda la información será útil para combatir el terrorismo y el tráfico ilegal de personas.

A decir verdad, en el tema migratorio los gobernantes europeos han puesto "parches" en todas las iniciativas, que, además, han sido puntuales, sin una intención seria de resolver un asunto de tanto calado, Las soluciones a largo plazo, han sido prácticamente inexistentes. Las Directivas que sobre la ordenación de los flujos migratorios se han publicado por parte de

\footnotetext{
${ }^{51}$ Europol también está desarrollando una base de datos con información relativa a cerca de 40.000 personas que están involucradas en el tráfico de inmigrantes irregulares, y también los oficiales de la agencia han sido enviados a los centros de migrantes en Italia y Grecia, los llamados hots spots, para cooperar con las autoridades nacionales. En: “Criminals Net \$7 Billion Smuggling Migrants To Europe, Says Europol”, The Wall Street Journal, May 4, 2016, en: http://www.wsj.com/articles/criminals-net-7-billion-smuggling-mig...

${ }^{52}$ Abellán, Lucía: "La policía accederá a las pistas que los migrantes facilitan sobre las mafias”, El País, 13 de octubre de 2016, en

http://internacional.elpais.com/internacional/2016/10/12/actualidad/1476290554_938221.html

${ }^{53}$ Agencia europea que lucha contra el terrorismo y el crimen organizado.
} 
la UE han sido hasta el momento actual, "papel mojado". No se han puesto en funcionamiento y así nos va. En ello también pesa la insolidaridad de los países que forman Schengen, con ello cuentan los que controlan los flujos migratorios irregulares, o sea las mafias, para "hacer su agosto". Al respecto, se acaba de detener en España una mafia que traía personas subsaharianas y las repartía por diversos puntos de Europa. Sólo en 2016 habían traído unas 500 personas a las que cobraron a cada una 3.000 euros por el viaje. Los traficantes las traían a España a bordo de pateras, aquí eran atendidas por ONGs y luego contactaban con el teléfono que los mafiosos previamente al viaje les habían facilitado, para ser trasladadas a pisos donde vivían en condiciones infrahumanas. Los tres países de destino eran Francia, Suecia y Alemania. ${ }^{54}$

15. Los nuevos desafíos para la seguridad de la Unión Europea y las posibles soluciones. Ante los nuevos desafíos de todo tipo que el mundo actual va sembrando en el camino, los ministerios de exteriores de cuatro países europeos ${ }^{55}$ encargaron a diversos institutos de investigación europeos, la elaboración de una evaluación de los asuntos más relevantes que afectaran a la seguridad de la Unión Europea e hicieran una proyección a largo plazo de las posibles soluciones y dónde incidir para prevenir futuras adversidades y que las evaluaciones resultantes se pudieran tener en cuenta para elaborar una estrategia europea en seguridad.

El documento en cuestión se titula: "Towards a European Global Strategy. Securing European Influence in a Changing World" ${ }^{56}$, publicado en mayo del año 2013, vino a destacar la importancia de la Unión Europea y la influencia que debía ejercer en un mundo en continuo cambio como el actual.

La Unión Europea a lo largo de 71 años de paz y de 23 años de haberse fundado por el Tratado de Maastricht, en 1993, ha creado un área con carácter único en el mundo, donde prevalecen, hasta el momento presente, unos valores como son los derechos humanos, el estado de derecho y la democracia, que el documento que aquí nos ocupa, los considera como el "ariete" que abre el camino y debe tenerse en cuenta en la cooperación internacional más profunda y estable para la Unión Europea.

Intereses que ganan partidarios a nivel mundial y que son de "interés vital" en las relaciones de la Unión Europea con su vecindario. Se subraya igualmente que, junto a los valores que distinguen a la Unión Europea, se deben tener en cuenta también la eficacia, la transparencia en la gestión pública, para tener la seguridad que el vecindario de la Unión Europea sea la vez seguro y próspero.

Haciendo una mínima reflexión y previamente teniendo una mínima idea del contenido de la Política Europea de Vecindad, nos llama poderosamente la atención, que desde la misma introducción del documento aquí esbozado, las premisas que lo sustentan sean las mismas que sustentaron en su día a la Política Europea de Vecindad, y que fueron puestas a prueba, precisamente en todos y cada uno de sus postulados, por las revoluciones árabes de 2011, mal llamadas primaveras.

Estudiando el Informe se aprecia que pocos son los puntos de los que se promovía en la Política Europea de Vecindad, que hayan sido descartados. Se sigue con el discurso de la

\footnotetext{
54 "Cae una red que sólo en 2016 ha traficado con unas 500 personas subsaharianas", La Razón, 15 de octubre de 2016.

${ }_{55}^{5}$ Italia, Polonia, España y Suecia.

${ }^{56}$ Towards a European Global Strategy. Securing European Influence in a Changing World. EGS. Mayo 2013.
} 
influencia global de la Unión Europea en su vecindario estratégico y se enfatiza esto cuando se subraya que, "vasta área (donde) la Unión Europea puede ejercer la más completa y exhaustiva participación", aplicando una serie de políticas de forma estructurada y a largo plazo.

Resulta bastante chocante que, en el tema que nos concierne, como son las migraciones irregulares, o el tráfico de personas, precisamente en el año 2013, cuando se publica el documento, se obviara de forma tan clara todo lo que sucedía en el norte de África, en concreto en el Magreb y el abultado número de migrantes que llegaban a las costas europeas. Y mucho más extraño nos parece que no se refleje, en el mismo, los derroteros por los que se "deslizaban" nuestros vecinos, que los alejaban cada día más de los valores únicos europeos, y que el documento refleja bien claro que son los valores que en esos mismos momentos eran los que la Unión Europea debía exportar.

Una clara distorsión de la realidad, que el documento en ciernes no tuviera en cuenta.

Y como si fuera poco, se sigue insistiendo en estos valores: derechos humanos, estado de derecho, sociedad civil robusta y la disminución de la brecha en la ideología de género, participación política y social, sin tener en cuenta, en primer lugar que, las premisas que se lanzan en el documento son una clara copia de la Política Europea de Vecindad, que ya se tuvo en cuenta en 2004 para los países del Magreb, y en segundo lugar que, en el año en que está publicado este Informe, los argumentos de atracción, ya van siendo superados por los acontecimientos reales que conformarán la vida de los países vecinos del Magreb, en clara confrontación con los valores que aquí se quieren promocionar. ${ }^{57}$

En lo que a migraciones se refiere, el documento en cuestión hace una apuesta segura por las migraciones regulares o legales. En el apartado: Engaging with the strategic neighbourhood, se apuesta por la realización de proyectos multinacionales en sectores como el transporte, infraestructuras y energía, con el objetivo de abrir fronteras y conectar regiones, buscar el desarrollo y la integración comercial y transfronteriza, con un mayor impacto en el Magreb, y la región Este de Europa. Se lanza la idea de liberar visados, de forma progresiva y ordenada, para "estudiantes y jóvenes profesionales", acompañado por un ambicioso programa de intercambio.

Para los institutos ${ }^{58}$ que suscriben este Informe, muy poco o nada significaron los mensajes que lanzaron las revoluciones árabes de 2011 desde el Magreb, rechazando claramente los valores europeos en su conjunto. Obviar este asunto, lo único que traerá es mayor distorsión en la evaluación de posibilidades de entendimiento con estos países, que no aceptan programas creados en una dirección, Unión Europea-Magreb, como es lo que se propone en cuanto a relaciones de vecindad en el documento aquí descrito.

En cuanto a las fortalezas del mismo, es importante destacar el apartado sobre temas de seguridad y vecindario, que de alguna forma, directa o indirectamente incide sobre los movimientos migratorios, especialmente los irregulares. En este sentido, el diálogo que se

\footnotetext{
${ }^{57}$ A este respecto existen estudios serios sobre la PEV y la conveniencia de revisión de la Política Europea de Vecindad. En: Guinea, Mercedes: "La política europea de vecindad hacia el Mediterráneo (2003-2015): Impotencia ante un entorno cada vez menos homogéneo y más hostil”, en Marquina, Antonio, (ed), (2015): La Unión Europea y el Magreb. Reestructurando un imaginario, Madrid, UNISCI, pp 423-456

${ }^{58}$ International Affairs Institute, The Polish Institute of International Affairs, Elcano Royal Institute, The Swedish Institute of International Affairs.
} 
pretende impulsar con los vecinos del sur del Mediterráneo se centra en el diálogo político sobre cuestiones de seguridad. Aunque este apartado está impregnado de todos los argumentos esgrimidos desde el principio sobre los valores europeos, se enumeran los cambios que a nivel mundial y regional pudieran producir crisis de seguridad en la zona estratégica del vecindario europeo, creando presión, y a lo que se tendría que hacer frente desde la Unión Europea.

En este apartado, titulado: "Taking comprehensive security responsibility in the strategic neighbourhood", se apuesta por asumir la responsabilidad de seguridad integral en el área de posible influencia europea respecto al Magreb. Se enumeraban los posibles cambios que se podían producir, como conflictos armados, la inestabilidad regional, Estados fallidos, amenazas para el suministro, que podrían poner en peligro vital los intereses europeos. Se sugería que la Unión Europea debía mejorar sus esfuerzos para combatir el terrorismo internacional, la proliferación de armas de destrucción masiva, el crimen organizado y el tráfico de armas, drogas y seres humanos.

¿Cómo se llevaría a cabo esto? Trabajando con socios estatales y no estatales en la región, (del Magreb), fomentando la capacidad del sector de la seguridad, por medio de la cooperación policial, el intercambio de inteligencia, la gestión de fronteras, la protección civil y también en materia judicial.

Propuestas generales que en algunos campos son de muy difícil interrelación como la colaboración en el intercambio de inteligencia. Pues cada país seguramente "se guarda sus cartas", como lo hemos estado viendo en el tema del terrorismo yihadista y los servicios de inteligencia europeos, concretamente belgas y franceses.

En este asunto de la seguridad, se dan recomendaciones para que la Unión Europea de forma autónoma lleve a cabo las misiones civiles y militares que crea oportunas y necesarias para proteger sus intereses vitales, de acuerdo con el derecho internacional. Lo cual implicaría la capacidad de vincular la gestión de crisis y la asistencia humanitaria en el momento oportuno, con un enfoque a largo plazo. La novedad en este punto consistía en que se recomendaba que la Unión Europea involucrara a los socios en la misiones militares y civiles, incluso delegar en actores regionales o globales este cometido. En este sentido también se aconsejaba que para tener mayor eficacia se trabajara con la NATO. Se sigue apostando por la muletilla de siempre, sin apostar por una seguridad autónoma europea.

En lo que a nuestro tema se refiere, el apartado "Promoting human development and preventing conflicts", como su título indica, el desarrollo humano y la prevención de conflictos eran áreas donde la Unión Europea tenía experiencia y legitimidad para llevar a cabo una acción global directa y según los redactores del documento los socios esperan para hacerlo. Se enumeraban los posibles factores que llevarían a conflictos inter e intra-estatales, como son la pobreza, el subdesarrollo, la exclusión social. De ahí que se enfatizara que la reducción de la pobreza debía seguir siendo una prioridad para la Unión Europea, de igual forma la ayuda al desarrollo hacia estos países debería estar condicionada a los progresos en libertades políticas y económicas, y en los derechos humanos, que son los que han traído prosperidad al mundo. Este discurso lo llevamos publicando desde hace muchos años y la reducción de la pobreza entre la mayor parte de los vecinos del sur del Mediterráneo, apenas si se ha producido, vista la progresiva oleada de migraciones irregulares, compuesta por personas necesitadas de ayuda económica que llegan a suelo europeo. Por si fuera poco, otros 
actores ya están ocupando la escena africana con transacciones que no exigen ningún compromiso a cambio. En este sentido, nos parece que el documento se queda obsoleto.

La mediación es a su vez una de las prácticas europeas para ayudar a distender los conflictos, abordando la causa de los mismos, más allá de las fronteras de la Unión Europeas.

En cuanto a los instrumentos para llevar a cabo esta gran batería de propuestas, dejando de lado otras muchas, que se explicarán en los capítulos correspondientes del libro que aquí presentamos, que proporcionarían éxito en un mundo en el que se tiene que actuar rápido y de forma coherente y sobre todo políticamente, se encuentran: la acción diplomática, el comercio, la ayuda, las medidas restrictivas, junto con una amplia gama de herramientas en gestión de crisis y de respuesta, "incluyendo el uso de la fuerza" de conformidad con el derecho internacional.

Capacidades e instrumentos que debían ser utilizados de acuerdo a cuatro principios rectores:

- Idear una voluntad política, de suma importancia para la acción exterior, que sea eficaz, buscando sinergias entre la Unión Europea y sus Estados miembros.

- La exhaustividad, debería ser una prioridad, en cuanto a la coordinación de herramientas, especialmente a nivel de toma de decisiones.

- Coherencia entre las ambiciones de la Unión Europea en toda la variedad de ámbitos de actuación y los recursos que se les asigna a ellos.

- Por último, la Unión Europea debe ser un marco atrayente para la acción del Estado miembro, mediante el fomento de la flexibilidad necesaria para que éstos puedan actuar en grupos de variables.

Entre los aspectos formales de la Unión Europea que deberían potenciarse está el impulso de un amplio acuerdo estratégico europeo sobre la Unión Europea, impulsando la capacidad de coordinación del Servicio Europeo de Acción Exterior, en particular, en política de competencia de la Comisión Europea.

Respecto al Alto Representante para Asuntos Exteriores y Política de Seguridad, que es a su vez vicepresidente de la Comisión, debería poseer más mecanismos formales de coordinación de los miembros de la Comisión responsable de la ampliación hacia el vecindario, del desarrollo y de la ayuda humanitaria, así como mayor voz en la dimensión exterior en cuanto a la energía, asuntos de interior y carteras de mercados internos.

Se recomendaba también clarificar el modelo de cooperación entre el Servicio Europeo de Acción Exterior y la Comisión, sobre todo cuando se trata de gestión de crisis.

El potencial de las delegaciones de la Unión Europea en el extranjero debería ser más explotado, equipándolos con la experiencia adecuada para analizar certeramente las condiciones políticas y de seguridad locales.

Otra de las propuestas del documento respecto al Servicio Europeo de Acción Exterior fue la de anclar en este servicio en términos presupuestarios y de personal a los representantes especiales de la Unión Europea, en concreto a los servicios consulares, para dar un mejor servicio a los ciudadanos europeos, dada la internacionalización de los viajes y de los negocios. Propuestas que a nuestro entender conforman otra de las fortalezas del Informe. 
En resumen, se puede decir que el documento en cuestión es una llamada de atención a los organismos de gobierno de la Unión Europea en su conjunto, para que se lleve a cabo una mejor coordinación y se potencien mejor todos los mecanismos de que dispone para ser un actor creíble en la forma de encontrar un buen entendimiento con los países vecinos. Sin embargo, y a pesar de introducir el derecho al uso de la fuerza, bajo las leyes del derecho internacional, el documento se queda corto en ambiciones, puesto que en las relaciones que la Unión Europea debe tener con su vecindario se echa en falta la puesta al día de otros argumentos que no sean los de la Política Europea de Vecindad, que se pusieron en "tela de juicio" a partir de las revoluciones árabes. En soluciones a largo plazo, como el documento pretende presentarse, tampoco se atisban grandes sugerencias, ya que pasa por alto la situación de clara descomposición política y social del vecindario así como que no explica cuál será el entendimiento entre sociedades pretendidamente laicas y sociedades impregnadas totalmente del factor religioso, como son respectivamente la europea y la del norte de África. El asunto de calado de las fronteras exteriores del espacio Schengen se pasa por alto, y la idea que se saca del Informe es que el Mediterráneo debe estar interrelacionado, el Norte-Sur y el Oeste y Este, a modo de un gran imperio, cuyo centro administrativo y "dador de bienes" fuese la Unión Europea y todos los países vecinos tuvieran libertad de movimiento como hoy día en el espacio europeo Schengen.

\section{6. ¿Por qué andamos de Cumbre en Cumbre y no se resuelven los problemas?}

El 3 de octubre de 2013 naufraga un barco en el Mediterráneo, que transportaba inmigrantes desde Libia a Italia, frente a la isla de Lampedusa, esta tragedia se cobró más de 360 muertos, eran personas procedentes de Eritrea, Somalia y Ghana, pocos días después, el 11 de octubre naufraga otro barco cerca también de Lampedusa y mueren 34 personas procedentes de Siria y Palestina.

Desde 1990 vienen sucediendo tragedias en el Mediterráneo, que han dejado innumerables muertos, se llega a decir que en el canal de Sicilia han perecido por lo menos 8.000 personas, de ellos 2.700 en 2011, migrantes que huían del conflicto de Libia. "Según el Alto Comisionado de Naciones Unidas para los Refugiados, desde el inicio de 2013, Malta y Lampedusa han acogido a 32.000 personas, de las que dos tercios han solicitado asilo". ${ }^{59}$

El ministro italiano de Interior, Angelino Alfano culpaba a la Unión Europea por la nefasta política migratoria y de asilo y protestaba por las competencias que se les exigía a los países de frontera exterior de Schengen: "Sicilia no es solo una frontera italiana, es también la frontera externa europea. Vamos a esforzarnos para conseguir un cambio en la política de asilo europea. Europa no nos puede pedir que nos hagamos cargo de los inmigrantes aquí sin levantar un dedo para ayudarnos". ${ }^{60}$

Ante las tragedias y las protestas del ministro italiano era de esperar que la Unión Europea tomara alguna acción. Sin embargo, no fue así, porque la cumbre que reunió en Luxemburgo a 28 ministros de Justicia e Interior de la Unión Europea, menciona al final del texto por medio de un breve comunicado que, el Consejo tomaba nota de las informaciones del ministro de Interior italiano, relativas a la tragedia ocurrida frente a las costas de la isla de Lampedusa y se prometía crear un grupo especial con la Comisión para determinar los

\footnotetext{
59 Pablo Ordaz: "Nueva tragedia al naufragar una barcaza que se dirigía a Lampedusa"

El País. 12 de octubre de 2013, en:

http://internacional.elpais.com/internacional/2013/10/11/actualidad/1381510115 315660.html

60 "Conclusiones tras la tragedia de Lampedusa" DW, 8.10.2013, en: http://www.dw.com/es/conclusiones-trasla-tragedia-de-lampedusa/a-17145288
} 
instrumentos de que dispone la Unión y poderse utilizar de manera eficaz. En conclusión no se venía a resolver nada. La reunión estuvo dedicada en mayor medida a los asuntos económicos. ${ }^{61}$ Se indicaba igualmente que Frontex había salvado a 16.000 personas en el Mediterráneo desde el año 2011, y que Italia no era el país que en esos momentos tenía mayor presión de refugiados. Los mayores receptores de refugiados eran Alemania, Francia, Suecia, Reino Unido y Bélgica, con un 70\% de las solicitudes de asilo en 2012, mientras que Italia venía después con 17.000 solicitantes. $^{62}$

En marzo de 2014, los acontecimientos en Ucrania, desviaron la atención hacia Rusia y los desafíos que se creaban al Este europeo. La migración continuaba aumentando y se desviaba también hacia Grecia.

La Cumbre Unión Europea- África, reunida en Bruselas en abril de 2014, resaltó la necesidad de un enfoque general para afrontar las graves consecuencias sociales y humanas de la migración irregular. Igualmente se reiteró el compromiso de luchar contra la trata de seres humanos y de garantizar el respeto de los derechos humanos para todos los migrantes, y resultado de esta iniciativa fue la Declaración Unión Europea-África sobre migración y movilidad de 2 y 3 de abril de $2014^{63}$.

Vale la pena recordar que desde el año 2000 se vienen celebrando estas cumbres Unión Europea-África, primero en el Cairo, después en Lisboa en el año 2007, la tercera en Trípoli en 2010 y la última en Bruselas el 2 y 3 de abril de 2014. En todas ellas se han repetido los temas que se vuelven a poner sobre la mesa en esta última de 2014 en Bruselas, sin embargo, poco ha cambiado en los dos continentes, por una parte, los dirigentes europeos no ponen en marcha todo lo que las Directivas sobre migración indican, y por su parte los dirigentes africanos, parece que hacen pero dejan mejor hacer a otros. Y nos encontramos con mayores problemas que debían haberse previsto y llevado a cabo las medidas que recomendaban todas las directivas desde el año 2003.

Volviendo a la Declaración UE-África sobre Migración y Movilidad, documento compuesto de 13 epígrafes, se reconoce que la movilidad aporta beneficios a todas las sociedades, pero no se especifica, más que hasta el quinto epígrafe, que la movilidad no puede ser de cualquier forma, es decir, no puede ser irregular, porque la movilidad irregular al que menos conviene es al inmigrante que busca caminos clandestinos para llegar a sociedades en donde va a tener una situación claramente de marginalidad, expuesto a todos los peligros inimaginables.

Se inicia este documento reconociendo los "beneficios que las migraciones y la movilidad pueden aportar a nuestros dos continentes", puesto que la movilidad es un aliciente para estimular el desarrollo económico, social y del medio ambiente en los países de origen, de tránsito y de destino, así como a los propios migrantes.

\footnotetext{
${ }^{61}$ Consejo de la Unión Europea. Comunicado de Prensa. Justicia e Interior. Luxemburgo 7 y 8 de octubre de 2013.

62“'Italia carga contra la Unión Europea por el naufragio de Lampedusa: 'Esta tragedia se repetirá'”. RTVE. Agencias. 4.10.2013, en:http://www.rtve.es/noticias/20131004/italia-carga-contra-ue-naufragio-lampedusaestatragedia-se-repetira/758464.shtml

63“"Declaration UE-AFRIQUE Sur La Migration el La Mobilite", UE-AFRICA Summit-Sommet UE-Afrique. Bruxelles 2014-Brussels. Quatrieme Sommet UE-AFRIQUE. 2-3 Avril 2014.
} 
Este preámbulo, si se deja tal cual, "abierto", lanza el mensaje a los aprovechados de turno, para interpretar que efectivamente las migraciones, las que sean legales e ilegales, son beneficiosas para todos, sin mayor requisito que pagar a los "pasadores de personas o mafias".

Destacamos el cuarto y quinto epígrafe de esta Declaración porque deberían haber sido los puntos que iniciaran la misma, en el cuarto se hace hincapié en la importancia de atacar las causas profundas de la migración irregular, teniendo en cuenta de buscar alternativas a los problemas que las incitan, como es el problema del desempleo juvenil. Y respecto a las migraciones irregulares, se apuesta por la migración legal y organizada, una movilidad que beneficie a todos los países, promoviendo políticas que faciliten la migración profesional y compromisos a nivel regional. Así mismo, se pronuncian sobre las graves consecuencias sociales y humanas de la migración irregular, así como la pérdida de vidas humanas.

Apostando por una solución global en la gestión de la migración clandestina, en el marco del estricto cumplimiento de los derechos humanos.

Como se puede apreciar, es "más de lo mismo", repetidos una y más veces todos los desafíos que implican las migraciones irregulares, pero que no se termina de poner en marcha ninguna medida para acabar con el problema. Muchas reuniones, pero pocos resultados.

\section{Fronteras exteriores Schengen y DD.HH. Empeoramiento de los flujos y reacción europea.}

Las fronteras exteriores de la Unión Europea podríamos decir que son demasiado permeables, así se opine lo contrario, como que se están convirtiendo en las fronteras de la Unión Europea fortaleza. No se sabe muy bien cuando se acuñan éstos eslogans, si de veras se conoce lo que es una frontera exterior, en este caso de un espacio en donde 28 países han eliminado sus fronteras internas y se circula libremente por este espacio denominado Schengen. Uno de los mayores logros europeos, no sólo en el plano social, sino también en el económico e intelectual.

Este macro-estado que se va construyendo lenta pero progresivamente, con capital administrativa en Bruselas, tiene una frontera marítima de $42.673 \mathrm{kms}$ y terrestre de 7.721 kms. La obligación de aquellos a quienes hemos elegido para gobernar este espacio Schengen es la de garantizar la seguridad en las fronteras exteriores para vivir con libertad en el interior de este espacio Schengen.

Expertos en seguridad llaman la atención sobre la vulnerabilidad de la UE respecto a las mafias de la migración, porque no cuenta con personal cualificado en los puntos críticos de donde parten las corrientes migratorias, para recabar datos en relación al número de migrantes que mueven estos delincuentes y también para persuadir a los migrantes desistir de un viaje que es puro espejismo. Se acusa igualmente a los dirigentes de Bruselas, de estar cambiando constantemente de políticas de fronteras, lo que hace que se cree inestabilidad en los países vecinos ${ }^{64}$. Más que cambios en políticas de fronteras, diríamos que no se llevan a cabo los acuerdos consensuados en Bruselas. De ahí que no se sabe a ciencia cierta a qué atenerse respecto a la política de migración y asilo, y mucho menos en relación a la seguridad de las fronteras exteriores. ${ }^{65}$

\footnotetext{
${ }^{64}$ Parkes. Roderick:’Migration to Europe: The numbers game”, European Institute for Security Studies, $\mathrm{n}^{\circ} 18$, June 2016, p.2. Confer. Nota. $\mathrm{n}^{\mathrm{o}} 10$.

${ }^{65}$ Véase la reacción de la Comisaria Mälmstron con la tragedia del Tarajal, en el mes de marzo de 2014, condenando a las fuerzas del orden que habían controlado la frontera española con Marruecos.
} 
Uno de los aspectos clave en la seguridad de la Unión Europea es el control y vigilancia de las fronteras exteriores del espacio Schengen. Sin esta premisa no deberíamos hablar ni de libertad ni de democracia ni de derechos humanos, ni de estado de derecho que son los valores que se esgrimen como europeizantes.

Con la denominada "crisis de los refugiados" desde el año 2015 hemos podido comprobar la importancia que tiene el controlar la entrada de personas por las fronteras exteriores de Schengen. La avalancha de gente que desde las costas de Libia, primero, y desde las costas turcas, después, llegaron a puntos cruciales como la costa italiana, principalmente la isla de Lampedusa y a las islas griegas de Kos, Lesbos y Dodecaneso, produjo auténtico temor en sendas poblaciones, por la forma desordenada y multitudinaria que sobrepasó todas las perspectivas de atención y de registro de semejante oleada de personas. Como ejemplo, tenemos Grecia, por donde pasaron 850.000 personas, durante el año 2015, pudiéndose contabilizar en una sola noche llegadas de hasta 5.000 refugiados y migrantes a Lesbos y a la mañana siguiente otras tantas, lo que creó el desconcierto en la población para la atención de tantísima gente. Sólo lo pueden contar los militares, voluntarios y personal de protección civil que allí estuvieron haciéndose cargo de este "fenómeno de masas". ${ }^{66}$

Económicamente el cierre de las fronteras interiores de Schengen puede suponer otra crisis económica de colosales consecuencias para los países europeos, así lo señalan informes sobre este aspecto realizados para el Parlamento europeo como "The Cost of Non-Schengen. Impact of border controls within Schengen on the Single Market" ${ }^{\prime 67}$. Se indica que los costes de los controles fronterizos temporales no sólo obstaculizan la libre circulación de personas, sino que tienen costes económicos significativos. Se estima que el restablecimiento completo de los controles interiores en el espacio Schengen generaría un coste directo de entre 5 a 20 millones de euros al año. Los controles fronterizos costarían 1,7 millones de trabajadores transfronterizos, y entre 1,3 y 5,2 millones de euros en tiempo perdidos. Al menos 13 millones de estancias de turistas se perderán, con un coste total de 1,2 millones de euros. Y para los gobiernos europeos, cada uno de ellos tendrían que gastar entre 0,6 y 5,8 millones de euros para pagar el aumento de personal encargado del control de fronteras, entre otras muchas problemáticas

Desde que estamos investigando temas migratorios, nos hemos preguntado: ¿Cómo abordar la seguridad de las fronteras exteriores y hacerla compatible con los Derechos Humanos $?^{68}$ Esta cuestión no está todavía claramente definida desde Bruselas, pues son tantos los agujeros en la política de asilo y migración, que prácticamente, en la práctica, queda a discreción de cada uno de los Estados miembros de la Unión Europea, y es cuestión también prioritaria que se debe estudiar y cambiar. Desde luego, que para las mafias que marcan las rutas de la migración, prevalecen los derechos humanos sobre el control de fronteras, y como no se da un mensaje claro desde Bruselas, el descontrol en las fronteras seguirá en progresivo aumento.

Vamos a ver cómo funciona la Guardia de fronteras y costas que se ha puesto en marcha este 6 de octubre ${ }^{69}$, cuerpo que debía haber sido uno de los primeros soportes con los

\footnotetext{
66 "Ha habido fallos, pero Grecia no merece las amenazas de la UE", El País, 10 de febrero de 2016, en http://internacional.elpais.com/internacional/2016/02/03/actualidad/1454521806_409750.html

${ }^{67}$ The Cost of Non-Schengen. Impact of border controls within Schengen on the Single Market. May, 2016.

${ }^{68}$ Ospina. Gloria Inés: “¿Alternativas a las políticas de fronteras de la UE?”, UNISCI, 20 de septiembre de 2015. Comentario UNISCI, $\mathrm{n}^{\circ} 92$

69 "La Guardia Europea de Fronteras y Costas", Comisión Europea, Estrasburgo, 15 diciembre 2015.
} 
que tendría que haber contado esta realidad de Schengen. Como ya hemos mencionado anteriormente esta nueva agencia de la Unión Europea cuenta con mayores competencias que las que tiene FRONTEX, y los datos que recabe de los migrantes los podrá transferir a Europol, que se encarga de la lucha contra el terrorismo y el crimen organizado.

\section{Alemania entra en escena.}

Cuando en el 24 de agosto de 2015, la canciller Angela Merkel "abre las puertas de Alemania" para que todos los refugiados sirios que entraban por Grecia se dirigieran a su país, donde serían bien recibidos, "saltó por los aires" todo el entramado de Dublín ${ }^{70}$, que había sido concebido para que el primer país por donde entraban los refugiados los registrara. Los refugiados mezclados con los migrantes fueron avanzando a pie por los diversos países de los Balcanes Occidentales, con dirección a Alemania y Suecia, que eran los países que "ellos habían elegido para vivir". Entrando y saliendo por las fronteras de diferentes países, fueran o no del espacio Schengen. La alarma no se hizo esperar. Países como Hungría, Eslovaquia ${ }^{71}$, Macedonia, Austria, Chequia, iniciaron el control en sus fronteras y aún más, algunos como Hungría se dispusieron a cerrar la frontera con vallas. A medida que la corriente migratoria avanzaba y se iba produciendo el cerramiento de la ruta desde Grecia al norte con dirección a Alemania, la corriente migratoria fue creando un auténtico "atasco" principalmente en el cruce de Grecia a Macedonia, donde las autoridades pusieron los primeros controles. Otra corriente migratoria fue desviada desde Líbano hacia Rusia, corriente compuesta por sirios exclusivamente, en tránsito hasta la frontera sueca del Ártico, que progresivamente fue instalando controles y también cerrando la frontera con vallas. De igual forma procedieron países como Dinamarca en la frontera con Alemania y Suecia, Austria con Alemania e Italia, Francia con Italia, e Inglaterra con Francia por el Estrecho de Calais provocando un autentico "desconcierto" en toda la Unión Europea.

El "cuello de botella" que se produjo en los Balcanes Occidentales, y luego el control de fronteras interiores de los demás países europeos occidentales, iba a producir la fractura de Schengen, o por lo menos, a partir de este momento se vislumbraba que las actuaciones en solitario de la canciller alemana traerían consecuencias graves para el futuro de la Unión Europea.

La primera de ellas, ponía en evidencia los fallos de la política de asilo y migración europea. La segunda, a partir de estos momentos se les exigirá a los dirigentes de Bruselas, la puesta en común de la defensa de fronteras exteriores de Schengen, y por último, se propició la división entre Occidente y Oriente en una Unión Europea que no tenía claro cómo resolver el tema y que se vio desbordada por los acontecimientos.

A partir de ahora, surgirán el Grupo de Visegrado, Chequia, Eslovaquia, Hungría y Polonia, que se resistirán a aceptar el reparto de migrantes que proponía Bruselas. Alemania en septiembre de 2015 esperaba recibir 40.000 refugiados. Otra de las consecuencias de esta "errática política" fue la salida de Gran Bretaña de la Unión Europea, lo que se conoce como Brexit, que es una fortísima llamada de atención a los dirigentes europeos, por la mala gestión de la migración y refugiados, y por el descontrol de las fronteras exteriores de la Unión Europea, entre otras muchas razones y también, el recule en la política de "acogida" de la canciller Merkel, debido a los graves incidentes de violaciones sexuales en la fiesta de fin de

\footnotetext{
70 “Convenio de Dublín. Unión Europea y Asilo". Diccionario de asilo CEAR, en: http://ceareuskadi.org/diccionario/convenio-de-dublin/ y también, "La Convención de Dublin" en: http://www.econ.unicen.edu.ar/attachments/6699_Dra.\%20Culaciatti.pdf

${ }^{71}$ Que en estos momentos ostenta la Presidencia de la Unión Europea, hasta finales de 2016.
} 
año de 2015, a lo que hay que añadir los resultados electorales adversos cosechados por su partido y consecuencia directa de su política migratoria de "puertas abiertas".

En política, si se trabaja conjuntamente, se debe consultar con los socios, cuestión esta que no parece haber sido la pauta de la canciller alemana, actuando en solitario y tal vez guiada por la sensibilidad de corazón, que no es válida para tomar decisiones que a la larga afectan a 500 millones de habitantes del espacio Schengen.

Desde luego, Schengen estaba "amenazado de muerte", todos los mandatarios de los diversos países que se vieron "inundados", por los flujos de refugiados y migrantes sin control alguno, se dispusieron a controlar sus propias fronteras interiores, para salvaguardar la libertad y seguridad de sus ciudadanos, nada más ni nada menos, y saber ¿quién entraba en sus territorios y para qué? El trastorno fue monumental y en las declaraciones de los dirigentes de todos los países europeos, lo único que se mencionaba era el desorden de la migración y el descontrol de las fronteras exteriores de Schengen.

\section{Principales rutas de entrada en 2015 y reacción de los dirigentes europeos}

- Rutas por el Mediterráneo Oriental y los Balcanes.

Según datos de Frontex en 2015, llegaron a la Unión Europea a través de la ruta del Mediterráneo Oriental unos 885.000 inmigrantes, que representan 17 veces más que en 2014, que fue un año records de llegadas. Fue Grecia la ruta que abordaron los migrantes que en su mayoría eran refugiados procedentes de Siria, alcanzando las islas de Lesbos, Kos y Dodecaneso. El número de llegadas aumentó gradualmente desde enero a marzo, pero empezó a subir en abril, alcanzando un máximo de 216000 en octubre. Ya en noviembre y diciembre van disminuyendo con la estación invernal, pero las cifras continuaban por encima de los mismos meses de $2014 .^{72}$

- Ruta por el Mediterráneo Central.

La ruta del Mediterráneo Central que comunica las costas libias con Italia se mantuvo bajo presión migratoria en el año 2015. El número de inmigrantes que llegaron a Italia fue de 154.000 personas, alrededor de una décima parte del record de llegadas en 2014. Según informaciones de Frontex, la razón de esta disminución estuvo en el cambio de los sirios por la ruta Oriental del Mediterráneo y la escasez de barcos con la que cuentan los contrabandistas en Libia. En 2015 la mayoría de los migrantes que fueron transportados por las redes de contrabando desde Libia fueron eritreos, nigerianos y somalíes. ${ }^{73}$

Como era de esperar, la reacción fue inmediata, a medida que la corriente de gente cruzaba una y otra frontera. Los mandatarios de países como Hungría primero, Austria después y Macedonia iniciaron el cierre de sus fronteras para seguridad de sus países. Uno de los dirigentes que primero protestó fue el primer ministro Viktor Orban ${ }^{74}$, quien responsabilizó directamente al gobierno alemán del caos creado en la estación Keleti de

\footnotetext{
${ }^{72}$ Frontex: "Migratory routes map", en http://frontex.europa.eu/trends-and-routes/eastern-mediterranean-route/

${ }^{73}$ Frontex: "Migratory routes map", en http://frontex.europa.eu/trends-and-routes/central-mediterranean-route/

${ }^{74}$ En estos momentos Hungría está construyendo una segunda face de muralla para impeder el acceso de migración irregular, por su frontera exterior, que es también frontera exterior Schenge. Feher, Margit, Hungary plans second fence to stop migrants. The Wall Street Journal, Budapest, August 26, 2016, en: http:/www.wsj.com/articles/hungary-plans-second-fence-to-stop-migrants-1472204029
} 
Budapest, por mandar un mensaje a los sirios "prometiéndoles asilo" "75. Sucesivamente se manifestaron en términos parecidos los mandatarios de Chequia, Slovaquia, Polonia, Rumanía $^{76}$ y Bulgaria. Todos países de los Balkanes Occidentales, que han tenido un tipo de gobierno dictatorial hasta el año 1989, cuando cayó “el muro de Berlín” y que no están acostumbrados a que las fronteras se violenten. Tampoco estaban de acuerdo con las cuotas de refugiados que solicitaban desde Bruselas, 120.000 migrantes para recolocar en toda la Unión Europea. Polonia, por ejemplo, aceptó a 7.000 inmigrantes a quienes daría trato de refugiados, sin embargo, el ejecutivo de ese país indicaba a la canciller Merkel que, los ataques de militantes del estado islámico de noviembre, en París, les hacía no acceder a la política de acogida. También llamó la atención a la señora Merkel señalándole que los países que no eran partidarios de las cuotas, simplemente sus gobernantes estaban recogiendo el sentir de sus opiniones públicas ${ }^{77}$.

Por su parte, el líder laborista holandés, Diederik Samson, explicaba en rueda de prensa que el gobierno de su país había presentado un nuevo plan europeo en el que se proponía el regreso a Turquía en ferris de los refugiados que llegaran a las islas griegas. ${ }^{78}$. Más tarde se les unieron los de países como Austria, Francia, Dinamarca, Noruega y Suecia. Todos solicitaban una solución rápida para controlar las fronteras del espacio Schengen, porque eran conscientes de la inestabilidad que se produciría con la llegada descontrolada de migración desde Grecia $^{79}$.

\section{Nueva tragedia en el Mediterráneo. ¿Cómo se aborda el desbarajuste desde la cúpula de Bruselas?}

En abril de 2015, una nueva tragedia sacude a la Unión Europea. En aguas de la costa Libia perecen 700 migrantes justo en el momento que iban a ser rescatados por un barco portugués, con la mala suerte que al levantarse para solicitar ayuda hicieron que el barco pesquero en que viajaban volcase, pereciendo la mayoría de sus ocupantes. Sólo hubo 24 supervivientes. ${ }^{80}$

En un primer momento se toman medidas de urgencia y en Junio 2015, los dirigentes de Bruselas se encuentran desbordados y consternados ante los acontecimientos. La Unión Europea autoriza la Misión Eunavfor Med, para reunir información sobre las mafias y actuar

\footnotetext{
75 “Orban dice que la crisis de refugiados “es un problema alemán” y les pide que se queden en Turquía”. RTVE. Bruselas. 3, 9, 2015.

${ }^{76} \mathrm{Su}$ posición era favorable al reforzamiento de FRONTEX por medio de la Guardia de Fronteras y Costas, que se proyectaba en esos momentos por parte de la Unión Europea. Selles, Alain et Ricard, Phillipe: "Dacian Ciolos, premier ministre de Roumanie: "La question des migrants ne doit pas se résumer à un nombre á repartir", Le Monde, 22, Janvier, 2016., en: http://www.lemonde.fr/europe/article/2016/01/22/dacian-ciolos-premierministre-de-roumanie-la-question-des-migrants-ne-doit-pas-se-resumer-a-un-nombre-arepartir 4852103 3214.html

${ }^{77}$ Szary, Wiktor and Pawlak, Justyna: "Poland says will honor UE migrant quotas but questions legality, Reuters, December, 30, 2015, en: http://www.reuters.com/article/us-europe-migrants-polandidUSKBNOUH0J020160103

78 "Holanda planea devolver a los refugiados a Turquía" El Mundo, Amsterdam, 28.1.2016, en: http://www.elmundo.es/internacional/2016/01/28/56a9f580268e3e250e8b45a3.html

${ }^{79}$ Preguntaba el primer ministro rumano en un encuentro con el presidente francés François Hollande, en el Elyseo, ¿el espacio Schengen está en peligro?, si nosotros nos adherimos a Schengen, es porque creíamos que era un conjunto solido y funcional. Tampoco aceptaba la imposición desde Bruselas de las cuotas de reparto de refugiados. Selles, Alain et Ricard, Phillipe:"Dacian Ciolos, premier ministre de Roumanie: "La question des migrants ne doit pas se résumer à un nombre á repartir”, Le Monde, 22, 1, 2016, en http://www.lemonde.fr/europe/article/2016/01/22/dacian-ciolos-premier-ministre-de-roumanie-la-question-desmigrants-ne-doit-pas-se-resumer-a-un-nombre-a-repartir_4852103 3214.html

80 "700 Inmigrantes desaparecidos tras hundirse su barco en aguas Libias", El País, 19 de abril de 2015, en http://internacional.elpais.com/internacional/2015/04/19/actualidad/1429431225_038632.html
} 
contra ellas. En el Consejo Europeo se acuerda la reubicación de 40.000 refugiados desde Grecia e Italia. Esta reubicación consiste en un mecanismo excepcional y temporal de dos años y destinado exclusivamente a todas las personas que necesiten protección internacional y que estén llegando desde el 15 de agosto de 2015 hasta el 16 de septiembre de 2017.

Dinamarca y Reino Unido no participaron en esta decisión. ${ }^{81}$ Se hacía un llamamiento a la solidaridad de todos los países de la Unión.

Y en octubre de 2015 se autoriza la Misión Sofía que permitiría el abordaje de las embarcaciones en aguas internacionales, bajo el permiso de la ONU. Se crean los hotspot, o "puntos calientes" para identificación de migrantes. Por primera vez la migración encabezó el programa de la Unión Europea. ${ }^{82}$

En este mismo mes, el 15 de octubre de 2015 “Turquía entra en escena”, el objetivo era persuadir a Turquía, que había sufrido unos días antes un ataque con bombas en Ankara ${ }^{83}$, para que se involucrara en el tema de la migración que salía de su país. Fue una iniciativa de la canciller alemana Ángela Merkel y también lo sugirió el ministro de migración griego, Yannis Mouzlas ${ }^{84}$. E1 5 de octubre de este año el Presidente Juncker, de la Comisión Europea, había entregado el Proyecto de Plan de Acción sobre apoyo a los refugiados y gestión de la migración al Presidente Erdogán durante la visita de éste a Bruselas. ${ }^{85}$ El 29 del mismo mes de noviembre de 2015 por medio de la Declaración conjunta Unión Europea-Turquía se activa el Plan de Acción, sobre la base de la responsabilidad compartida, acordado por los dos países, ad referendum del 15 de octubre de 2015. El objetivo es intensificar la cooperación entre los dos países para ayudar a los ciudadanos sirios bajo protección temporal y la gestión de la migración para hacer frente a la crisis creada por la situación en Siria. Se hace hincapié en la necesidad de conseguir resultados en relación a contener la afluencia de inmigración irregular desde Turquía a la Unión Europea. Se aseguraba que el plan de acción conjunto pondría orden en los flujos migratorios y contribuiría a detener la migración irregular. Se comprometían ambas partes a reforzar con "efecto inmediato", su cooperación activa en materia de migrantes que no necesitaran protección internacional, evitando así los desplazamientos a Turquía y a la Unión Europea ${ }^{86}$, garantizando, además, la aplicación de las disposiciones bilaterales en materia de readmisión establecidas y repatriando con rapidez a sus países de origen a aquellos migrantes que no necesiten protección internacional. Ambos países, asimismo, se comprometían a intensificar su lucha contra las redes delictivas de tráfico de inmigrantes. A cambio se aceleraría las negociaciones sobre la adhesión de Turquía a la

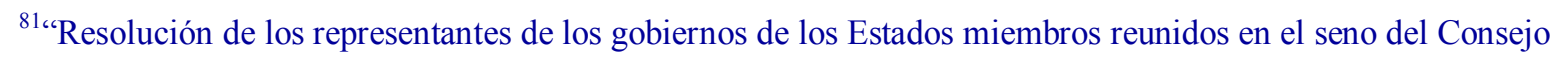
sobre la reubicación de 40.000 personas claramente necesitadas de protección internacional que en la actualidad se encuentran en Grecia e Italia", Consejo de la Unión Europea. Bruselas, 22 de julio de 2015. Y también, "El Consejo acuerda la reubicación de 40.000 refugiados desde Grecia e Italia”, Consejo de la Unión Europea. Bruselas, 14.092015.

82 "Migration Summits: A timeline of failures", Politico, 3.7.2016, en: http://www.politico.eu/interactive/migration-summits-timeline-of-failures-european-council-meetings-migration/ ${ }^{83}$ Ibid. nota 67

84 “Tenemos una propuesta muy concreta. Toda Europa está de acuerdo en que la llave la tiene Turquía. Turquía necesita ayuda. Así que propongo un acuerdo generoso, que se le dé dinero para que construya campamentos de refugiados; en segundo lugar, una vez apartados éstos, la devolución de todos los inmigrantes irregulares a Turquía al día siguiente. Esto enviaría también un mensaje al extranjero". Sánchez Vallejo, María Antonia: "Ha habido fallos, pero Grecia no merece las amenazas de la UE”, El Pais, 10 de febrero 2016, en http://internacional.elpais.com/internacional/2016/02/03/actualidad/1454521806_409750

85 "UE-Turquía: Publicación del Proyecto de Plan de Acción sobre apoyo a los refugiados y gestión de la migración", Comunicado de Prensa. Bruselas, 5 de octubre de 2015.

${ }^{86}$ Reunión de los Jefes de Estado o de Gobierno de la UE con Turquía, 29-11-2015-Declaración UE-Turquía. Consejo de la Unión Europea. Bruselas, 29.11.2015
} 
Unión Europea que desde 1999 era país candidato, y cuyas negociaciones se llevaban a cabo desde 2005. También se prometía la liberalización de visados para los turcos.

Acuerdos que no se tiene una firme convicción de ser cumplidos en el futuro, debido al intento de golpe de estado de julio de este año, y también que representa un cierto lastre para la Unión Europea, encadenada como siempre con la servidumbre de las prebendas económicas. A este respecto, la Unión Europea a prometido una ayuda a Turquía de 3.000 millones de euros inicialmente, "para fijar a los refugiados en su territorio". Una vez que esta partida haya sido utilizada se le darán otros adicionales de 3.000 millones de euros hasta el final de $2018 .^{87}$

Dos meses antes, el director para Europa del Alto Comisionado de La ONU para los Refugiados (ACNUR) ${ }^{88}$ sostenía en una entrevista al periódico El Mundo, que era "importante recordar a los ciudadanos europeos los fuertes valores sobre derechos humanos que compartimos. Hacen falta sistemas justos y eficientes que analicen de forma rápida las solicitudes de asilo y devolver a los que no necesitan protección. Es la forma en que los ciudadanos toman conciencia de que los que se quedan deben ser protegidos. Sólo así la población entiende que los que se quedan realmente necesitan protección. Esa es la mejor respuesta a los xenófobos".

Concluye indicando que, "simplemente hay que hacer las cosas bien, como por ejemplo las repatriaciones. El 40\% de las expulsiones no se realizan, y los emigrantes sin tener derecho a protección se quedan en suelo europeo".

Era evidente que no se habían hecho bien las cosas, tal vez por negligencia, o tal vez también porque en la Unión Europea el "consenso" es lo que prevalece y alarga la puesta en marcha de los acuerdos anteriores.

\section{Tercera Cumbre UE-Turquía. 18 de Marzo 2016. Acuerdos de la UE- Turquía.}

Reunión dedicada a profundizar en las relaciones bilaterales y a tratar la crisis migratoria. Ha sido una iniciativa de la canciller alemana Ángela Merkel. "Un pour un" es la forma del dispositivo, elaborado en el acuerdo. En la actualidad hay cerca de 2.7 millones de refugiados sirios en suelo turco. Y en cuatro meses solamente 849 personas han sido "réinstallés" (reinstaladas) en la Unión Europea, en Alemania y Suecia.

Los acuerdos con Turquía van dando resultado, el número de refugiados y migrantes ha bajado un $88 \%$ en un mes, según la Organización Internacional para las Migraciones. Desde enero de 2016 las entradas por Grecia eran de 31.244 migrantes y refugiados, lo que representaba un 21 veces más que las 1.472 personas registradas en el mes de enero de 2015 . En el mes de marzo llegaron 26.971 personas a Grecia frente a las 3.360 del mes de abril, cuando ya estaban en marcha los acuerdos. ${ }^{89}$

\footnotetext{
${ }^{87}$ “Le destin de 1'Europe se joue en mer Egée", Le Monde. 25.01.2016. http://www.lemonde.fr/idees/article/2016/01/25/le-destin-de-l-europe-se-joue-en-mer-egee $4853079 \quad 3232 . \mathrm{html}$

${ }^{88}$ Entrevista a Vincent Cochetel, director para Europa del ACNUR."Europa tiene que decidir entre regular la migración o el caos actual", El Mundo, 8.8. 2015, en http://www.elmundo.es/internacional/2015/08/08/55c6f11146163f36138b456e.html

${ }^{89}$ Organización Internacional para las Migraciones, "Grecia”, 1.19.2016, en: https://www.iom.int/es/news/laoim-informa-que-en-enero-las-llegadas-de-migrantes-grecia-aumentaron-dramaticamente-al-2100. También: "Le destin de l'Europe se joue en mer Egée", Le Monde, 25.01.2016, en:

http://www.lemonde.fr/idees/article/2016/01/25/le-destin-de-l-europe-se-joue-en-mer-egee_4853079_3232.html
} 
En cambio por Italia en el mes de abril se registraron más llegadas que a Grecia, contabilizándose 9.149 personas.

Sin embargo, desde el "intento de golpe de Estado contra Erdogán” de julio pasado se teme que este acuerdo flaquee en aspectos tan importantes como que Turquía no sea un país seguro para los refugiados. ¿Cómo considerarlo seguro, con la masiva represión que Erdogán ha realizado todos estos meses atrás? Como lo decía el propio Jean-Claude Juncker, acuerdo fragile, sans cacher un "risque élevé de le voir capoter. Nous pouvons alors nous attendre à ce que les migrants recommencent à venir en Europe". ${ }^{90}$ En la cumbre celebrada el 7 de junio de Estrasburgo, sostenía la Alta Representante para la política Exterior de la Unión Europea que, la cooperación con Turquía era fundamental para hacer frente a la explotación de personas vulnerables que trataban de cruzar el mar Egeo ${ }^{91}$. Sorprendente afirmación, porque las mafias de la migración en Turquía han campado a lo largo y ancho del país y nadie hizo nada por evitar que la corriente migratoria pasara a Europa, estamos seguros, que por el contrario se alentó.

\section{Cumbre de la Valeta: Reunión Unión Europea-África. 11 de noviembre de 2015.}

El 11 de noviembre de 2015 se celebra la denominada Cumbre de la Valeta (Malta), entre los dirigentes de la Unión Europea y los de la Unión Africana cuyo objetivo principal fue encontrar soluciones comunes a los desafíos compartidos. Se abordó atacar las causas profundas de la migración, establecer y organizar canales de migración legal, potenciar la protección de los migrantes y solicitantes de asilo, combatir la explotación y el tráfico de migrantes, así como cooperar en materia de retorno eficaz y humana que no contradice una política migratoria más abierta y una cooperación con los países de origen de los migrantes para negociar y celebrar acuerdos de readmisión, estableciendo las normas para el retorno de las personas que se encuentran en situación irregular ${ }^{92}$. A largo plazo, se prometían incentivos para el desarrollo e inversión en países de origen de la migración, como se abordó en la cumbre Unión Europea-África de abril de 2014.

Cinco puntos, que en diversas cumbres, reuniones y directivas se han estado barajando y proponiendo como meta alcanzable para resolver los trastornos que causan las migraciones irregulares. Sin embargo, no parece que los resultados fueron positivos y de nuevo los flujos migratorios aumentaron en las costas europeas. Por más reuniones que se sigan convocando, sino hay disposición seria para proceder de acuerdo a lo que se formaliza, no habrá solución alguna a este fenómeno imparable de las migraciones irregulares. Lo más destacado es la creación de un Fondo Fiduciario de Emergencia de la Unión Europea ${ }^{93}$ para la estabilidad y para abordar las causas profundas de la migración irregular y del desplazamiento de personas en África. Fondo que permitirá financiar proyectos destinados a crear oportunidades de

\footnotetext{
90 "Acuerdo frágil, sin ocultar un alto riesgo en su colapso, entonces podemos esperar que los migrantes vuelvan a venir a Europa." L'Union européenne craint la fin de l'accord avec la Turquie", Le Monde, 6.8.2016, en: http://www.lemonde.fr/europe/article/2016/08/06/1-union-europeenne-craint-la-fin-de-1-accord-avec-laturquie $4979191 \quad 3214 . h t m l$

91 "La Comisión anuncia un nuevo marco de Asociación en materia de migración: una Cooperación Reforzada con terceros países para gestionar mejor la migración", Estrasburgo, 7 de junio de 2016.

92 "Cumbre de la Valeta sobre migración 2015. Material relativo a la actuación de la Unión Europea”, Valeta, 11.11.2015. Hasta ahora la Unión Europea ha celebrado 17 acuerdos de readmisión y otros están en negociación. Además, el Acuerdo de Cotonú entre la UE y los países de África, el Caribe y el Pacífico incluye también una cláusula relativa a la readmisión.

${ }^{93}$ Se aspira alcanzar los 3.600 millones de euros. El nuevo fondo de ayuda de emergencia para África dispondrá de 1.878 millones de euros, de los que 1.800 millones serán aportados por el presupuesto comunitario y tan solo 78 por los estados miembros.
} 
empleo y apoyar los servicios básicos destinados a las poblaciones locales. Su importe es de 1.800 millones de euros en programas de cooperación al desarrollo. Las regiones a las que está destinada esta ayuda son: el Sahel, la región del lago Chad, la región del Cuerno de África, Marruecos, Argelia, Túnez y Egipto.

\section{La Guardia Europea de Fronteras y Costas protegerá las fronteras exteriores de Europa. 15 de diciembre de 2015.}

En Estrasburgo, la Comisión propuso la creación de la Guardia Europea de Fronteras y Costas $^{94}$ para garantizar una gestión rigurosa y compartida de las fronteras exteriores. Con el objetivo de reforzar aún más la seguridad de los ciudadanos europeos. La crisis de refugiados y migrantes había puesto de manifiesto grandes debilidades y carencias en los diversos mecanismos destinados a garantizar el cumplimiento de las normas de la Unión Europea. Se indicaba también que se "estaba construyendo más Europa” y, por lo tanto, se debía de gestionar mucho mejor las fronteras exteriores, se debía intensificar los retornos de inmigrantes irregulares y permitir que el sistema de asilo funcionara correctamente para quienes lo necesiten, reforzando los controles en las fronteras exteriores. La Guardia englobará a la Agencia Europea de Guardia de Fronteras y Costas, formada a partir de Frontex y a las autoridades responsables de la gestión de fronteras en los Estados miembros, que seguirían ejerciendo la gestión cotidiana de las fronteras exteriores.

La Guardia dispondrá de una reserva rápida de guardia de fronteras y un parque de equipos técnicos, compuesto por 1.500 expertos que podrán desplegarse en 3 días. Tendrán la función de seguimiento y supervisión, y dispondrán de un centro de seguimiento y análisis de riesgos con el fin de controlar los flujos migratorios hacia y dentro de la Unión Europea y de llevar a cabo análisis de riesgos y evaluaciones obligatorias de la vulnerabilidad para identificar y abordar los puntos débiles.

Tendrá derecho a intervenir y desplegar equipos de la Guardia Europea de Fronteras y Costas para garantizar que se tomen medidas sobre el terreno, incluso en el caso de que un Estado miembro no pueda o no quiera tomar medidas necesarias.

Los guardacostas nacionales formarán parte de la nueva guardia. Tendrá un mandato para operar en terceros países, con envío de agentes de enlace y puesta en marcha de operaciones conjuntas. Tendrá también un papel decisivo en materia de retorno, por medio de la creación de una Oficina Europea de Retorno con el fin de permitir el despliegue de equipos europeos de intervención en materia de retorno. Ya el presidente Juncker en su discurso sobre el Estado de la Unión el 9 de septiembre anunció que la Guardia formaba parte de las medidas previstas en la Agenda Europea de Migración para reforzar la gestión y la seguridad de las fronteras exteriores de la Unión Europea.

El 6 de octubre pasado se puso en marcha la nueva Guardia Europea de Fronteras y Costas. Según el comisario de migración, asuntos de interior y de ciudadanía de la Unión Europea, "de ahora en adelante, la frontera exterior de la Unión Europea de un estado miembro es la frontera exterior de todos los estados miembros, tanto legal como

\footnotetext{
${ }^{94}$ Comisión Europea: "La Guardia Europea de Fronteras y Costas protegerá las fronteras exteriores de Europa", Estrasburgo, 15 de diciembre de 2015. "The latest: Italian FM:UE should compromise with Turkey", The Washington Post, October 6, 2016, en https://www.washingtonpost.com/world/europe/the-latest-afghanmigrants-in-balkans-fear-deportation/2016/10/06/8934f150-8bc8-11e6-8cdc-4fbb1973b506_story.html
} 
operativamente". ${ }^{95}$ ("From now onwards, the external UE border of one member state is the external border of all member states- both legally and operationally"- said Dimitris Avramopoulos, the UE commissioner for migration, home affairs and citizenship.)

Un instrumento tan necesario como este, parece mentira que no hubiera sido creado hace muchos años, precisamente en el momento de poner en marcha Schengen. Es una acción reactiva por parte de la Unión Europea, que parece siempre ir a rastras de los acontecimientos.

\section{La cuestión del asilo es prioritaria.}

Si nos atenemos a lo que refleja la Comunicación que el 6 de abril de 2016 emitió la Comisión europea al Parlamento y al Consejo, sobre el estado de la cuestión del asilo y refugio, se puede concluir que la política de asilo y migración de la Unión Europea era un auténtico "queso de gruyere". Tenía "fugas de agua" por todas partes, y en nuestra opinión, los acuerdos que se fueron pergeñando por los países europeos a lo largo de los años, fueron una puesta en escena, más que un decidido interés por cumplir con sus obligaciones, pues cada país hizo de "su capa un sayo", es decir, cada uno hizo caso omiso a lo acordado entre todos, y como hemos visto en Grecia, ante una avalancha de cientos de miles de refugiados y migrantes que pasaban todos los días desde Turquía, abrumada por los acontecimientos y sin equipos suficientes para hacer frente a lo que estaba sucediendo y mucho menos para registrarlos como era su obligación, ${ }^{96}$ los dejó pasar, ayudada por la Canciller Ángela Merkel.

El 6 de abril de este año 2016, se emite una Comunicación por parte de la Comisión al Parlamento europeo y al Consejo, que evalúa la necesidad de una reforma del sistema europeo común de asilo y de crear vías legales para entrar a Europa. ${ }^{97}$ Es un documento que invita al debate de las instituciones europeas y dónde se hace una evaluación del estado de la cuestión en lo que se refiere a asilo, protección y migraciones irregulares y legales.

La Comunicación pone en evidencia los fallos en el diseño y aplicación que se han producido en la política de asilo y migración de la Unión Europea, fallos que han quedado "a la luz", gracias a la ingente cantidad de personas que se volcaron hacia las costas europeas y tomaron camino por Grecia hacia los Balcanes Occidentales con la finalidad de buscar refugio y de llegar a Alemania. Diríamos que gracias a la canciller Ángela Merkel, con su actitud irreflexiva respecto al asilo, puso en evidencia los vacíos que existía en la política de asilo y migración de la Unión Europea.

Se especifica por parte de la Comisión que, para la Unión Europea es una obligación moral y jurídica proteger a quien lo necesita, sin embargo, los fallos y las negligencias en la aplicación de todo el acerbo de asilo de Dublín, deja a las claras que sin un auténtico programa que implique de forma sustancial a todos los países miembros de la Unión Europea,

\footnotetext{
95 Ibid.

${ }^{96}$ En diciembre de 2015 solamente el centro de recepción y registro de migrantes de Lesbos estaba funcionando. Los cuatro restantes que se habían prometido desde Bruselas estaban en construcción y se activarían en este año 2016. Con el agravante que ese centro de Lesbos tenía capacidad para registrar 4.000 personas diarias. La situación en Grecia sobrepasaba la voluntad humana. Así lo describe el ministro de migración del gobierno griego de Syriza:'En noviembre si hubo fallos en el registro (de migrantes), pero nosotros habíamos pedido 100 máquinas Eurodac (base de datos europea de huellas digitales) y nos mandaron solo 48..., 48 máquinas funcionando las 24 horas del día pueden registrar 4.800 personas. Pero si en un día llegan 8.000, la mitad se queda sin registrar". "Ha habido fallos, pero Grecia no merece las amenazas de la UE", El País, 10 de febrero 2016, en http://internacional.elpais.com/internacional/2016/02/03/actualidad/1454521806_409750.html

${ }^{97}$ Comunicación de la Comisión al Parlamento Europeo y al Consejo. Hacia una reforma del sistema europeo común de asilo y una mejora de las vías legales a Europa. Comisión Europea. Bruselas 6.4.2016
} 
que se comprometan a cumplir la ley, no se resolverá ninguno de los problemas que hoy en día plantean tanto el asilo como las migraciones irregulares.

Así se desprende de la respuesta que quiere dar este Comunicado a las demás instituciones europeas, donde se enfatiza la necesidad prioritaria de promover los instrumentos con los que cuenta la Unión Europea y reforzarlos con los que se proponen como la creación de la Guardia Europea de Fronteras y Costas, los Planes de Acción contra el tráfico ilícito de migrantes y en materia de retorno, para "atajar los flujos incontrolados de migración irregular", proteger las fronteras exteriores y salvaguardar la integridad del espacio Schengen. Las acciones a este respecto se deberán abordar de conformidad con la Agenda Europea de Migración. ${ }^{98}$

¿Cuál es entonces el objetivo propuesto por la Comisión Europea para la reforma del Sistema de Asilo europeo?

Sencillamente, pasar de un sistema que hace responsable a un solo Estado del control de la inmigración irregular y de los solicitantes de asilo, para implicar a todos los Estados miembros de la Unión Europea. Como lo refleja claramente el documento aquí analizado. Pasar del sistema que asigna una responsabilidad desproporcionada a determinados Estados, (léase de fronteras exteriores), y pasar a otro donde se garantice itinerarios seguros y ordenados hacia la UE a los migrantes procedentes de terceros países necesitados de protección o que puedan contribuir al desarrollo económico de la UE. Sistema que debe estar basado en los principios de responsabilidad y solidaridad.

Responsabilidad y solidaridad, que han estado ausentes desde que las primeras Directivas de la UE sobre migraciones preservarán a los países centrales de la UE de la llegada masiva de migrantes irregulares, que en cambio si lo sufrían los países con frontera exterior como España, Italia y Grecia.

Se pone de relieve también que, como consecuencia del aluvión incontenible de migrantes y refugiados durante los meses de verano de 2015 y hasta bien entrado el otoño cruzando por Grecia y avanzando por los países de los Balcanes Occidentales, gracias a la pretendida política de "puertas abiertas" impulsada por Angela Merkel, muchos países se vieron desbordados en esta cuestión y reclamaron respuestas fiables de cómo manejar este asunto, atajando la migración irregular y gestionando las fronteras exteriores de la UE de manera más eficiente. El primero que alzó la voz fue el primer ministro italiano, Mateo Renzi, quien solicitó ayuda a la Unión Europea; por su parte los dirigentes de los países de los Balcanes Occidentales, como el primer ministro de Hungría y Macedonia, dieron la orden de construir vallas para evitar el paso a los inmigrantes y refugiados.

Continuando con el comunicado de la Comisión europea, los tres asuntos claves para abordar de una forma efectiva la política de asilo y migración son:

1- Reforzamiento del Sistema Europeo Común de Asilo y Migración.

2- Reforzar vías seguras y legales hacia Europa. Promoviendo la migración legal.

3- Luchar contra las causas últimas de la migración.

\footnotetext{
${ }^{98}$ Todos estos compromisos se hacían visibles para la Comisión, a partir de las reuniones del Consejo Europeo de 18 y 19 de febrero y 17 y 18 de marzo, y de la reunión de jefes de Estado o de Gobierno de 7 de marzo.
} 
En cuanto al reforzamiento del Sistema Europeo Común de Asilo, se incide en la necesidad de hacer más eficaz el sistema de Dublín, que establece criterios y mecanismos para determinar qué Estado miembro es el responsable del examen de una solicitud de protección internacional, como también que los solicitantes de protección no tienen derecho a elegir el Estado miembro en el que desean asentarse.

Otra cuestión importante y que la crisis migratoria ha dejado al descubierto es que el sistema de Dublín no fue concebido para garantizar un reparto de responsabilidad sostenible en relación con los solicitantes de asilo en todo la Unión Europea. ${ }^{99}$ Por tanto, en una situación de afluencia masiva de migrantes sobre la frontera exterior, el actual sistema hace recaer la responsabilidad por ley, para la gran mayoría de los solicitantes de asilo, en un número limitado de Estados miembros concretos, situación que desborda las capacidades de cualquier Estado miembro.

Relacionado con lo anterior, y que hace inviable el actual sistema de asilo es que a menudo los migrantes se niegan a presentar solicitudes de asilo o a identificarse en el Estado miembro de la primera llegada y se desplazan al Estado miembro en el que desean instalarse, solicitando asilo allí. Consecuencia de esto, es el aumento del número de solicitudes de asilo en Estados miembros que no son los del primer punto de entrada, provocando una serie de movimientos secundarios que han dado lugar a que varios Estados miembros hayan establecido controles en las fronteras interiores para gestionar la afluencia. ${ }^{100}$ Otro problema que presenta el sistema de Dublín, es la dificultad para trasladar a los solicitantes de asilo a Estados miembros con deficiencia sistémicas en aspectos críticos de procedimientos de asilo o sus condiciones de acogida.

También el Sistema Europeo Común de Asilo falla en la diferencia de trato respecto a los solicitantes de asilo, especialmente en cuanto a la duración del proceso, debido al carácter discrecional por parte de los Estados miembros, lo que incentiva a los movimientos secundarios. Por consiguiente la falta de convergencia en lo que se refiere a las decisiones para conceder el estatuto de refugiado ${ }^{101}$, o el estatuto de protección subsidiaria ${ }^{102}$ a los solicitantes que proceden de un país de origen determinado, provocan siempre movimientos secundarios, al igual que las variaciones en la duración de los permisos de residencia, así como en el acceso a la asistencia social y la reagrupación familiar.

Otra grave distorsión que se pone de manifiesto es que la protección internacional en los Estados miembros de la Unión Europea, en la práctica, ha dado lugar a la residencia permanente, mientras que su objetivo original "y principal era conceder protección únicamente mientras persistiera el riesgo de persecución o daños graves". Una vez desaparecen estas circunstancias, se indica que la protección deja de ser necesaria. Cuestión esta que no se ha llevado a cabo en la práctica.Como vamos viendo, la serie de irregularidades y de falta de aplicación de las Directivas es la que ha dado lugar a este caos migratorio que se conoce por toda la Unión Europea.

\footnotetext{
${ }^{99}$ La lógica de este criterio se basaba en la premisa de que debía establecerse una vinculación entre la asignación de responsabilidades en el ámbito del asilo y el respeto por parte de los Estados miembros de sus obligaciones en materia de protección de la frontera exterior.

${ }^{100}$ Aun cuando los Estados miembros aceptan las solicitudes de traslado, sólo en torno a una cuarta parte de esos casos acaban en traslados efectivos. De tal forma, que si un solicitante de asilo permanece fugado durante un largo período de tiempo en un Estado miembro sin ser trasladado efectivamente, este Estado miembro acabará siendo el responsable.

${ }^{101}$ Que se otorga a personas que huyen de la persecución.

${ }^{102}$ Que se otorga a personas que huyen del riesgo de daños graves, incluidos los casos de conflictos armados.
} 
Para abordar estas deficiencias estructurales, la Comisión propone cinco prioridades ${ }^{103}$ : Crear un sistema sostenible y justo para determinar el Estado miembro responsable de la tramitación de solicitudes de asilo, reforzar el sistema Eurodac, lograr una mayor convergencia en el sistema de asilo de la Unión Europea, impedir los movimientos secundarios dentro de la Unión, y crear un nuevo mandato para la Agencia de Asilo de la Unión Europea, (EASO). Cabe destacar en este apartado, la propuesta de transferir la responsabilidad de la tramitación de las solicitudes de asilo del nivel nacional al nivel de la Unión Europea, transformando EASO en una agencia decisoria de primera instancia a nivel de la Unión, con delegaciones nacionales y creando una estructura de apelación a escala de la Unión Europea. ${ }^{104}$

En relación a garantizar y mejorar rutas migratorias seguras y legales, la Comisión propone una política "firme encaminada a atajar los flujos irregulares, garantizando la protección a quienes la necesitan" y también una política "proactiva" de vías legales sostenibles. Se reconoce que las migraciones contribuyen al crecimiento inclusivo y que representan una realidad pluridimensional que exige respuestas coherentes e integrales, como se recoge en la Agenda 2030 para el Desarrollo Sostenible. Introduciendo este mecanismo de vías legales y seguras la Comisión pretende reducir las migraciones irregulares y desmantelar el modus operandi de los traficantes de seres humanos. De paso, la responsabilidad de protección no sería sólo de la Unión Europea, sino también seria asumida por la comunidad internacional, pues en la actualidad se compartía de forma muy desigual.

Se lanza la idea de una necesaria migración laboral más proactiva para atraer a los talentos, pero como veremos un poco más adelante, ni esto ha funcionado como se esperaba.

Como seguimos viendo la tónica general del entramado de asilo y migración y su puesta en práctica, deja bastante que desear.

Respecto al sistema de reasentamiento, se insta a que se avance hacia un enfoque más gestionado de protección de refugiados en la Unión Europea y hacia un sistema de reasentamiento estructurado, con un enfoque común para la llegada segura y legal a la Unión de personas necesitadas de protección. Para ello se insta también a reforzar su apoyo a iniciativas internacionales destinadas a abordar los desafíos en materia de migración y asilo, como los programas de reasentamiento del ACNUR ${ }^{105}$. A través de su escrito, el informe de la Comisión deja clara la mala praxis de todo el entramado de asilo y migración. Señala que la política en este asunto debía tener como objetivo general "la asunción por la Unión de la parte de responsabilidad que le toca para dar refugio a los refugiados del mundo, responsabilidad que ha de compartir la comunidad internacional en su conjunto". Premisa que se anuncia en la Estrategia Europea de Seguridad de este año y también por parte de la Comisión europea, en la reunión de Estrasburgo de 7 de junio, donde se pone el acento en la gestión de la migración

\footnotetext{
${ }^{103}$ Cada prioridad incluye un objetivo y una acción. Todos en clara armonía para corregir las deficiencias del Reglamento de Dublín, para pasar a un nuevo sistema basado en la distribución. Además, se incide en la necesidad de garantizar que el funcionamiento del mecanismo de Dublín no sea entorpecido por los abusos y las solicitudes múltiples por parte de los solicitantes de asilo y los beneficiarios de protección internacional.

${ }^{104}$ Propuesta con perspectiva a largo plazo. Si incluye la posibilidad de un proceso de toma de decisiones único y centralizado.

${ }^{105}$ Señala el Informe de la Comisión, la reunión de Alto nivel del ACNUR sobre reparto de responsabilidades a nivel mundial a través de vías de admisión de los refugiados sirios,celebrada en Ginebra el 30 de marzo de 2016. También la cumbre de la AGNUR sobre grandes movimientos de refugiados y migrantes, que se celebró en Nueva York el 19 de septiembre de este año, que ha aplazado hasta el año 2018 todas sus actuaciones en este asunto.
} 
dentro de un marco de asociación de cooperación reforzada ${ }^{106}$, sumando esfuerzos para colaborar con los terceros países.

Sin embargo, en el siguiente epígrafe, sobre una política de migración legal más inteligente y bien gestionada, se hace hincapié en la necesidad de completar los regímenes específicos de reasentamiento ${ }^{107}$ y de admisión humanitaria con regímenes de admisión regulares existentes como las categorías para estudiantes e investigadores y trabajadores, se comete el primer desliz, mezclando regímenes de entrada a la Unión Europea, que no tienen nada que ver con la protección, como es el caso de los estudiantes que vienen de países sin problemas y otro régimen, como es el de protección que debe aplicarse a las personas vulnerables y necesitadas de protección internacional, por la procedencia desde un país en conflicto o amenazado por su religión, sexo o persecución política. Se plantea por parte de Comisión que sería conveniente el "patrocinio privado", para apoyar el asentamiento de las personas necesitadas de protección, porque "pueden desempeñar un papel importante a la hora de multiplicar las posibilidades de entrada legal". Una especie de padrinazgo, sin supervisión de los gobiernos, a nuestro entender, se dará pié para que entren unos solicitantes de asilo y no otros, en función de las ideologías, creencias religiosas o tendencias sexuales, etc.

Vamos a ver si esto queda claro. Si la Unión Europea en los valores que esgrime en todas partes señala como el más importante ser defensora de los derechos humanos convirtiéndose en el "adalid de la protección y el refugio internacional", ¿cómo puede ser que se le aconseje, desde un organismo comunitario como es la Comisión, renegar de este valor y convertirse en la potencia que no cumple lo que predica? Si de veras es protectora de los solicitantes de asilo que lo necesitan, todos los países que forman la Unión Europea tienen la obligación de dar protección a los refugiados que lo necesiten. Cuántas veces hemos preguntado ¿cómo podían ser compatibles los Derechos Humanos con el control de las fronteras exteriores de la Unión Europea? Los dirigentes que hemos elegido en las pasadas elecciones ${ }^{108}$ para el Parlamento europeo deben ya aclararse en este asunto, porque no se pueden abandonar los pocos valores humanitarios que creemos defender.

Aquí, la propuesta de combinar el reasentamiento con vías de entrada legal, a nuestro juicio, nos parece una mera componenda que no debe llevarse a cabo. Que la readmisión sea un instrumento de protección, pero no una forma de quitarse de en medio la obligación moral de proteger a las personas necesitadas de ello. Una persona protegida, no es un estudiante o un trabajador que viene normalmente a la Unión Europea a estudiar o trabajar. Una persona

\footnotetext{
106 “La Comisión anuncia un Nuevo Marco de Asociación en Materia de Migración: una cooperación reforzada con terceros países para gestionar mejor la migración”, Estrasburgo, 7 de junio de 2016.

107 "Manual de Reasentamiento de ACNUR", 2011, en http:/www.acnur.org/que-hace/solucionesduraderas/reasentamiento/manual-de-reasentamiento-del-acnur/ Según ACNUR, el reasentamiento implica el traslado permanente de refugiados a un tercer país. Además de una solución duradera, es un instrumento de protección para aquellos refugiados cuya vida, libertad, seguridad, salud y otros derechos fundamentales estén en riego en el primer país de asilo y un mecanismo de repartición de las responsabilidades entre los Estados.

${ }^{108}$ Elecciones al Parlamento Europeo de 2014 que tuvieron lugar entre el 22 y 25 de mayo. Fueron las primeras elecciones tras la entrada en vigor del Tratado de Lisboa que introdujo cambios en la composición de la cámara y dio más poder al Parlamento. Esta cámara nombra al Presidente de la Comisión Europea a propuesta del Consejo Europeo en función de los resultados de las elecciones, por mayoría cualificada. Parlamento Europeo.

"Elecciones europeas", Parlamento Europeo, en http://www.europarl.europa.eu/atyourservice/es/20150201PVL00036/Elecciones
} 
protegida, como su nombre indica debe ser amparada y asistida económicamente por el país que le da protección y debe tener su estatuto de protección o refugio propio.

Parece que la Comisión Europea en la reunión de 13 de julio de 2016 aclara ya este "entuerto", por medio del refuerzo de las vías legales, como expresaba el comisario europeo de Migración, Asuntos de Interior y Ciudadanía, Dimitris Avramopoulos ${ }^{109}$, presentando la propuesta que suponía un gran avance, abriendo una ventana legal para conseguir cerrar la puerta trasera de la ilegalidad, por medio de un procedimiento unificado en materia de reasentamiento en toda la Unión Europea.

En cuanto a la política de migración legal se pone la atención por parte de la Comisión Europea, en la necesidad de terminar con la "fragmentación de las políticas de admisión", como sucede con los trabajadores altamente cualificados, por lo que el sistema de la Tarjeta Azul no ha funcionado como debía, y se enumeran varios fallos, como que las condiciones de admisión son bastante restrictivas, la Directiva en sí misma prevé poca coherencia y armonización y la movilidad para sus titulares es muy limitada. Además, de no haberse promocionado como debía dentro del empresariado. Igualmente la migración circular ${ }^{110}$ no ha funcionado, cuestión que se viene alentando desde 2005 y que hubiera propiciado la migración regular.

Vemos que la política de asilo y de migración europea no ha funcionado, por la negligencia y mala práctica de cada uno de los países miembros. Una política de asilo y migración, prácticamente "a la carta", donde cada gobierno ha hecho lo que le ha parecido conveniente, sin una coordinación ni en los informes ni en las ayudas que se le otorgan a los refugiados, ni tampoco en la aplicación de Directivas, que desde el año 2003 se emitieron con el fin de poner en común todo el entramado sobre migración irregular y asilo.

Parece como si esta política de asilo y migración no hubiera sido importante para la seguridad europea, más que cuando han "saltado las alarmas" con la llegada masiva de migrantes a partir de 2015 .

Por otra parte, es sorprendente que los expertos en asilo y migración de toda la Unión Europea no hubieran caído en la cuenta de todas éstas deficiencia que denuncia la Comisión Europea, y no hayan denunciado ellos mismos las negligencias que se cometían al respecto.

\section{Giro de la política de "puertas abiertas" de Angela Merckel: hacia las restricciones.} La decisión del 4 de septiembre de 2015 de parte de la Canciller Ángela Merkel de abrir las puertas de Alemania a los refugiados sirios han traído serias consecuencias, que transcurrido unos meses han obligado a cambiar el rumbo de esa política a la canciller alemana.

En un primer momento introdujo un elemento de controversia entre los socios europeos, como hemos visto a partir del cruce de fronteras indiscriminado por la corriente migratoria con dirección a Alemania. Más tarde, los mismos miembros de su gabinete ante la evidencia de los hechos, cambiaron su discurso a favor de los refugiados. Así por ejemplo: el vicecanciller Sigmar Gabriel y el ministro de Relaciones Exteriores, Frank-Walter Steinmeier,

\footnotetext{
109 "Refuerzo de la vías legales: La Comisión propone crear un marco común de la UE en materia de reasentamiento", Comisión Europea. Bruselas, 13 de julio de 2016.

${ }^{110}$ Para antiguos emigrantes que ya han regresado a su país, por caducar su permiso de residencia o su contrato de trabajo, la posibilidad de tener prioridad para obtener un nuevo permiso de residencia para un nuevo empleo en la UE. Se indicaba también que se crearía una base de datos al respecto. No se ha elaborado esta base de datos. Plan de Politica en materia de migración legal,. Comisión Europea. 2005.
} 
que después de haber criticado duramente como xenófobos a todos los críticos de la política migratoria de la Canciller Merkel, recientemente reconocían que con la crisis migratoria se corría el riesgo de dividir a la sociedad alemana. Igualmente en una entrevista publicada por Der Spiegel, los dos estuvieron de acuerdo en que "Alemania no podía absorber e integrar indefinidamente a más de un millón de refugiados al año" "111. Del mismo modo, el ministro de finanzas de Baviera Markus Sóder, opinaba que Alemania tenía que tener claro que debía haber límites y cuotas para la migración. "No podemos salvar al mundo entero", comentaba y proponía que era fundamental asegurar las fronteras externas de Schengen y enviar una señal clara de que no todo el mundo puede venir a Alemania.

Pocos meses después, durante la fiesta de San Silvestre, en diferentes ciudades alemanas, cuando se estaba celebrando la despedida del año 2015, en medio del tumulto, se produjeron cientos de agresiones sexuales por parte de refugiados y migrantes que habían entrado en los meses anteriores por Grecia. A esto se une, la pérdida de escaños de su partido, Unión Cristianodemócrata (CDU), en las elecciones en los landers como Sajonia-Anhalt, Baden-Wütetmberg, Renania Palatinado, en marzo; Mecklenburg-Vorpommern, y la ciudad de Berlín, en septiembre de este año.

El gran problema de toda esta incertidumbre, ante la migración desordenada e irregular, es que parece que no tenemos políticos que piensen y tengan visión de futuro. Dan la impresión de improvisación en sus decisiones y de ir siempre detrás de los acontecimientos. Grave cuestión para los ciudadanos de la Unión Europea. Abundan las políticas reactivas, más que las anticipativas.

En estos momentos se revisa toda la política de ayudas y de reagrupación familiar, no sólo en Alemania, sino también en países con larga trayectoria de acogimiento de refugiados como Suecia y Austria, Noruega y Dinamarca, por citar unos pocos. En Noruega, por ejemplo, la confusión llegó al límite, en la frontera del Ártico que limita con Rusia, los refugiados que llegaban vía Moscú eran inmediatamente devueltos a Rusia. Cientos de migrantes y refugiados que Noruega ${ }^{112}$ quiso devolver fueron rechazados por Moscú, por la presión de los defensores de los derechos humanos. Moscú llegó a culpar a Noruega de no tener asegurada su frontera. Los detenidos eran enviados al campo de detención de Kirkenes, siendo luego liberados. Sin embargo, los 13 detenidos y enviados en autobús a Murmansk, no tuvieron la misma suerte. El refugiado yemení que iba entre los detenidos, fue luego expulsado de Rusia. Por su parte, Alemania, en la primera mitad del año 2016 rechazó a más de 13.324 personas, que representa más del doble de las que fueron rechazadas en 2015, todos procedentes de Austria. ${ }^{113}$ Respecto a Suecia y Dinamarca, países de tradición de acogida de refugiados, en estos momentos están revisando todas las políticas de asilo y que el número de refugiados no sea superior a los de años pasados. El ejecutivo noruego ha sido mucho más duro que el sueco, sin embargo este último, "no quiere forzar la generosidad de sus ciudadanos ni más presión sobre los presupuestos". Exigen normas menos porosas en las fronteras exteriores de la Unión Europea. ${ }^{114}$ Además, exige que se recorten las subvenciones que se dan a las autoridades locales para alojar a los menores que vienen a Suecia sin sus

\footnotetext{
111“Gabriel und Steinmeier fordern Begrenzung der Zuwanderung”. Der Spiegel, 09.10.2015

112 "Norway's asylum policy in chaos amid Russian intransigence", The Guardian,. 24 January 2016, en https:/www.theguardian.com/world/2016/jan/24/norway-halts-return-of-asylum-seekers-who-entered-via-russia ${ }^{113}$ En la frontera germano-austriaca, la policía impidió la entrada a Alemania a 10.620 personas, en la frontera con Francia, 240 y otras 118 en la frontera con Holanda y unas 2.030 en los aeropuertos. Alemania había introducido los controles en sus fronteras en septiembre de 2015.

114، Denmark, Sweden toughen up asylum rules despite falling numbers”, The New York Times, August 30, 2016, en http://www.nytimes.com/reuters
} 
padres, "el año pasado Suecia recibió el 40\% de todos los menores que llegaron a la Unión Europea y es una asignación insostenible", comentó el ministro de Integración Yla Johansson. ${ }^{115}$

En la cumbre de los Balkanes, de 27 de agosto de 2015, la propia Canciller Merkel señalaba ante los participantes que, "la normativa de Dublín no funciona" ${ }^{116} \mathrm{y}$ apelaba para una solución común entre los socios sobre el tema de la migración y asilo. En esta misma reunión, celebrada en Viena, se puso sobre la mesa el tema de la devolución de refugiados. Alemania se veía en un aprieto monumental. Al invitar a los refugiados ir directamente a su país, no se registraron en Grecia, de ahí que fuera Alemania en esos momentos el primer país de llegada de refugiados, con lo cual, ante la imposibilidad de atenderlos, no los podía devolver. Así lo había estipulado el Tribunal Europeo de Justicia y la Corte Constitucional alemana. La Canciller Merkel aludió igualmente a que en esta crisis migratoria no había necesidad de modificar los tratados comunitarios. La encrucijada en la que se encontraba Alemania era preocupante y solicitaba ahora ayuda a todos los socios europeos.

\section{6. ¿Cómo se aborda el problema? ¿Base para la propuesta de la nueva Estrategia Europea de Seguridad 2016?}

\subsection{Restablecer Schengen.}

La Comisión Europea, en la reunión de 4 de mayo de $2016^{117}$, con la intervención de Frans Timmermans, vicepresidente primero y del comisario de Migración y Asuntos de Interior, Dimitris Avramopoulos, hicieron una evaluación de lo que estaba suponiendo el cierre de fronteras interiores del espacio Schengen. Al mismo tiempo dieron la posibilidad de ampliar el período de cierre, por seis meses más, a los países que tomaron las medidas al respecto acogiéndose al Código de fronteras Schengen, ${ }^{118}$ ya que a pesar de los progresos que "significativos realizados por Grecia", todavía se detectaban graves deficiencias que no habían podido ser subsanadas en el plazo de tres meses. El objetivo de la Comisión es volver a un funcionamiento normal del espacio Schengen y a suprimir los controles de las fronteras interiores para finales de $2016^{119}$.

Países a los que se permite mantener el control de sus fronteras internas durante seis meses más: Austria, en la frontera terrestre entre Austria y Hungría y en la frontera terrestre entre Austria y Eslovenia. Alemania, en la frontera terrestre entre Alemania y Austria. Dinamarca, en los puertos daneses con enlaces de transbordador con Alemania y en la frontera terrestre entre Alemania y Dinamarca. Suecia, en los puertos suecos, en la región policial sur y oeste y en el puente de Öresund. Noruega, en los puertos noruegos con enlaces de transbordador con Dinamarca, Alemania y Suecia.

\footnotetext{
${ }^{115}$ De un gobierno de centro izquierda. Ibid.

${ }^{116}$ Merkel dice que la normativa de Dublín no funciona y pide una solución común. EFE. Viena, 27 de agosto de 2015, en http://www.efe.com/efe/espana/portada/merkel-dice-que-la-normativa-dublin-no-funciona-y-pide-unasolucion-comun-europea/10010-2697698

117 "De vuelta a Schengen : La Comisión da los siguientes pasos para la supresión de los controles fronterizos internos temporales", Comisión Europea. Bruselas, 4 de mayo de 2016. Estas medidas, previstas en el Código de fronteras Schengen, actúan como salvaguardia para el funcionamiento general del espacio sin controles en las fronteras interiores.

118 "Regulation (UE)2016/399 of the European Parliament and of the Council of 9 March 2016", 23.03.2016, en http://eur-lex.europa.eu/legal-

content/EN/TXT/?toc=OJ:L:2016:077:TOC\&uri=uriserv:OJ.L_.2016.077.01.0001.01.ENG

119 "Back to Schengen: Commission proposes Roadmap for restoring fully functioninng Schengen system", Brussels, 4 March 2016
} 
La última cumbre celebrada en agosto de 2016, en la isla italiana de Ventotene, entre los tres líderes europeos Merkel, por Alemania, Hollande por Francia y Renzi por Italia, se ha querido dar una imagen de unión entre los impulsores de la iniciativa europea para reforzar la endeble armonía entre los llamados países que componen Schengen. Los puntos que se abordaron como destacados fueron: acuerdos sobre seguridad de las fronteras exteriores de Schengen, sobre crecimiento económico y el futuro de los jóvenes. Predominando sobre todo una respuesta al brexit inglés, en base a la unidad de la Unión Europea y a la proyección de futuro.

\subsection{Nada nuevo en cuanto a integración. Todo lo recogía el Programa Estocolmo 2010- 2014.}

Se especula sobre los cambios que se están introduciendo, en países como Alemania, respecto a la integración de los inmigrantes que llegan a suelo alemán, como a los solicitantes de protección. No hay nada nuevo, pues todo se estipulaba en el Programa Estocolmo 2010-14 y en su Plan de Acción. A nuestro juicio es lo que se debería estar haciendo. Se recogía en el mismo Plan, el aprendizaje del idioma, buscar trabajo por medio de las oficinas de empleo y cursar estudios que contribuyeran a mejorar la preparación. A cambio se otorgarían ayudas. De otra forma, es decir, recibir las ayudas sin más, no se haría, por ejemplo en Alemania, pues lo nuevo es que se puede perder el derecho al asilo.

¿Cómo puede criticarse que los países europeos exijan de los emigrantes regulares e irregulares, como a los solicitantes de asilo, que aprendan el idioma del país en que residen, un mínimo de Historia, para saber dónde se encuentran y que valores culturales les rodean y que se controlen las ayudas que se les dan?

Semejante disparate sólo favorece a las mafias, que controlan los movimientos de la inmigración irregular y a los refugiados desde sus países, y de los mafiosos que se encuentran en los países europeos y que quieren impedir que los inmigrantes conozcan el idioma y los valores culturales del país a dónde han querido venir a vivir para así tenerlos controlados, para crear sociedades "paralelas". También parece un despropósito que no se quieran controlar las ayudas que se les dan a acogidos en los países europeos. ¿No se controlan todas las ayudas que se dan a los ciudadanos europeos, en cualquier ámbito?

Todo esto de la ilegalidad por principio es algo que si se sigue reivindicando se tendría que investigar, ¿por qué y a quién beneficia la ilegalidad? Desde luego que al inmigrante irregular no le beneficia en nada. Le beneficia a las mafias que se aprovechan de esas circunstancias de ilegalidad y de marginalidad, para hacer con esta gente lo que les "apetezca".

Ejemplo de la integración en Alemania hoy. El coste y la dificultad de integración porque los que llegan no quieren integrarse. Gabrielle, viceministro alemán: "Sólo quieren vivir en países occidentales con sus propias costumbres, pero no aceptan los valores laicos de las sociedades europeas". En estos momentos Alemania ha endurecido las políticas de refugiados, como la reunificación familiar ${ }^{120}$, que no se podrá hacer hasta dentro de dos años.

Otro ejemplo, en los países nórdicos, en concreto en Suecia, es el de ofrecer 4.000 euros a los inmigrantes "irregulares" para que vuelvan a sus países.

\footnotetext{
120 “Germany toughens refugee policy”, Politico, 1-29-2016, en http://www.politico.eu/article/germanytoughens-refugee-policy-gabriel-merkel-asylum-seekers-family-reunification/
} 
Noruega, por su parte, está proyectando cerrar su frontera con Rusia, para impedir el paso de migración hacia su país, especialmente sirios provenientes de Rusia.

\section{Menores no acompañados. Una grave responsabilidad para la Unión Europea.}

Es uno de los asuntos más delicados y diríamos graves que tiene toda la Unión Europea. Permitir que niños y adolescentes vengan sin familia a los países europeos. La situación de los mismos es desde el principio cuando llegan, hasta el final, cuando cumplen la mayoría de edad, a los 18 años, de total desamparo jurídico, entran en el denominado "limbo jurídico" ante cualquier administración de cualquier país europeo.

El problema es de calado y ninguna de las reuniones, cumbres o encuentros a propósito de la denominada "crisis de los refugiados" ha hecho referencia a este crucial problema con el que la Unión Europea tiene una grave responsabilidad.

Desde el año 2010 cuando se aprueba el Programa Estocolmo y se incluye en el mismo la llegada y atención de MENAS, o menores no acompañados, por parte de las administraciones europeas, el aumento de llegadas a la Unión Europea de menores cada año va en aumento. Sólo por poner unos pocos ejemplos, el año pasado, según informes de la ONG Save the Children, llegaron 26.000 menores sin compañía de ningún adulto. Con el caos que se produjo por la frontera griega la entrada de niños también ha preocupado a las autoridades, especialmente a Europol, cuando saltó la alarma de los niños que se habían perdido en Italia y en Alemania, nada más llegar a suelo europeo. En la información de los medios de comunicación se señala que los responsables de Europol, como Brian Donald no cree que 10.000 niños estén perdidos en Europa, algunos estarán con familiares y no todos están en manos de redes criminales. ${ }^{121}$ Esta es una de las cuestiones que más preocupa también a las ONGs que atienden durante una larga etapa de su niñez y adolescencia a estos menores no acompañados. Cuando salen de la tutela, a los 18 años, la mayoría de ellos no tienen un trabajo ni un hogar a dónde acogerse. Gran parte de estos jóvenes se les ve deambulando por las calles de nuestras capitales en busca de clientes, porque generalmente terminan en la prostitución. Al respecto recordamos las declaraciones del responsable de Europol en Londres, "en mayo, los oficiales en Italia alertaron de que al menos 5.000 niños habían desaparecido de los centros de asilo en el último año. En octubre, las autoridades de Trelleborg (Suecia), dijeron que alrededor de 1.000 niños y jóvenes refugiados sin compañía de un adulto habían llegado a la ciudad el mes previo que desde entonces habían desaparecido".

El descontrol, la falta de vigilancia, la desidia de parte de autoridades y de responsables de atender a estos menores, está en el origen de la existencia de mafias, que ya los traen y los controlan una vez están en suelo europeo. Prácticamente lo corroboran las informaciones de Europol, cuando se refieren a las "infraestructuras criminales paneuropeas" que son relativamente nuevas y enormemente sofisticadas, que han fijado su objetivo en los refugiados. Organización con epicentro en Alemania y Hungría.

Naciones Unidas indica que más de un tercio de los refugiados que cruzan el Mediterráneo en barco para llegar a Europa son niños. Marie-Pierre Poirier, coordinadora especial de Unicef para la crisis de refugiados y migrantes en Europa ha indicado que es necesaria una mayor implicación de la Unión Europea para ayudar a estos menores que junto

\footnotetext{
${ }^{121}$ Townsend, Mark: “10.000 refugee children are missing, says Europol”, The Guardian, 30 January, 2016, en https:/www.theguardian.com/world/2016/jan/30/fears-for-missing-child-refugees. The Editorial Board.:"10.000 Child Refugee Are Missing”, The New York Times, Febrruary, 10, 2016, en http://www.nytimes.com/2016/02/10/opinion/10000-child-refugees-are-missing.html
} 
con las mujeres han aumentado en proporción el movimiento de migrantes hacia suelo europeo. $^{122}$

Desde luego, que en este asunto de los MENAS la Unión Europea tiene un reto difícil de resolver. Por que cuando se permitió la llegada de menores, se hizo tal vez muy alegremente, resultaba muy conmovedor y había que acogerlos y dejar que vinieran solos. Es una de las iniciativas más sangrantes que tuvo la presidencia española en 2010. ¿Quién hay detrás de todo este trasiego de menores, que cruzan con adultos, que nos son sus padres, por los países de origen y tránsito de la migración? Las personas más vulnerables son estos niños y adolescentes que llegan a la Unión Europea con la ilusión de encontrar una vida distinta y más positiva, que la que posiblemente dejaron atrás, y sin más van desapareciendo de los centros que les acogen. Algo habrá que hacer en este aspecto porque la irresponsabilidad es la mejor señal que podemos enviar a las mafias existentes en Europa para que se lucren a base de los menores. Nos parece que la Unión Europea está amparando oficios que degradan a los seres humanos permitiendo el tráfico de menores. Es hora ya de perseguir a los criminales y regular la estancia de estos menores que les impida salir hacia una vida de miseria y degradación. Así le obligan los convenios que Europa ha firmado al respecto, como es el de proteger a los niños, como personas más vulnerables, por la Convención de Naciones Unidas sobre el Derecho del Niño ${ }^{123}$.

\section{La nueva propuesta de Federica Moguerini: "Shared Vision, Common Action: Stronger Europe. A global Strategy for the European Union's Foreign and Security Policy".}

"Clara visión, Común acción: Una Europa fuerte. Estrategia global para la política exterior europea y de seguridad" 124 . Este es el grandilocuente título de la nueva estrategia Europea de Seguridad que propone la Unión Europea por medio de la Alta Representante de la Unión para Asuntos Exteriores y Política de Seguridad y Vice-presidente de la Comisión Europea, Federica Moguerini, cuyo objetivo es afrontar los nuevos retos y amenazas de todo tipo, especialmente la del terrorismo yihadista, que se ha convertido hoy en día en uno de los desafíos que más preocupa a los dirigentes europeos.

Documento de 51 páginas que pretende ser la guía estratégica para Europa en los próximos años con el objetivo de fortalecer a la Unión Europea. El documento original del cual se nutre este nuevo escrito es el Informe anual de la Alta Representante de la Unión Europea para Asuntos Exteriores y Política de Seguridad al Parlamento Europeo, Catherine Ashton, cuya resolución se emitió por el Parlamento Europeo el 12 de marzo de $2015 .^{125}$

\footnotetext{
${ }^{122}$ Se informa también por parte de la representante de Unicef que, el 70\% de la migración el año fueron hombres, Ibid.

${ }^{123}$ La Convención sobre los Derechos del Niño (CDN) es un tratado internacional que recoge los derechos de la infancia y es el primer instrumento jurídicamente vinculante que reconoce a los niños y niñas como agentes sociales y como titulares activos de sus propios derechos. El texto fue aprobado por la Asamblea General de Naciones Unidas el 20 de noviembre de 1989 y entró en vigor el 2 de septiembre de 1990. UNICEF "Convención sobre los derechos del niño", en http://www.unicef.es/infancia/derechos-del-nino/convencionderechos-nino

${ }^{124}$ Shared Vision, Common Action: A stronger Europe. A Global Strategy for the European Union's Foreign and Security Policy, June 2016.

${ }^{125}$ Informe anual de la Alta Representante de la Unión Europea para Asuntos Exteriores y Politica de Seguridad al Parlamento Europeo, Parlamento Europeo. 3.3.2015. También se entrevé parte del discurso del presidente del Consejo Europeo, Donald Tusk y de la intervención del presidente de la Comisión, Jean-Claude Jucker en la reunión de 15 de septiembre de 2015, sobre el acuerdo alcanzado para frenar la migración y reforzar las fronteras exteriores, que según Donald Tusk, "la protección de nuestras fronteras es la principal prioridad ahora".
} 
El prólogo, firmado por la Alta Representante para Asuntos Exteriores y Política de Seguridad europea, está cargado de buenos propósitos y anhelos, los verbos en futuro expresan lo que se pretende conseguir, con unión entre todos los miembros de la Unión Europea, y con compromisos que implican a todos los países miembros, que en solitario sería imposible llevar a cabo. Las propuestas que se incluyen en el documento pretenden ser una apuesta por una visión compartida por todos los países que forman la Unión, que constituye el fundamento de lo que aquí se propone.

La herramienta más efectiva y fuerte que se esgrime para conseguir estos objetivos es la diplomacia y una colaboración unívoca sin fisuras de todos los europeos que comparten el proyecto de la Unión Europea.

Los logros de la Unión Europea son manifiestos, y así se ponen en evidencia en todo el documento. La Unión Europea está en el G3 del mundo, es el primer socio comercial y el primer inversor extranjero para casi todos los países del mundo. En conjunto de países es el mayor inversor en cooperación al desarrollo, en comparación con el resto del mundo. Pero la Unión Europea no hace buen uso de todo su potencial. Hace hincapié Moguerini, en la responsabilidad que tiene la Unión Europea de ser un actor importante, incluso como "proveedor de seguridad global".

Quinientos millones de "ciudadanos" reclaman mayor responsabilidad de la Unión Europea en el mundo y reclaman también mayor unidad de acción en las políticas europeas. Hace mención de la importancia que tiene la situación exterior a la Unión Europea y sus repercusiones en la vida cotidiana de los ciudadanos europeos.

Hace también hincapié en la inestabilidad que nos afecta a todos, en las crisis fuera de nuestras fronteras que implican también inseguridad en el interior de la Unión Europea, ".The crises within and beyond our borders are affecting directly our citizens' lives".

También hace referencia a amenazas como la del referéndum británico, que deberían hacer pensar en la necesidad de una mayor colaboración entre los europeos, y de reconsiderar la forma de funcionamiento de la Unión Europea.

Es importante, a nuestro entender, la última frase del anterior párrafo, cuando se refiere a la necesidad de una "mayor colaboración y de reconsiderar la forma de funcionamiento de la Unión”. Aquí estriba el meollo de la cuestión. Porque hasta ahora, por lo menos en el tema que aquí nos ocupa, como es el de las migraciones irregulares, la desunión es evidente dentro de los socios, las iniciativas particulares a la orden del día, la improvisación y la falta de visión de futuro es la regla general en actuaciones relativas a la política de asilo y migración.

Una palabra que se repite constantemente es "fuerte", lo que nos hace pensar que la Unión Europea no es fuerte, y necesita ser fuerte precisamente ahora en este año 2016, cuando ha experimentado un suceso sin precedentes como fue la llegada masiva de migración y la entrada sin control por las fronteras europeas desde Grecia. Necesita ser fuerte, ante la amenaza, que ya es un hecho, de la salida de la Gran Bretaña de la Unión, que a la larga se notarán las consecuencias. Visión compartida y acción común será el lema que impregne este nuevo intento de estrategia de seguridad europea, lema que en definitiva es lo que determinará

“Acuerdo para reforzar las fronteras de Schengen.”, Servicio Europeo de Acción Exterior. 15.10.2015, en: http://www.elfinanciero.com/mundo/union-europea-alcanza-acue... . 
que la Unión Europea sea más fuerte. En los 4 epígrafes que ocupan 44 páginas, se hace un repaso a todo el entramado mundial, regional y local que afecta a la Unión Europea. En primer lugar se aborda la necesidad de una estrategia global para promover los intereses de los ciudadanos europeos, se pasa luego, a los principios que guían la acción exterior de este programa, las prioridades de la acción exterior de la Unión, la seguridad, el estado de las sociedades, la resiliencia, que viene a ser como la capacidad de superación ante fenómenos adversos, respecto a los países del Este y del Sur. Más adelante se propone un enfoque integrado de conflictos y crisis, cooperación regional, gobernanza mundial para el siglo XXI, y un último apartado dedicado a la visión que se tiene de la Unión Europea en el mundo y la que se quiere proyectar en un futuro inmediato, titulada de la visión a la acción, destaca sobre todo que para participar de manera responsable en el mundo, es esencial la credibilidad. Y en el mundo actual, frágil, el poder blando no es suficiente:"in this fragile world, soft power is not enough". ${ }^{126}$

En el apartado 3, titulado: Las prioridades de nuestra acción exterior, en el epígrafe 3.2, que está dedicado al estado de las sociedades, la resiliencia a nuestro Este y Sur, se incluyen una serie de sub-apartados ligados entre sí, como son: Enlargement Policy, Our Neighbours, Resilience in our Surrounding Regions y A more Effective Migration Policy, que es el apartado que hace referencia a nuestro trabajo.

En esta propuesta sobre "una política migratoria más eficaz" se pone la atención sobre los países de origen y tránsito de los migrantes y refugiados. Se señala que se aumentará la ayuda humanitaria hacia estos países, centrándose en la educación, las mujeres y los niños. Se promete tener una visión conjunta con los países de origen y tránsito de la migración para impulsar la migración legal, la gestión de fronteras, la readmisión y los retornos, por medio de la diplomacia. La Unión Europea trabajará conjuntamente con los países de origen para tratar de prevenir las causas fundamentales que originan los desplazamientos, apoyará la gestión de la migración y la lucha contra la delincuencia transfronteriza, los medios que se utilizarán serán a través del desarrollo, los fondos fiduciarios, la diplomacia preventiva y la mediación. Se trabajará conjuntamente con los países de origen de la migración mediante la mejora de la capacidad de acogida y de asilo, trabajando también en la mejora de la educación de los migrantes, por medio de la formación profesional, creando medios de vida y oportunidades.

La prioridad es la de contener los flujos irregulares, haciendo más eficaces los canales regulares de movilidad humana más seguros ${ }^{127}$. Esta Estrategia Global incide en la importancia de la implementación de canales legales y circulares ya existentes para la migración. También esto requiere trabajar unidos todos los países que forman la Unión Europea para lograr un sistema de asilo que haga valer el derecho a solicitar asilo, garantizando la llegada segura, regulada y legal de los refugiados que buscan protección internacional en la Unión Europea.

A este respecto, y según nuestra opinión, sería conveniente volver a abrir las embajadas de los países de la Unión Europea a los solicitantes de asilo en los países donde se encuentren estas personas. Este es uno de los problemas que no se han explicado nunca, por qué se determinó cerrar la posibilidad de solicitar asilo en las embajadas europeas en el

\footnotetext{
${ }^{126}$ Shared Vision, Common Action: A stronger Europe. A global Strategy for the European Union's Foreign and Security Policy, June 2016. From visión to Action. A credible Union, p. 44.

${ }^{127}$ En relación a este punto hay que señalar que el Plan de Política en materia de migración legal se propuso por parte de la Comisión Europea en 2005.
} 
exterior, cuestión que fue uno de los logros de la presidencia española en la Unión Europea en el año 2010.

También se lanza la idea de la responsabilidad compartida y solidaridad global, para trabajar con los socios internacionales en este tema de la migración y los refugiados que es un asunto internacional mundial, no solamente de la Unión Europea. En este sentido se propone establecer asociaciones más eficaces en la gestión de la migración con la ONU, agencias internacionales, países emergentes, organizaciones regionales, la sociedad civil y comunidades locales.

Como se vislumbra, todo el acervo comunitario está ahora al servicio de procurar un mundo más justo. Si todos los problemas que tenemos hoy en día ya se percibían desde hace más de 15 años, ¿por qué no se ha determinado de verdad contribuir al desarrollo de vecinos como los del África subsahariana? Siempre andamos con las políticas reactivas de parte de los países ricos, como la Unión Europea.

En todo el texto se aboga por la consecución de la paz en los países vecinos, que es posible por medio de la cooperación internacional, de la diplomacia preventiva y de la prevención de conflictos más que por la resolución de los mismos. Si de veras se actuara en consecuencia, esta sería otra de las fortalezas de esta estrategia.

En el apartado: A Peaceful and Prosperous Mediterrnean, Middle East and Africa, se insiste en la necesidad de promover el desarrollo y los derechos humanos, para hacer frente a la amenaza del terrorismo. Se indica igualmente que entre los desafíos más importantes están, la demografía, la migración y el cambio climático. La Unión Europea apuesta en esta Estrategia por la prosperidad compartida. Por ello se impulsará la cooperación con las organizaciones regionales y sub-regionales africanas, así como con las de Oriente y el Este. La Unión Europea debe actuar de puente, por medio de la movilización de las políticas bilaterales y multilaterales, así como mediante la asociación con las sociedades civiles de la región. Se vuelve a lanzar la idea de la PEV y de la Unión por el Mediterráneo. Políticas que ya han sido rechazadas por países del Magreb, a partir de 2011. Tal vez un mejor planteamiento de las mismas pueda dar resultado en el futuro, pero no se debe imponer los valores de la Unión Europea, por más maravillosos que sean, a sociedades que no tienen ningún interés en los mismos. A nosotros nos van funcionando, pero tenemos que conocer a los vecinos, y a ellos puede ser que ni les interese e incluso sean contrarios a sus convicciones culturales y religiosas.

En nuestra opinión, lo más novedoso y sensato que se propone en este apartado es la proyección hacia África subsahariana y el Cuerno de África. Una política de acercamiento con la Unión Africana y la Comunidad Económica de África Occidental y el G-5 ${ }^{128}$ en el Sahel. Propósitos a conseguir: invertir en la paz y el desarrollo de África como una inversión a nuestra propia seguridad y prosperidad. Se hará un "salto cuantitativo" en inversiones europeas en África, para apoyar un desarrollo sostenible. Se insta a construir también vínculos más fuertes en políticas de seguridad en África para el comercio y mezclar los esfuerzos en desarrollo con el trabajo sobre migración, salud, educación, energía, ciencia y tecnología, en

\footnotetext{
${ }^{128}$ Burkina Faso, Chad, Mali, Mauritania y Níger. Marco constitucional de coordinación y seguimiento de cooperación regional para políticas de desarrollo y de seguridad, creado en el año 2014. "Países subsharianos crean en Nuakchot el G-5 del Sahel", La Información, 16.2.2014, en http://www.lainformacion.com/politica/cumbre/paises-subsaharianos-crean-en-nuakchot-el-g5-delsahel_Shvbz8rEP1OcuyR5WxUbN5/
} 
especial para mejorar la seguridad alimentaria. Se seguirá apoyando los esfuerzos en paz y seguridad en África por medio de la diplomacia europea, la PCSD y el desarrollo, así como los fondos fiduciarios.

Toda una batería de buenos propósitos que esperamos "vean la luz" no a muy largo plazo. Propósitos que también se han asegurado de prometer en las cumbres pasadas, como la de la Valeta de noviembre de 2015 y se han puesto de relieve en la reunión de la Comisión Europea en Estrasburgo de 7 de junio de 2016. ¿Por qué se ha tenido que llegar a esta situación, si ya el continente africano estaba clamando a gritos que estaba dejado de lado de participar del desarrollo mundial y de las oportunidades de prosperidad que también merece? Sin embargo, es preciso contar con "el imaginario" africano, que no es el europeo. Los dirigentes de esos países han tenido ya oportunidad de hacer progresar a sus pueblos, pero entre la corrupción y las etnias que se disputan el poder, no se ha salido de un círculo vicioso de miseria y de conflictos. ${ }^{129}$

En este intento de clarificar la postura de la Unión Europea respecto a los desafíos que hoy en día le "sacuden" y en un intento también de mostrar su postura frente a los ciudadanos europeos, esta Estrategia Europea de Seguridad pone sobre la mesa todos los buenos propósitos que de cumplirse tienen irremediablemente que llevarnos a conseguir un mundo mejor, donde todos nos entendamos. Pero como el mundo está poblado por seres humanos, y cada uno de nosotros somos una unidad irrepetible, en ello estriba la incertidumbre.

La postura de reconocer los errores y de pretender corregirlos es lo que tiene esta Estrategia como otro valor más positivo ${ }^{130}$. Se aparta de la complacencia de la del año 2003 y en cierto modo sigue los pasos del Informe Final de la Alta Representante de la Política Común de Seguridad y Defensa del 15 de octubre de 2013. ${ }^{131}$ Como debilidades llama la atención que siga con la idea de impulsar la Política Europea de Vecindad y la Unión Mediterránea, que tan pocos éxitos han logrado, y cuyas políticas han sido cuestionadas a partir de 2011 por los países del Magreb. También "bebe" del informe que hicieron los institutos en 2012-13, y repite muchos de sus enunciados.

Lo que queda claro es que las migraciones desordenadas e incontroladas y las tragedias de los migrantes en el Mediterráneo y en el desierto del Sahara, han sido los revulsivos para que los políticos que nos gobiernan desde Bruselas hayan caído en la cuenta que no se puede seguir actuando como hasta ahora y si los vecinos viven en condiciones de miseria y conflicto, esa miseria y los conflictos nos llegará también a nosotros.

\footnotetext{
${ }^{129}$ Para un conocimiento profundo de las culturas, la sociedad, gobiernos de los países africanos es necesario empaparse en estudios como el que realizó Bartolomé Burgos, miembro de la Sociedad de Misiones de África, que saca a la luz lo que infinidad de escritos no lo han hecho, sobre todo lo que impide el desarrollo en África, que no viene de afuera, sino que pervive en el interior de cada africano. Burgos, Bartolomé (2007): Culturas Africanas y Desarrollo. Intentos africanos de renovación, Fundación Sur, Madrid, 613 páginas.

${ }^{130}$ En la reunión del Consejo Europeo del 28 de junio de 2016, en el epígrafe dedicado a la política exterior se felicita a la Alta Representante por la presentación de la Estrategia Global sobre Política Exterior y de Seguridad de la Unión, instándola a que prosiga su labor al respecto. "Reunión del Consejo Europeo", Bruselas, 28 de junio de 2016

${ }^{131}$ Preparing the December 2013 European Council on Security and Defence Final Report by the High Representative/Head of the EDA on the Common Security and Defence Policy

Brussels, 15 October 2013, en https://eeas.europa.eu/statements/docs/2013/131015_02_en.pdf
} 


\section{Conclusión.}

En primer lugar, debemos afirmar que las migraciones irregulares sí son un desafío para la Unión Europea, más en concreto un reto para la seguridad del espacio Schengen.

Para llegar a esta conclusión, hemos partido del estudio y análisis que las estrategias de la Unión Europea han publicado desde 2003 hasta la última de 2016. En todas ellas, los movimientos migratorios irregulares han tenido un tratamiento particular y han sido denominados como "delincuencia organizada" 132 . Ya desde el año 1992 se puso sobre aviso, a los dirigentes europeos, de los problemas que estamos sufriendo hoy en día, relacionados con la inestabilidad de nuestros vecinos del sur del Mediterráneo, con la presión demográfica, el subdesarrollo económico, las fracturas culturales, en suma, por la desestabilización del Sur, como lo dejo claro la Declaración de Petersberg ${ }^{133}$.

Han tenido que pasar veinticuatro años para volver a caer en la cuenta que las políticas que se han llevado a cabo por parte de los dirigentes europeos han sido muy desacertadas y erróneas, sembradas de buenos propósitos, pero también de improvisación y de falta de coordinación, como lo demuestra el hecho de que hasta este mismo año 2016, no se haya creado una Guardia de Fronteras y Costas, que debía haber sido el primer instrumento "disuasorio" para la seguridad de las fronteras del espacio Schengen.

La apuesta de la Estrategia Europea de Seguridad de 2016 es claramente por fortalecer a la Unión Europea y dar respuesta de su actuación ante los ciudadanos europeos y ante el mundo. Se apuesta claramente por favorecer la migración legal, incluido el refugio, creando vías seguras, evitando de esta forma las tragedias en el Mediterráneo y en el desierto del Sahara y de paso "acorralando a las mafias" que trafican con personas y se lucran a base del padecimiento de los migrantes irregulares.

La estrategia de 2016 lanza una serie de objetivos y prioridades que son la pauta que asegura el logro final de toda la política exterior y de seguridad de la Unión Europea, sólo con la condición de poner en marcha cada uno de las propuestas. Porque si seguimos como lo estamos haciendo hasta ahora, la situación para los ciudadanos europeos y para los migrantes que lleguen será cada vez de mayor incertidumbre ante el futuro. Así lo reconoce la estrategia de 2016 y por eso insta a cambiar la manera de actuar, siendo menos individualistas y actuando al unísono. Como lo expresaba el presidente de la Comisión Europea, Jean-Claude Juncker, ${ }^{134}$ en el discurso sobre el Estado de la Unión 2016: "Hacia una Europa mejor: Una Europa que proteja, empodere y vele por la seguridad". "Nunca antes había escuchado a tantos dirigentes hablar exclusivamente sobre problemas domésticos y mencionar a Europa, si lo hacen, solo de pasada". Esta queja expresa muy bien lo que ha sido la Unión Europea hasta ahora, una suma de países que esperan recibir, pero que muy poco o nada ofrecen para poner

\footnotetext{
${ }^{132}$ Incluso en la revisión de la aplicación de la Estrategia en 2008 se le incluye en el apartado de "terrorismo y delincuencia organizada”. Véase el epígrafe $n^{\circ} 6$. ¿Por qué?

${ }^{133}$ Desde 1992 se tuvo la posibilidad de prevenir buena parte de los problemas que hoy tenemos en los países del norte de África y especialmente en el Sahara en su conexión directa con Libia, por no mencionar Oriente Próximo y su "cuasi eterna disputa", hoy agravada con la guerra en Siria. Entre los siete principios de la Declaración de Petersberg prevalecía la idea de "crear un área de confianza y estabilidad". Los riesgos en esta área vendrían principalmente de la "desestabilización del Sur, provocada por la proliferación de armas de destrucción masiva, el acceso al poder de grupos radicales, la presión demográfica, el subdesarrollo económico y las fracturas culturales". Véase: Sánchez Mateo, Elvira: "La Seguridad Global en el Mediterráneo", Revista CIDOB d'Afers Internacionals, , $\mathrm{n}^{\circ}$ 57-58, (2002), p.10.

${ }^{134}$ Juncker Jean-Claude: “ Discurso sobre el Estado de la Unión 2016: Hacia una Europa mejor: una Europa que protege, empodere y vele por la seguridad". Comisión Europea. Estrasburgo, 14 de septiembre de 2016.
} 
en común las políticas, que en el caso de la política de migración y asilo, prácticamente cada uno de los países buscó su propia política y su propio interés. La nueva propuesta que se hace en la estrategia de 2016, esperamos que ayudará a superar atavismos nacionalistas y llevarnos a todos los países europeos hacia la unidad de acción, en el compromiso, en la defensa de la seguridad y de los valores europeos en el mundo. A este respecto se preguntaba el presidente de la Comisión europea, en el discurso antes citado, ¿hablará Europa con una sola voz, cuando esté en juego la integridad territorial, en violación del Derecho Internacional? O ¿desaparecerá de la escena internacional y dejará que otros conformen el mundo? Y se respondía: “...es preciso que nuestras palabras vayan seguidas de una acción conjunta, de lo contrario, no serán más que eso, palabras". Como vemos todos en Bruselas "sangran por la herida", que puso de manifiesto la entrada masiva y caótica de migración irregular y refugiados en 2015 por Grecia, frontera exterior del espacio europeo Shengen.

Por tanto, y como lo venimos reiterando desde hace años, la seguridad en las fronteras exteriores de Schengen es primordial; el sistemático desmantelamiento de las mafias que trafican con los migrantes, desde sus países de origen y también en los países europeos es una obligación, perseguirlas y ponerlas ante la Justicia, por parte de las fuerzas del orden; implicar a los países de origen y tránsito de los flujos clandestinos para que tomen las riendas de su propia seguridad y no la dejen en manos de los delincuentes; exigir reciprocidad a los países de la orilla sur del Mediterráneo pues los valores culturales europeos no pueden quedar en estado de sitio en Estados terceros, como sistemáticamente está ocurriendo y se está consintiendo, cuando no fomentando valores culturales de terceros en función de acuerdos económicos, y esta es la base para el buen entendimiento, el respeto mutuo entre los Estados y sus habitantes..

Por último, no dejamos de preguntarnos, como siempre hemos hecho, desde que estamos dedicados a este tema de las migraciones: ¿Por qué los solicitantes de asilo tienen que llegar a las puertas de Schengen?, ¿Será posible potenciar vías legales para la migración laboral circular, que hasta ahora pocos resultados ha tenido? Desde luego, así lo denuncia la Comisión Europea en su Informe sobre los cambios que hay que ejecutar en la política de asilo y migración de la Unión Europea ${ }^{135}$. ¿Interesa este tipo de migración irregular? ¿A quién y a qué países? En este asunto de calado, se debería investigar, especialmente, la situación de los Menores No Acompañados que llegan a la Unión Europea, y parece que no reciben la atención que deberían tener para poder emprender una vida digna y satisfactoria para ellos e integrados en nuestra sociedad, sino que hay razones de peso para creer que se pierden, cayendo en manos de redes de crimen organizado.

No perdemos la esperanza en las actuaciones y propuestas que los dirigentes europeos han iniciado a partir de la denominada "crisis de los refugiados", para encontrar soluciones a este problema que nos afecta a todos los países, de origen, tránsito y destino de la migración irregular y de los refugiados. Pero como se ha dejado que el problema crezca como "bola de nieve" cada vez más grande y se ha permitido también que "el monstruo" de la delincuencia que trafica con las personas migrantes se haya extendido cada vez más, estamos seguros que las consecuencias a la hora de dar las soluciones que se pretenden, producirán choques y controversias, para lo que se debe estar preparado. No va a ser fácil la consecución de los objetivos que los dirigentes de Bruselas se han propuesto y es lo que deberían haber hecho

\footnotetext{
${ }^{135}$ Comunicación de la Comisión al Parlamento Europeo y al Consejo. Hacia una reforma del sistema europeo común de asilo y una mejora de las vías legales a Europa, Comisión Europea, Bruselas 6.4.2016
} 
desde hace veinticuatro años, de forma especial desde la adopción de la Estrategia Europea de Seguridad de 2003 y su Informe de aplicación, y no lo han hecho. ${ }^{136}$

\section{Bibliografía Seleccionada}

ACNUR: "Manual de Reasentamiento de ACNUR", 2011, en http://www.acnur.org/que-hace/solucionesduraderas/reasentamiento/manual-de-reasentamiento-del-acnur/

ACNUR:"Llevando esperanza a los refugiados de Mali", diciembre de 2012, en: $\underline{\text { http://www.acnur.org/que- }}$ hace/respuesta-a-emergencias/mali/

"Acuerdo para reforzar las fronteras de Schengen.", Servicio Europeo de Acción Exterior. 15.10.2015, en: http://www.elfinanciero.com/mundo/union-europea-alcanza-acue

"Back to Schengen: Commission proposes Roadmap for restoring fully functioninng Schengen system", Brussels, 4 March 2016

Bensaad, Alí: "Viaje al final del miedo", en http://diarioinmigracion.blogspot.com.es/2011/05/viaje-al-final-delmiedo.html

Alta Representante de la Unión para Asuntos Exteriores y Política de Seguridad.: Comunicación Conjunta al Consejo Europeo, al Parlamento Europeo, al Consejo, al Comité Económico y Social Europeo y al Comité de las Regiones. Asociación para la Democracia y la Prosperidad Compartida con los países del Mediterráneo Meridional. Bruselas 8. 32011.

Barras, Raquel y García, David: "Hacia un nuevo y diferente "flanco sur" en el Gran Magreb-Sahel.", en Marquina, Antonio (ed.) (2015): La Unión Europea y el Magreb. Reestructurando un imaginario, Madrid, UNISCI.

Bensaad, Alí:, “Os clandestinos do Sahel”, Le Monde Diplomatique. nº 27, (2001),

Bensaad, Alí: "Le Sahara, vecteur de mondialisation", Maghreb-Maachrek, nº 185 (Otoño 2005),

Bensaad, Alí: "Les migrations transsahariennes. Une mundialisation pour la marge", Magreb-Maachrek, n 185 (Otoño 2005)

Bensaad, Alí: "Viaje al final del miedo", en http://diarioinmigracion.blogspot.com.es/2011/05/viaje-al-final-delmiedo.html

Burgos, Bartolomé (2007): Culturas Africanas y Desarrollo. Intentos africanos de renovación, Fundación Sur, Madrid,

Comisión Europea: Medidas Prácticas para la Reducción de la Migración Irregular. Comisión Europea. Red Europea de Migración. ANEXOS. Octubre 2012.

Comisión Europea: "La Guardia Europea de Fronteras y Costas protegerá las fronteras exteriores de Europa", Estrasburgo, 15 de diciembre de 2015.

Comité Internacional de la Cruz Roja: "Mali: una urgencia humanitaria en un contexto muy inestable". 27/04/2012, en: https://www.ic rc.org/spa/resources/documents/update/2012/mali-update-2012-04-27.htm

\footnotetext{
${ }^{136}$ Cumplir con la obligación de llevar a cabo los retornos de todos los migrantes que no tengan derecho a la protección internacional. "No habrá solidaridad a la carta, sino que trabajaremos en una solidaridad eficaz", señaló Donald Tusk, presidente del Consejo Europeo. "Comercio, migración y Rusia en el Orden del Día de la Cumbre", Reunión del Consejo Europeo 20-21 de octubre, 2016, en: http://www.consilium.europa.eu/es/home/ . "The Latest: EU leaders want more migrants deported", The New York Times, October, 20, 2016, en http://www.nytimes.com/aponline/2016/10/20/world/europe/ap-eu-europe-migrants-the-latest.html?_r=0
} 
Comunicación de la Comisión sobre las prioridades políticas en la lucha contra la inmigración ilegal de los nacionales de terceros países. Bruselas 19.7.2006.

Comunicación de la Comisión al Parlamento Europeo y al Consejo. Hacia una reforma del sistema europeo común de asilo y una mejora de las vías legales a Europa. Comisión Europea. Bruselas 6.4.2016

Consejo de la Unión Europea. Comunicado de Prensa. Justicia e Interior. Luxemburgo 7 y 8 de octubre de 2013.

“Convenio de Dublín. Unión Europea y Asilo". Diccionario de asilo CEAR, en: http://ceareuskadi.org/diccionario/convenio-de-dublin/

“Cumbre de la Valeta sobre migración 2015. Material relativo a la actuación de la Unión Europea”, Valeta, 11.11.2015

"De vuelta a Schengen : La Comisión da los siguientes pasos para la supresión de los controles fronterizos internos temporales", Comisión Europea. Bruselas, 4 de mayo de 2016.

"Declaration UE-AFRIQUE Sur La Migration el La Mobilite", UE-AFRICA Summit-Sommet UE-Afrique. Bruxelles 2014-Brussels. Quatrieme Sommet UE-AFRIQUE. 2-3 Avril 2014.

FRONTEX: "Migratory routes map", en http://frontex.europa.eu/trends-and-routes/eastern-mediterranean-route/

FRONTEX: "Migratory routes map", en http://frontex.europa.eu/trends-and-routes/central-mediterranean-route/

Guinea, Mercedes: "La política europea de vecindad hacia el Mediterráneo (2003-2015): Impotencia ante un entorno cada vez menos homogéneo y más hostil", en: Marquina.Antonio (ed) (2015): La Unión Europea y el Magreb. Reestructurando un imaginario, Madrid, UNISCI, pp. 423-456.

Herrero, Rubén. y Machín, Nieva: "El Magreb-Sahel: La amenaza del terrorismo”, en: Marquina, Antonio ( ed.) (2015): La Unión Europea y el Magreb. Reestructurando un imaginario, Madrid, UNISCI.

Informe anual de la Alta Representante de la Unión Europea para Asuntos Exteriores y Política de Seguridad al Parlamento Europeo, Parlamento Europeo. 3.3.2015

Informe sobre la aplicación de la Estrategia Europea de Seguridad. Ofrecer seguridad en un mundo en evolución. Bruselas 11 de diciembre de 2008.

Juncker Jean-Claude: “ Discurso sobre el Estado de la Unión 2016: Hacia una Europa mejor: una Europa que protege, empodere y vele por la seguridad”. Comisión Europea. Estrasburgo, 14 de septiembre de 2016.

OIM: "Informe sobre las Migraciones en el Mundo 2013. El bienestar de los migrantes y el desarrollo". Ginebra (2013).

IOM : “Mali.”, agosto 2014,en: https://www.iom.int/es/countries/mali.

IOM: “Grecia”, 1.19.2016, en: https:/www.iom.int/es/news/la-oim-informa-que-en-enero-las-llegadas-demigrantes-grecia-aumentaron-dramaticamente-al-2100

"La Comisión anuncia un nuevo marco de Asociación en materia de migración: una Cooperación Reforzada con terceros países para gestionar mejor la migración”, Estrasburgo, 7 de junio de 2016.

“La Convención de Dublin” en: http://www.econ.unicen.edu.ar/attachments/6699_Dra.\%20Culaciatti.pdf

“La Guardia Europea de Fronteras y Costas”, Comisión Europea, Estrasburgo, 15 diciembre 2015.

Marquina Antonio (ed) (2008): Flujos migratorios subsaharianos hacia Canarias-Madrid, Madrid, UNISCI.

Marquina. Antonio: "Nota Editorial”, UNISCI DISCUSSION PAPERS, .n 14 (mayo 2007), en:

http://www.ucm.es/data/cont/media/www/pag-72527/UNISCI14Nota.pdf 
Marquina, Antonio (ed), (2015): La Unión Europea y el Magreb. Reestructurando un imaginario, Madrid, UNISCI.

"Migración Internacional en su máximo histórico". Banco Mundial. 2015, en: http://www.bancomundial.org/es/news/press-release/2015/12/18/international-migrants-and-remittancescontinue-to-grow-as-people-search-for-better-opportunities-new-report-finds

Ministerio de la Presidencia: "15 Medidas urgentes de la UE contra la inmigración ilegal” Vicepresidencia Primera del Gobierno. Centro de Prensa, 24 de mayo de 2006.

Ospina, Gloria Inés: "Del vaivén de las políticas de extranjería hacia la convergencia”, en Marquina, Antonio (ed), (2008): Flujos migratorios subsaharianos hacia Canarias-Madrid, Madrid, UNISCI, pp.309-441

Ospina. Gloria Inés: “¿Alternativas a las políticas de fronteras de la UE?”, UNISCI, 20 de septiembre de 2015. Comentario UNISCI, $\mathrm{n}^{\circ} 92$

Ospina, Gloria Inés:” La inmigración desde el Magreb. Un reto para la Unión Europea”, en: Marquina, Antonio (ed), (2015): La Unión Europea y el Magreb. Reestructurando un imaginario, Madrid, UNISCI

Ospina, Gloria Inés: "Los movimientos migratorios irregulares en la Estrategia de Seguridad Nacional 2013", en Marquina, Antonio (ed), (2015): La Estrategia de Seguridad Nacional 2013. Un pavimento deslizante. Madrid, UNISCI.

Pacto europeo sobre migración y asilo. Consejo de la Unión Europea. Bruselas, 24 de septiembre de 2008

Plan de Política en materia de migración legal,. Comisión Europea. 2005.

Parkes Roderick: "Migration to Europe: the numbers game", European Union Institute for Security Studies (EUISS). n ${ }^{\circ}$ 18, junio 2016, en: http://www.iss.europa.eu/uploads/media/Brief 18 Migration.pdf

“Promover una migración equitativa”, Oficina Internacional del Trabajo. 105ª Reunión.(2016).

Preparing the December 2013 European Council on Security and Defence Final Report by the High Representative/Head of the EDA on the Common Security and Defence Policy

Brussels, 15 October 2013, en https://eeas.europa.eu/statements/docs/2013/131015 02 en.pdf

Refugees/Migrants Emergency Response-Mediterranean”. UNHCR, en:

http://data.unhcr.org/mediterranean/regional.php

"Regulation (UE)2016/399 of the European Parliament and of the Council of 9 March 2016", 23.03.2016, en http://eur-lex.europa.eu/legalcontent/EN/TXT/?toc=OJ:L:2016:077:TOC\&uri=uriserv:OJ.L_2016.077.01.0001.01.ENG

"Refuerzo de la vías legales: La Comisión propone crear un marco común de la UE en materia de reasentamiento", Comisión Europea. Bruselas, 13 de julio de 2016.

Reunión del Consejo Europeo. Secretaría General del Consejo Europeo. Bruselas, 28 de junio de 2016.

Reunión de los Jefes de Estado o de Gobierno de la UE con Turquía, 29-11-2015-Declaración UE-Turquía. Consejo de la Unión Europea. Bruselas, 29.11.2015

Sánchez Mateos, Elvira: “La Seguridad Global en el Mediterráneo”, Revista CIDOB d'Afers Internacionals, $\mathrm{n}^{\circ}$ 57-58, (2002).

Shared Vision, Common Action: A Stronger Europe. A Global Strategy for the European Union's Foreign and Security Policy, en https://eeas.europa.eu/top_stories/pdf/eugs_review_web.pdf

Study on smuggling of migrants. Characteristics, responses and cooperation with third countries. Case study: Pakistan, Turkey, Greece. European Commission. 2014 
The Cost of Non-Schengen. Impact of border controls within Schengen on the Single Market. May, 2016.

Towards a European Global Strategy. Securing European influence in a changing world, May 13, 2013, en http://www.realinstitutoelcano.org/wps/wcm/connect/4c2675804fc8b86b80b5caccba746acc/EGS_Report.pdf?M $\mathrm{OD}=$ AJPERES\&CACHEID $=4 \mathrm{c} 2675804 \mathrm{fc} 8 \mathrm{~b} 86 \mathrm{~b} 80 \mathrm{~b} 5 \mathrm{caccba} 746 \mathrm{acc}$

Una Europa que actúa para hacer frente a los desafios actuales. Programa de Trabajo, Presidencia francesa del Consejo de la Unión Europea. 1 de julio-31 de diciembre de 2008

Una Europa Segura en un mundo mejor. Estrategia Europea de Seguridad, Bruselas, 12 de diciembre de 2003.

UNICEF:" Convención sobre los derechos del niño", en http://www.unicef.es/infancia/derechos-delnino/convencion-derechos-nino

"UE-Turquía: Publicación del Proyecto de Plan de Acción sobre apoyo a los refugiados y gestión de la migración”, Comunicado de Prensa. Bruselas, 5 de octubre de 2015. 